Florida International University FIU Digital Commons

$10-15-2013$

\title{
Exploring Calling Work Orientation: Construct Clarity and Organizational Implications
}

Kerry A. Newness

Florida International University, knewn001@fiu.edu

DOI: $10.25148 /$ etd.FI13112203

Follow this and additional works at: https://digitalcommons.fiu.edu/etd

Part of the Industrial and Organizational Psychology Commons

\section{Recommended Citation}

Newness, Kerry A., "Exploring Calling Work Orientation: Construct Clarity and Organizational Implications" (2013). FIU Electronic Theses and Dissertations. 980.

https://digitalcommons.fiu.edu/etd/980

This work is brought to you for free and open access by the University Graduate School at FIU Digital Commons. It has been accepted for inclusion in FIU Electronic Theses and Dissertations by an authorized administrator of FIU Digital Commons. For more information, please contact dcc@fiu.edu. 


\title{
FLORIDA INTERNATIONAL UNIVERSITY
}

Miami, Florida

EXPLORING CALLING WORK ORIENTATION:

\section{CONSTRUCT CLARITY AND ORGANIZATIONAL IMPLICATIONS}

\author{
A dissertation submitted in partial fulfillment of the \\ requirements for the degree of \\ DOCTOR OF PHILOSOPHY \\ in \\ PSYCHOLOGY
}

by

Kerry Ann Newness

2013 
To: Dean Kenneth G. Furton

College of Arts and Sciences

This dissertation, written by Kerry Ann Newness, and entitled Exploring Calling Work Orientation: Construct Clarity and Organizational Implications, having been approved in respect to style and intellectual content, is referred to you for judgment.

We have read this dissertation and recommend that it be approved.

$\begin{array}{r}\text { Tonette Rocco } \\ \hline \text { Chockalingam Viswesvaran } \\ \hline \text { Valentina Bruk-Lee } \\ \hline \text { Jesse Michel, Major Professor }\end{array}$

Date of Defense: October 15, 2013

The dissertation of Kerry Ann Newness is approved.

Dean Kenneth G. Furton College of Arts and Sciences

Dean Lakshmi N. Reddi University Graduate School

Florida International University, 2013 


\section{DEDICATION}

I dedicate my dissertation to two of the most amazing women I know: my proud grandmother who did not have the opportunity to finish high school and my mother who told me you can accomplish anything you set your mind to doing 


\section{ACKNOWLEDGMENTS}

First, I wish to thank God for blessing me with the opportunity to attend graduate school and for guiding me along the way. Next, I would like to recognize and thank my advisor, Jesse Michel, and my committee members: Chockalingam Viswesvaran, Valentina BrukLee, and Tonette Rocco. Without the help and guidance of these incredible people, I would have had difficulty in the development and execution of my dissertation. I would also like to thank my colleagues and classmates who provided me with motivation to complete my dissertation. Finally, I must thank my family and the people who have accepted me as family. 


\title{
ABSTRACT OF THE DISSERTATION \\ EXPLORING CALLING WORK ORIENTATION: \\ CONSTRUCT CLARITY AND ORGANIZATIONAL IMPLICATIONS
}

by

\author{
Kerry Ann Newness
}

Florida International University, 2013

Miami, Florida

\section{Professor Jesse Michel, Major Professor}

Employees maintain a personal view toward their work, which can be referred to as their work orientation. Some employees view their work as their life's purpose (i.e., calling work orientation) and they tend to be 1) prosocially motivated, 2) derive meaning from work, and 3) feel that their purpose is from beyond the self. The purpose of the current dissertation was to differentiate calling work orientation from other similar workplace constructs, to investigate the most common covariates of calling work orientation, and to empirically test two possible moderators of the relationship between calling work orientation and work-related outcomes of job satisfaction, job performance, and work engagement. Two independent samples were collected for the purpose of testing hypotheses: data were collected from 520 working students and from 520 non-student employees. Participants from the student sample were recruited at Florida International University, and participants from the employee sample were recruited via the Amazon Mechanical Turk website. Participants from the student sample answered demographic questions and responded to self-report measures of job satisfaction, job performance, work engagement, spirituality, meaningful work, prosocial motivation, and work 
orientation. The procedure was similar for the employee sample, but their survey also included measures of counterproductive work behaviors, organizational citizenship behaviors, conscientiousness, and numerical ability. Additionally, employees were asked whether they would be willing to have a direct supervisor, peer, co-worker, client, or subordinate rate their job performance. Hierarchical regression findings suggest calling work orientation was predictive of overall job performance above and beyond two common predictors of performance, conscientiousness and numerical ability. The results for the covariate analyses provided evidence that prosocial motivation, meaningful work, and spirituality do play a significant role in the development of an employees' work orientation. Perceived career opportunities moderated the relationship between calling work orientation and job performance for the employee sample. Core self-evaluations moderated the relationship between calling work orientation and job performance, and core self-evaluations moderated the relationship between calling work orientation and work engagement. Collectively, findings from the current study highlight the benefits of examining work orientation in the prediction of workplace outcomes. 


\section{TABLE OF CONTENTS}

CHAPTER

PAGE

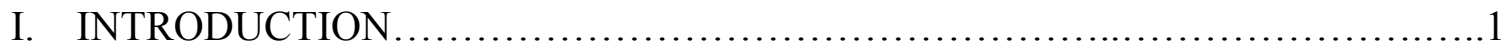

II. LITERATURE REVIEW AND CONSTRUCT CLARITY ........................12

Calling as Motivation................................................... 12

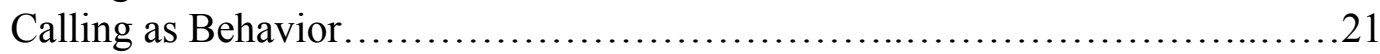

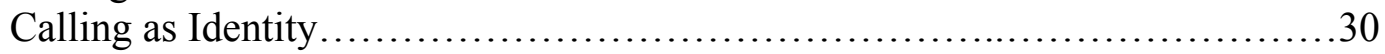

Calling as an Attitude........................................................

Attitude Formation and Calling as a Process.....................................42

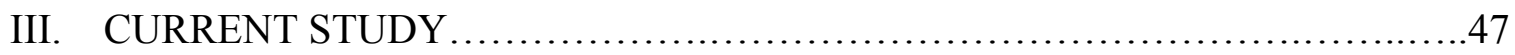

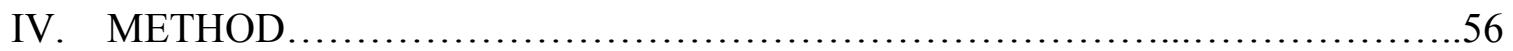

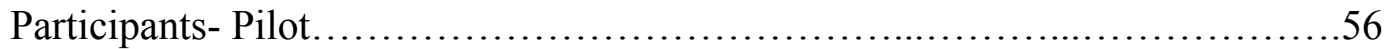

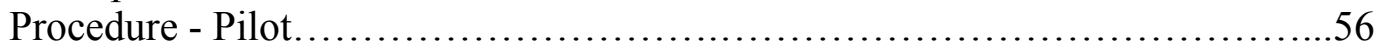

Participants -Work ...................................................... 57

Procedure - Work ....................................................... 59

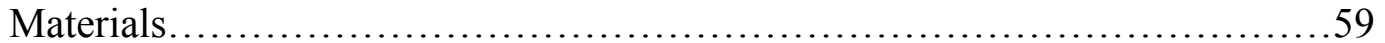

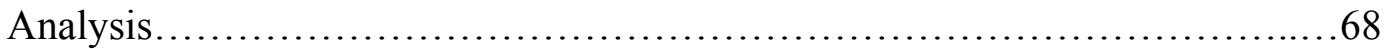

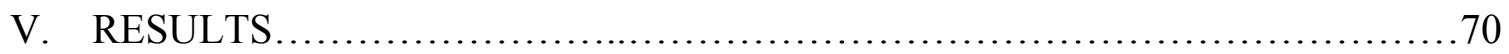

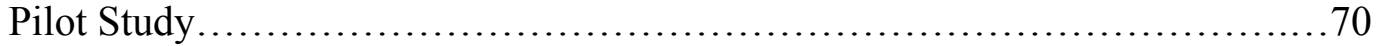

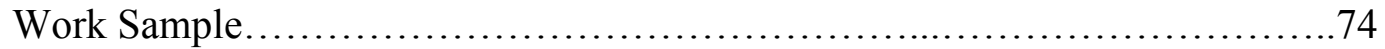

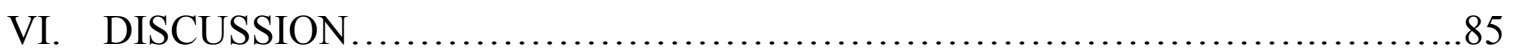

Work Orientation and Job Performance.................................. 86

Covariates of Calling Work Orientation..................................... 96

Perceived Career Opportunity as a Moderator.................................102

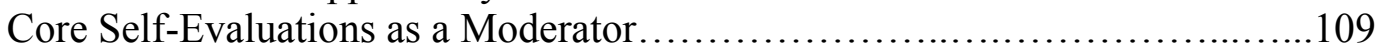

Concluding Remarks.................................................... 115

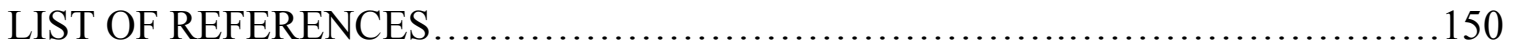

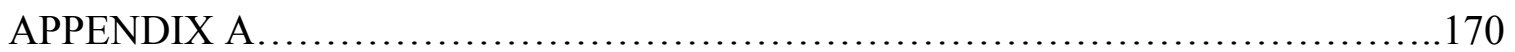

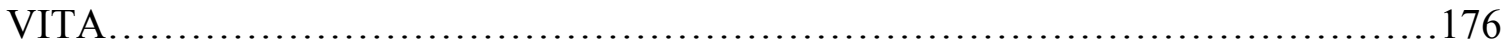




\section{LIST OF TABLES}

TABLE

PAGE

1. Pilot Sample Gender and Ethnicity Summary...............................117

2. Pilot Sample $-\mathrm{O} *$ Net Occupation Categorization Summary $\ldots \ldots \ldots \ldots \ldots \ldots \ldots \ldots \ldots \ldots$

3. Work Sample Gender and Ethnicity Summary................................ 119

4. Work Sample - Level of Education Summary..............................120

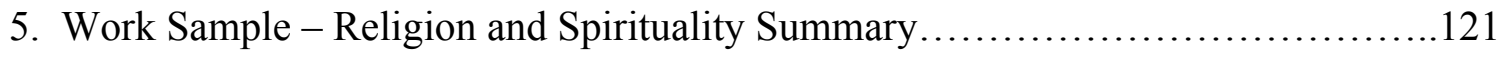

6. Work Sample - O*Net Occupation Categorization Summary.....................122

7. Breakdown of Occupation Type for Calling, Career, and Job Work Orientations....123

8. Correlations, Means, Standard Deviations, and Reliabilities for Pilot Sample.......124

9. Hierarchical Regression for Job Performance, Calling, and Covariates - Pilot......125

10. Hierarchical Regression for Job Satisfaction, Calling, and Covariates - Pilot......126

11. Hierarchical Regression for Engagement, Calling, and Covariates - Pilot..........127

12. Moderated Regression Calling, Performance, and Career Opportunities - Pilot....128

13. Moderated Regression Calling, Satisfaction, and Career Opportunities - Pilot.......129

14. Moderated Regression Calling, Engagement, and Career Opportunities - Pilot.....130

15. Moderated Regression Calling, Performance, and Core Self-Evaluation Pilot.......131

16. Moderated Regression Calling, Satisfaction, and Core Self-Evaluation Pilot........132

17. Moderated Regression Calling, Engagement, and Core Self-Evaluation Pilot.......133

18. Correlations, Means, Standard Deviations, and Reliabilities for Work Sample......134

19. Incremental Validity for Numeracy, Conscientiousness, and Calling.............135

20. Hierarchical Regression for Job Performance, Calling, and Covariates - Work....136

21. Hierarchical Regression for Job Satisfaction, Calling, and Covariates - Work.....137 
22. Hierarchical Regression for Engagement, Calling, and Covariates - Work.........138

23. Moderated Regression Calling, Performance, and Career Opportunities - Work....139

24. Moderated Regression Calling, Satisfaction, and Career Opportunities -Work.......140

25. Moderated Regression Calling, Engagement, and Career Opportunities - Work....141

26. Moderated Regression Calling, Performance, and Core Self-Evaluation Work......142

27. Moderated Regression Calling, Satisfaction, and Core Self-Evaluation Work......143

28. Moderated Regression Calling, Engagement, and Core Self-Evaluation Work......144 


\section{LIST OF FIGURES}

FIGURE

PAGE

1. Interaction Graph for Calling, Job Performance, and PCO (Employee)..............145

2. Interaction Graph for Calling, Engagement, and PCO (Working Student)...........146

3. Interaction Graph for Calling, Engagement, and PCO (Employee)................147

4.Interaction Graph for Calling, Performance, and CSE (Employee)..................148

5. Interaction Graph for Calling, Engagement, and CSE (Employee)................149 


\section{CHAPTER ONE: INTRODUCTION}

In recent years, organizational researchers have observed a trend whereby individuals are voluntarily leaving their current employment in search of better alternatives. An evaluation of employee tenure (i.e., the duration of employment in the same job or company) and "lifetime" work trends conducted in the early 1980's projected that most employees would ultimately end up working in lifetime work, defined as remaining with an organization for twenty or more years (Hall, 1982). At the time these findings were released, the average tenure for employees was about 8 years (Hall, 1982). According to the Bureau of Labor and Statistics (BLS, 2010), the average tenure for U.S. employees in 2010 was about 4.4 years, meaning employees today only remain with an organization about half as long as employees in 1980. With these statistics in mind, several questions should be considered: 1) what cognitive and affective factors are involved in how employees view their current employment? 2) what do individuals desire when in search of new employment?, and 3) do individual differences such as personality affect how an employee perceives his or her work? All of these questions seem to center around the idea that employees maintain a personal view toward their work, which can be referred to as their work orientation (Davidson \& Caddell, 1994).

From the employee's perspective, while work is a mechanism to obtain basic human needs, it can also serve a deeply personal function depending on how employees identify with or define themselves by their work (Elangovan, Pinder, \& McLean, 2010). Work makes up a significant portion of most people's lives; in fact, it has been estimated that about one-third of all waking moments for adults is spent working (Wrzesniewski, McCauley, Rozin, \& Schwartz, 1997). Men and women from all cultures, geographic 
locations, spanning a wide range of ages, engage in some form of goal-directed behavior they call work. Cross-cultural research provides evidence to suggest job satisfaction is a significant predictor of life satisfaction (Oishi, Diener, Lucas, \& Suh, 1999). Satisfaction with one's work has been found to predict about nine percent of the variance in overall life satisfaction in longitudinal studies (Rode, 2004; Tait, Padgett, \& Baldwin, 1989). When asked to describe themselves, many people identify with the tasks they engage in at work and their occupations to fill a void in their self-concept (Stryker \& Serpe, 1994). Taken together, these findings highlight the significance of studying people's work orientation because of the amount of time spent at work and because of its indirect effect on overall life satisfaction. In other words, the theoretical framework of the work orientation literature implies a possible mediating effect of orientation on the relationship between work hours and life satisfaction.

Increased voluntary turnover not only has implications for employees, organizations are affected by these trends as well. These trends in voluntary turnover have affected how managers make decisions regarding human resources. Employee turnover has been identified as a particularly important trend to study because it results in increased direct and indirect costs to the organization (Morrell, Loan-Clarke, \& Wilkinson, 2001). When an employee voluntarily chooses to turnover, the organization must fill vacancies through recruitment and selection procedures that can be costly (Berry, 2002). Voluntary turnover has also been associated with decreases in morale and motivation of remaining employees, thus, creating further costs for the organization (Dess \& Shaw, 2001). Given the possible negative effects of turnover, research should attempt to better understand work orientation and perhaps set in motion initiatives 
designed to help place employees in work environments that will facilitate more meaningful work orientations.

The current state of work orientation literature is founded upon the idea that some people identify so much with their work roles and go through a cognitive process of evaluating their occupations to determine if they are fulfilling a greater sense of personal purpose. Alternatively, some people prefer to compartmentalize their work as simply a means of providing income. Cognitive appraisals an employees make regarding their work have been defined and categorized as a calling, career, or job (Davidson \& Caddell, 1994; Wrzesniewski et al., 1997). The distinction between these categories reflects differences in the role employees' work plays in their lives. Researchers speculate that this orientation toward one's work is likely to infiltrate other aspects of a person's life, guide their career decisions, and have significant implications on organizational outcomes (Dik \& Duffy, 2009). According to the framework set forth by Davidson and Caddell (1994), individuals who maintain a calling work orientation feel that the tasks they engage in at work fulfill their life's purpose, that they would experience a personal void in the event that they could no longer serve in this capacity. Employees with a career work orientation are primarily concerned with their personal advancement in their current line of work; they tend to be motivated by the status and fulfillment of ego needs associated with promotions. Lastly, employees who report having a job work orientation in this model see their work simply as a means for fulfilling their financial obligations, to "pay the bills" or "put food on the table."

Studying the construct of calling has recently garnered the attention of researchers from a variety of disciplines perhaps because they are recognizing the complexities and 
implications an employee's view of their work has on performance, satisfaction, and well-being outcomes. The avenues for future research in the area of calling work orientation are promising and may also lead to a greater understanding of work-related behavior such as motivation, satisfaction, stress, commitment, and organizational citizenship behaviors (OCB; Elangovan et al., 2010). One of most fundamental challenges that researchers have had to overcome with regard to calling work orientation is that the construct has been defined and conceptualized from different disciplines and, as a result, there is little consistency regarding its operational definition (Elangovan et al., 2010). Recently, researchers have begun to hone in on an operational definition consisting of three overarching characteristics of calling: 1) a desire to engage in specific work that originated from beyond the self, 2) an orientation toward finding a sense of purpose, and 3) a motivation to help people or society (Dik \& Duffy, 2009). Although progress has been made, operationally defining the construct of calling remains a challenge for researchers, partly because the construct itself has evolved and has taken on new meaning in recent years (Bunderson \& Thompson, 2009). Even within the last few decades, for example, researchers have defined calling in terms of the following: something performed for its own sake and for personal value or meaning (Bellah, Madsen, Sullivan, Swindler, \& Tipton, 1985), the belief that work helps make the world a better place (Wrzesniewski, 2003), working toward a personal passion (Dobrow, 2006), and work originating from something beyond the self, a transcendental summon (Duffy $\&$ Sedlacek, 2007). With all of the possible definitions and considering the evolution of the term from a Judeo-Christian context, it appears that there is still little clarity or consensus across researchers and disciplines regarding the definition. The recent 
increased interests in calling and potential organizational outcomes have led to the fundamental aim of characterizing the facets of calling and differentiating them from separate, but similar constructs. The primary aim of the following construct clarity chapter will be to evaluate the current literature on calling and to highlight the distinctions between this construct and other similar constructs.

Another challenge in studying calling work orientation has been that, until recently, the scales used to measure calling were not developed and validated according to psychometric standards. As a result, the modern conception of calling to one's line of work is still in its infancy in terms of empirical research. Researchers even within the last few years have claimed that the measures for calling were insufficient (Elangovan et al., 2010). Within the last year, for example, researchers have validated three new measures for calling on the basis of suggestions and theoretical underpinnings of the calling literature (Dik, Eldridge, Steger, \& Duffy, 2012; Dobrow \& Tosti-Kharas, 2011). While there has been progress in the right direction, there is still some debate regarding the most effective method for measuring calling work orientation. The most recently validated measure includes two dimensions, the search for a calling and the presence of a calling (Dik, et al., 2012). Though the operational definition of calling has evolved over years, the common thread binding them together is that calling is an individual's orientation toward his or her work. If the consistency in definition holds true, one can infer that employees within similar working conditions but who maintain a different work orientation would report different tasks, value different aspects of their work, and approach their work according to the function is serves them. These recent contributions 
to the literature have essentially lifted some of the previous limitations, making the further study of calling work orientation possible.

In general, researchers have adopted several different theories related to the construct of calling work orientation. One such theory highlights the idea that although the concept of calling was derived from the Judeo-Christian religions, calling is not limited to individuals who hold such beliefs (Hall \& Chandler, 2005). The theme of finding meaning and purpose for an individual's life has been observed in many religions and even non-religious people. For example, Bogart (1994) found themes of calling throughout the Bhagavad Gita, a scripture from the Hindu faith. Individuals can feel a sense of calling to any area of work, not just those commonly associated with vocation or calling such as religious, teaching, or social services (Dik \& Duffy, 2009). More recently, calling has been defined by an emphasis of "doing" rather than "being"; it is an actionoriented term (Elangovan et al., 2010). For example, a person may feel called to advocate for social justice rather than simply being a social worker. The distinction is that the underlying motives for social workers vary, whereas, the motive for social justice is specific to the individual's calling (Elangovan et al., 2010). In an extension to the theory, a recent qualitative study used open-ended questions to allow undergraduate students to define what a calling meant to them and the scope of calling work orientation (Hunter, Dik, \& Banning, 2010). In their analysis, Hunter et al. found that several themes emerged: calling as a guiding force, calling as the compatibility or fit of skills and abilities with a particular line of work, and calling as something altruistic and prosocial. These findings were consistent with the current, widely accepted operational definition provided by Dik and Duffy (2009). More interestingly, however, qualitative responses to 
the question regarding the scope of a person's calling support the idea that calling can even extend well beyond the work environment. Consolidating these key components of both theories, this suggests that having a calling work orientation can partially fulfill an individual's larger life calling if work behaviors are in alignment with an individual's motives.

Another popular view of calling theory has been examined within the field of vocational counseling; whereby, researchers are primarily interested in discovering what type of work would leave employees feeling like their work is fulfilling a greater life's purpose (Dik \& Duffy, 2009). One of the assumptions of this theory suggests that calling work orientation is salient for most people. In fact, findings regarding the prevalence of employees who endorse having a calling to their career suggest that between 33 and 50 percent report feeling called (Wrzesniewski et al., 1997). Even people who find themselves employed in socially defined "dirty" jobs report deriving meaning and a sense of purpose from work tasks (Ashforth \& Kreiner, 1999). Vocational counselors suggest that, while there may be defining moments of discovery and perhaps concrete examples of how major events shape a person who feels a calling, it is something that is always evolving as a result of the continual evaluation of work activities and the perceived impact of those behaviors. It has been proposed that the basis of this evaluation is selfattribution theory (Elangovan, et al., 2010). The convergence of the ideal, actual, and ought selves is thought to occur when an individual is fulfilling their sense of calling.

On the basis of self-discrepancy theory, it is possible for an individual to sense a calling but not currently be fulfilling that calling. When it comes to unanswered callings, people may pursue a different path for the sake of earning more money or because it is 
more socially acceptable, they may lack certain skills to fulfill the calling, or they may already be employed in a job and cannot leave to pursue a calling (Berg, Grant, \& Johnson, 2010). The urge to discover calling work orientation is a consequence of an overwhelming need to find meaning or purpose, which could be the result of dissatisfaction with current life or work conditions or a response to a critical event (Weiss, Skelly, Haughey, \& Hall, 2004). The exploration or discernment process of discovering calling work orientation must be precluded by a willingness to pursue new paths, or being open to new experiences. It involves the evaluation and trial of things that are closely tied with one's identity, a process that can result in the increased levels of stress and anxiety (Pratt \& Ashforth, 2003). Instead of pursuing a completely different calling, however, some employees may choose to adjust their current job to find enjoyment and meaning that was missing from their formal job descriptions (Berg, et al., 2010). Some strategies employees use to adjust their current work include: shaping the parameters of the job (i.e., job crafting), dedicating more time to aspects of the job that are in alignment with the unanswered calling (i.e., task emphasizing), adding new tasks that incorporate the unanswered calling (i.e., job expansion), or cognitively adjusting how tasks influence people on a social level (i.e., role reframing). In addition to altering a job or how an employee thinks about the parameters of a job, people also report using leisure time to pursue unanswered callings by pursuing certain hobbies or experiencing callings through other people (i.e., vicarious experiences).

In the same vein of research, it is thought that discovering one's calling to work is something of an active or deliberate process rather than something someone stumbles upon or is automatically revealed through specific circumstances (Weiss et al., 2004). 
The cognitive evaluation of calling can also involve the reframing or justification of a current job in terms of finding or deriving purpose when the job is not ideal (Ashforth \& Kreiner, 1999; Dik \& Duffy, 2009), thus, resolving the cognitive dissonance the individual experiences. For example, individuals can come to the conclusion that their job does in fact help to fulfill their life's purpose; they may have the knowledge of a calling and reframe their current job, or may begin actively seeking alternative employment to find purpose (Duffy \& Sedlacek, 2010). Considering the influence of cognitive evaluations, it should not come as a surprise that these groups of individuals face various challenges at each stage of the career decision process.

These various perspectives and theories all provide the foundation upon which calling work orientation research should be based, but the scope is still somewhat limited and there are gaps in the literature. The implications of work orientation obviously spill over into the realm of human resources and industrial-organizational psychology; however, few researchers have adopted this perspective. The literature would benefit from examining the construct of calling work orientation by integrating both employee and organizational outcomes. When the field of industrial-organizational psychology was emerging, researchers focused their attention on individual and organizational outcomes in a vacuum, strictly confined to the environment of the workplace and disregarded the spillover from personal and family environments (Grzywacz \& Marks, 2000; Pedersen-Stevens, Minnotte, Mannon, \& Kiger, 2007). Within the last few decades, however, work-family conflict and enrichment research has broken down the barriers between personal and work environments (Greenhaus \& Beutell, 1985). The benefit of examining employees' orientation toward their work is that it examined some 
of a person's most fundamental motives that are salient across all environments. The exploration of constructs such as calling has been and to some degree remains somewhat taboo because of its original ties to religion and spirituality. It was not until recently that spirituality has been explored with regard to employee productivity and effectiveness; profit-focused organizations are beginning to recognize the benefit of spiritual well-being at work (Tischler, Biberman, McKeage, 2002). Researchers suggest that organizations may have ignored the topic of spirituality and religion because of the negative connotations that are associated with these terms (Egan, 1999). Now that calling has been defined and used colloquially, it is possible to explore the potential organizational facilitating effects on job performance and job satisfaction. Although employers tend to value their employees on a personal level, in many instances, the bottom line for organizations tends to focus on return on investments (ROI) and organizational gains.

After surveying the extant literature on calling work orientation, it has become evident that one commonly employed strategy has been to conduct qualitative interviews aimed at identifying what makes calling different from other work orientations. While these qualitative findings provided insight, one of the major limitations of this type of research is that they cannot be backed up with quantitative evidence. The final goal of the current study, therefore, will be to quantitatively explore the relationships between work orientation and various organizational outcomes such as job performance and job satisfaction. To investigate whether calling work orientation is predictive of positive work outcomes above and beyond its covariates of meaningful work, prosocial motivation, and spirituality, the current research will also include an analysis of incremental validity. Lastly, the current study will involve testing whether individual 
differences in core self-evaluations (i.e., generalized self-efficacy, locus of control, selfesteem, and emotional stability) and perceived career opportunity moderate the relationship between work orientation and job-related outcomes. In summary, the purpose is two-fold: 1) to clarify the construct of calling work orientation, and 2) to empirically investigate whether calling work orientation is related to job outcomes and how individual differences in personality and perception may influence this relationship. 


\section{CHAPTER TWO: LITERATURE REVIEW AND CONSTRUCT CLARITY}

The primary objective of chapter two is to clarify the construct of calling work orientation by creating a nomological network, highlighting similarities and differences between calling and related constructs. The construct clarity chapter has been divided into five major sections: calling as motivation, calling as behavior, calling as identity, calling as an attitude, and a cognitive process model of calling. The five major sections have been further divided into subsections that address more specific organizational constructs, how these constructs are similar to calling work orientation, and how these constructs differ. The cognitive process model section within the chapter includes a discussion of the interdependence of attitudes and behaviors and how they relate to the adoption of a work orientation. Although empirical evidence may not exist between calling work orientation and some work outcomes, inferences will be drawn in all of the following sections based on theory, qualitative findings, and empirical evidence. Explaining how calling work orientation is similar and different from other organizational constructs will essentially provide a better understanding of what makes this calling work orientation unique. This section highlights the findings from the work orientation literature to support the idea that calling work orientation can explain variance in employee experience above and beyond commonly measured work outcomes.

\section{Calling as Motivation}

Work motivation has been defined and conceptualized in a number of ways in the current literature, but several components can be generalized across theories (Ployhart, 2008). One common component connecting various theories and definitions of motivation is the concept of energy and effort. Proponents of self-determination theory 
have defined motivation as concerning, "energy, direction, persistence, and equifinality" (Ryan \& Deci, 2000). In goal-setting theory, Locke and Latham (1990) define motivation in terms of effort and performance on given tasks while taking into account factors such as difficulty, clarity, commitment, feedback, and complexity. Theories of job design as a determinant of motivation also include energy and effort as an outcome because in motivation-hygiene theory, motivators are thought to effectively increase employee effort as a function of job satisfaction (Hackman \& Oldham, 1976). In an attempt to consolidate these components of motivation, Pinder (1998) defines work motivation as "a set of energetic forces that originate both within as well as beyond an individual's being, to initiate work-related behavior, and to determine its form, direction, intensity, and duration”.

In one vein of motivation research it has been predicted that motivation acts as a buffer and, thus, moderates the relationship between task demands and the feeling of exhaustion or depletion at work (Baumeister, Vohs, \& Tice, 2007). Additionally, drawing from the job design theories of motivation such as motivation-hygiene theory, researchers suggest that the work environment does significantly affect motivational potential (Hackman \& Oldham, 1976). Social psychological researchers have found evidence to suggest tasks that require self-regulation or self-control are more depleting of motivation (Baumeister, Vohs, \& Tice, 2007). Complementing these findings, cognitive research proposes that there is a dissonance between motives that impacts motivation on a given task (Kehr, 2004). The following sub-sections will explore some of the aforementioned theories of work motivation as they relate to calling work orientation. The primary 
objective will be to tease out the social, cognitive, and affective components of work motivation from similar components of calling work motivation.

Prosocial and Intrinsic Motivation. When making a distinction between calling and motivation, one must first consider the fact that prosocial motivation, which is defined by a desire to benefit or help others with one's own actions, has been identified as a key component of calling (Dik \& Duffy, 2009). Both motivation and calling have been classified as a person's orientation toward their goal-directed tasks (Amabile, Hill, Hennessey, \& Tighe, 1994; Davidson \& Caddell, 1994). The underlying assumption of prosocial motivation is the desire to benefit other people; however, researchers have examined a number of specific characteristics of prosocial motivation (Grant, 2008a). The main characteristic of this type of motivation, similar to most other conceptualizations and definitions, is that it includes energy, endurance, and direction for work tasks (i.e., Grant, 2007; Latham \& Pinder, 2005; Thompson \& Bunderson, 2003). People who feel a sense of calling to their work also tend to have an increased energy, endurance, and direction toward tasks that are perceived as fulfilling their calling. Though the fundamental outcomes of persistence, performance, and productivity are similar across various types of motivation, prosocial motivation has unique characteristics. Individuals who are prosocially motivated feel a sense of moral responsibility, are committed to the people they serve above and beyond the organization, and their desire to perform at a high level is derived from autonomous feelings of work identity and value instead of organizational pressure or obedience (Grant, 2008a). Although having a calling has only recently begun to include secular work contexts, there 
is compelling support that individuals who feel called maintain a moralistic view of their work (Elangovan et al., 2010).

The autonomous feelings that prosocially motivated people experience are not identical to those experienced by intrinsically motivated individuals, those who engage in a task because the task itself is enjoyable (Grant, 2008a). Self-determination theory draws upon the three basic human needs of 1) autonomy, 2) relatedness, and 3) competence (Ryan \& Deci, 2000). Researchers suggest that prosocial motivation is somewhat less autonomous because prosocial individuals are driven by moral self-regulation instead of by personal enjoyment (i.e., hedonism; Grant, 2008). Recent definitions of calling highlight similar moral regulation; however, the regulation is said to originate from outside of the self (e.g., God, fate, a civil duty; Dik \& Duffy, 2009; Elangovan et al., 2010). Therefore, individuals who maintain a sense of calling to their line of work have yet another type of autonomy within self-determination theory. In fact, researchers suggest the motive behind helping behaviors can vary between people and these differing motives have been linked to differences in helping outcomes (Batson \& Oleson, 1991; Weinstein, 2010). Intrinsically motivated individuals tend to value the process of completing tasks; whereas, prosocially motivated individuals value the outcome of truly helping others (Batson, 1998). In addition to being outcome focused, prosocially motivated individuals tend to have a future-focused perspective of the tasks they undertake (Grant, 2008a). In other words, these individuals would cognitively evaluate their current task in the context of how completion of the task will bring about desired outcomes in the future. On the other hand, intrinsically motivated individuals prefer to focus on the immediate task at hand because they derive pleasure from merely 
participating in that task (Ryan \& Deci, 2000). These individuals undertake tasks and cognitively recognize the immediate and personal benefit of their contribution.

Drawing upon calling work orientation literature and the limited findings regarding motivation, one might expect an employee with a calling to his or her work would not only be motivational by the immediate and personal benefits but also view their work as fulfilling an even larger social need. In other words, people who report a calling work orientation may see the immediate benefit, the future benefit, and the ultimate or existential benefit their behavior has on society. When considering an example of calling work orientation such as an individual who feels a desire to join the U.S. Marines because he or she comes from a long line of Marines, it is evident that a multitude of factors are motivating that individual. Specifically, these individuals may recognize the immediate feelings of patriotism and prestige of serving their country, the future legacy that will continue to be passed down through their family, and the ultimate satisfaction of knowing that they were part of something much bigger than themselves. Mayfield and Taber (2010) make an important distinction that is important to consider when examining the motivation behind individuals with a calling work orientation:

"Motivation based on self-concept is not extrinsic because it does not stem from the expectancy that an external reward will result from the behavior; nor is it intrinsic since it does not stem from pleasure in the behavior itself. Self-concept-based motivation stems from the need to express those values with which one closely identifies. (p.72)"

It is reasonable, with these findings in mind, to predict calling work orientation would be moderately correlated to both intrinsic and extrinsic motivations but not to the 
extent that they are conceptually similar. As part of the validation study for a new calling measure, researchers measured intrinsic and extrinsic motivation along with calling work orientation (Dik, et al., 2012). They found the presence of a calling $(r=.27, p<.01)$ and search for a calling $(r=.31, p<.01)$ were both positively related to intrinsic motivation. Moreover, the presence of calling $(r=.12, p<.05)$ and search for calling $(r=.16, p<$ .01) were both positively related to extrinsic motivation. As these correlations are weak to moderate in strength, they do not suggest that calling work orientation is merely a combination of motivational factors. Alternatively, it seems a calling work orientation is comprised of several layers of motivation that include elements of prosocial, intrinsic, and to a lesser extent extrinsic motivation. Calling work orientation may be unique partly because it involves the cognitive processing of how behaviors and career decisions an employee makes now will fulfill his or her individual overall life purpose.

Within the motivation literature, there has been a motion to consolidate the various theories and to develop meta-theories (Colquitt, LePine, \& Noe, 2000). In his study, Grant (2008a) proposed that the intrinsic motivation is a factor contributing to prosocial motivation and, thus, increased employee persistence and performance. Essentially, the findings from this article suggest that perhaps there are a number of layers of motivation at work when we undertake and complete tasks. In the case of Grant (2008a), it was found that both feeling in control of the task choice and personally responsible, deriving a sense of satisfaction from the task itself and the outcome, and being able to see the immediate and long-term effects of the task related to increased performance. Calling to work, unlike the construct of prosocial motivation, is a more existential desire to benefit others. In other words, the employee who maintains a calling 
work orientation is driven by the need to find a deeper meaning or ultimate purpose for his or her existence. Adding these existential motivational layers forces individuals who feel called to evaluate how the whole of their existence impacts the well-being of the people they encounter over the course of their lifetime. In other words, the scope of calling extends beyond the immediate and intermediate goals to help others and includes the ultimate impact of one's life. Another distinction between calling, prosocial, and intrinsic motivations is related to the specificity. Drawing upon the qualitative evidence that suggests people with a calling are focused on "doing" rather than "being," another distinction can be inferred between calling and prosocial motivation (Elangovan et al., 2010). Specifically, we can infer that the parameters for someone who is called might be narrower in the sense that just engaging in a job that helps people (e.g., a firefighter or nurse) might not be fulfilling their calling. Someone with a calling is usually motivated by a particular cause or objective such as ending societal injustice, advocating for a marginalized population, or increasing other people's general well-being. Additionally, prosocial motivation has been operationally defined to include any behavior that benefits others; however, someone's calling could in fact indirectly benefit people (e.g., an environmentalist who feels called to preserve the rainforest ecosystem). It appears that prosocial motivation has a tendency to ebb and flow in people's lives, but a calling is a more specific and consistent drive toward an ultimate goal.

Meaningful Work. One early theory of motivation developed by Hackman and Oldham (1975) proposed the model that job characteristics could be motivational for employees. As part of the job characteristic model, a trend emerged for organizations to redesign work or enrich jobs to increase employee motivation. The second defining 
characteristic of calling in addition to prosocial motivation is meaningful work (Dik \& Duffy, 2009). Hackman and Oldham (1975) categorized meaningful work in terms of skill variety, task identity, and task significance with the ultimate personal and work outcomes of internal work motivation. Breaking down meaningful work into three factors, a job with skill variety would require employees to utilize many different skills or abilities when completing work tasks. A job that includes task identity would provide employees with the opportunity to start and finish a project in its entirety. Lastly, task significance would involve the extent to which a job makes an observable impact on the lives of other people (Hackman \& Oldham, 1975). Although an empirical link has been drawn between these job characteristics and motivation, more recent findings suggest this relationship may be contingent upon values such as self-concern (DeDreu \& Nauta, 2009). These studies collectively highlight the interplay of both environmental/contextual factors and individual differences. Perhaps no amount of job redesign and autonomy will successfully motivate employees who feel like they are not fulfilling a greater purpose with their work.

When considering the role of meaningful work in one's calling, researchers find that work done for purely economic or career advancement reasons do not fulfill a calling. Those individuals who view their work as a calling derive personal and social significance, a transcendent meaning (Bunderson \& Thompson, 2009; Pratt \& Ashforth, 2003). Since calling to work is both personal and social, there is an alignment between one's egoistic and transcendent needs which researchers suggest provides a stronger and deeper connection to meaningful work (Hall \& Chandler, 2005). In fact, a deeper connection to work is precisely why authors Beadle and Knight (2012) argue that the 
relationship between work orientation and meaningful work is reciprocal. They suggest that it is possible for employees in service-type jobs to derive meaning from their work on a social level and this environmental influence begins to shape their view of work as a calling. Furthermore, it is equally as likely for employees to have an idea of their calling prior to engaging in their work (i.e., a part of their self-concept) and that orientation influences their perceptions of their work as meaningful.

While Hackman and Oldham's (1975) job characteristic model does highlight some similar components of calling, the experience of calling is from the employee's perspective instead of from the organization's perspective. As a result, the attempt to increase skill variety, task identity, and task significance from the organizational perspective would be more general and global; whereas, an employee may have a more specific definition of what is significant to them. Perhaps this organizational outlook serves to explain how empirical research has found evidence that using job redesign to reduce employee feelings of boredom and malaise have been marginal at best (Bolman \& Deal, 1991). Another possible distinction between calling and meaningful work would be in the frequency of appraisal. In a study of activists, for example, researchers found that those with a calling were more amenable to redesign and job changes instead of burning out of becoming behaviorally disengaged compared to employees without a calling (Kovan \& Dirkx, 2003). These findings suggest that there may be individual differences in the frequency or willingness engage in the appraisal of the work environment. It is possible to infer, therefore, that individuals who feel called may appraise the impact of their work more often than individuals with other work orientations (e.g., job or career 
orientations). On the organizational level, the intent is simply to increase motivation; therefore, the appraisal may not occur again until motivation wanes.

\section{Calling as Behavior}

While employee's motives are important for understanding how likely an individual will behave in a particular manner, organizations are especially interested in employee behavior. Specifically, organizations want employees who are going to exceed the minimum expectations for their job description (Katz \& Kahn, 1978; Morrison, 1994). It is possible that the organizational behaviors of employees who maintain a calling work orientation are no different than employees who are working for other reasons; however, the deeply personal aspects of work as a calling are likely to influence subsequent work-related behavior. The following sub-sections will attempt to examine the major behavior-based outcomes as they relate to calling work orientation. The types of behaviors that will be discussed include those behaviors that distinguish average and exemplary employees such as organizational citizenship behavior (OCB), engagement, embeddedness, and commitment. Furthermore, a final section will include a discussion of calling work orientation and overall job performance, which includes a variety of productive behaviors within an organizational setting.

Organizational Citizenship Behavior (OCB). Motives are the foundation upon which we justify much of our behavior. Within the context of work and organizations, researchers have studied the circumstances where employees go above and beyond the typical expectations, constructs such as extra-role behavior and organizational citizenship behavior (OCB; Organ, 1997). The most widely accepted definition of organizational citizenship was proposed by Organ (1988): "Individual behavior that is discretionary, not 
directly or explicitly recognized by the organization." In a more recent article addressing some criticisms of this operational definition, Organ (1997) clarifies that the behavior is observable, cannot be enforced for all employees, does not include formal rewards, but can ultimately create a positive impression leading to possible advancement or salary increase. Van Dyne, Cummings, and Park (1995) suggest that some behaviors fall within the parameters of the job description (i.e., in-role) and others are beyond the scope of the job, extra-role behaviors. One of the key differences between in-role and extra-role behaviors on the job is that in-role behaviors can be found in an employee's job description and the employee is rewarded or compensated for these behaviors (Van Dyne \& LePine, 1998). Furthermore, if an employee fails to perform his or her in-role behaviors adequately, they will likely experience negative repercussions (Van Dyne \& LePine, 1998). While categorizing behavior as in-role or extra-role is theoretically important for clarifying organizational citizenship behavior, other researchers point out that the possibility that employees' perceptions of their job expectations differ, even if formal job descriptions are in place (Organ, 1997).

Given the assumption that OCB is discretionary and voluntary, some researchers have begun referring to these behaviors as "contextual performance" or "prosocial organizational behavior" (Borman \& Motowidlo, 1993, 1997; Brief \& Motowidlo, 1986). As with prosocial motivation, individuals choose to engage in OCB for many reasons. Traditionally, employees who reported OCB were consiered "good soldiers" wanting to make a prosocial impact on other individuals or the organization as a whole (Bateman \& Organ, 1983). According to the functional perspective of OCB, employees may engage in OCB because they are 1) generally concerned with the organization, 2) they care about 
the wellbeing of others, or 3) they want to create a good impression (Findelstein \& Penner, 2004). Those employees who engage in OCB as a form of impression management tend to engage in fewer risky OCB that may threaten their position or status in the organization (Grant \& Mayer, 2009). Alternatively, in the same study, it was found that individual reporting prosocial values did engage in these more difficult and potentially sacrificial forms of OCB. Furthermore, some employees who choose to engage in OCB to create a positive image would only do so when they believe the behavior would be visible and result in increased status (Grant \& Mayer, 2009; Hui, Lam, $\&$ Law, 2000).

Considering the general definition of $\mathrm{OCB}$, Organ et al. have broken down the overarching construct into sub-categories: altruism, compliance, courtesy, civic virtue, sportsmanship, cheerleading, and peacemaking (Organ, 1990; Organ, 1994). The behaviors that individuals who feel called to their work engage in parallel those of OCB; however, there are some exceptions. Organizational citizenship behavior research suggests that altruism is the tendency to engage in helping behavior at work and courtesy involves the consideration of others when making organizational decisions. Individuals who are called to a specific cause may not feel like they need to be particularly loyal to an organization; however, as previously mentioned, they tend to have a helping mentality regardless of the context (i.e., religious or secular). Furthermore, individuals who report having a calling to their work also have a future-focus, so they will likely consider the implications their decisions have on others. While some components of OCB are universal for people who have a calling, it is essential to account for the possibility that calling is not necessarily toward a particular job or organization. If an organization 
proves that its business ethics and mission are in alignment with the individuals calling, the individual will more likely go above and beyond the expectations outlined in the job description. There are other situations where the individuals feel called to a specific organization (e.g., an individual is reared under a particular religious faith denomination and later in life they feel called to serve in ministry in that same faith denomination). In this case, calling would be strongly related to organizational citizenship behaviors because the loyalties of the person lie in the organization. In summary, there are many components of OCB that are consistently present in people with a calling (i.e., altruism, courtesy, and peacemaking); however, these two constructs are independent and may depend on the organization's role in the individual's calling.

Work Engagement. Within the past few years, engagement and embeddedness have become topics of interest within organizational research (Halbesleben \& Wheeler, 2008). Because the construct of calling involves an employee's view of their work as fulfilling, it is important to make a clear distinction between calling, engagement, and embeddedness. Depending upon individual and environmental factors, employees set boundaries regarding how much of themselves (i.e., physical, emotional and cognitive selves) they can invest at work (Kahn, 1990). In accordance with this statement, Kahn has defined work engagement as, "the behaviors by which people being in or leave out of their personal selves during work role performances." Perceptions of meaningfulness, defined as seeing value in one's work and personal contribution, are a major contributing factor for work engagement according to Kahn's theory of engagement. Clearly these perceptions of meaningfulness are similar to those experienced by employees with a calling work orientation; however, Kahn also highlights the importance of safety to 
express aspects of the self and the availability of emotional and cognitive resources to invest in one's work. The human resource development (HRD) research has also found a relationship between perceived person-organization fit and work engagement $(r=.66)$, whereby, employees who feel like their skills and abilities match those required by the job, they are more likely to report feeling engaged at work (Shuck, Reio, \& Rocco, 2011). Interestingly, many of the qualitative interviews with employees who report a calling toward their work also report a perceived match between skills and job requirements. Given the scope of the calling literature and the notion individuals may pursue callings outside of the work environment; it would be premature to claim all employees with a calling have perceived organizational fit (P-O fit).

Another one of the most widely accepted definitions of work engagement is a "positive, fulfilling, work-related state of mind that is characterized by vigor, dedication, and absorption" (Schaufeli, Salanova, Gonzalez-Roma, \& Bakker, 2002). The first component of engagement, vigor, is defined as having increased energy for completing work-related tasks (Schaufeli \& Salanova, 2007). If considered independently from other factors, therefore, vigor parallels the energy component of motivation. With regard to calling, perhaps, vigor is merely an outcome when there is the cognitive perception that one's work is an opportunity to engage in prosocial behavior. Dedication in the definition of engagement has been conceptualized in terms of a strong involvement or investment in one's work, which leads to positive outcomes such as inspiration (Schaufeli \& Salanova, 2007). Given the fundamental characteristics of calling, the distinction that can be drawn with regard to dedication is that a calling actually precedes dedication. In other words, someone with a calling has identified behaviors and outcomes that will be fulfilling and 
seek employment opportunities that correspond with the calling (i.e., they are actively pursuing fulfillment and purpose before even engaging in work). The third component of engagement, absorption, involves the process of becoming totally immersed in one's work, to the point that the individual has difficulty detaching from it (Schaufeli \& Salanova, 2007). Rather than merely deriving personal fulfillment from the aspects of one's work, individuals who feel a sense of calling are probably more cognizant of the humanistic benefits of their work roles (Dik \& Duffy, 2009). Absorption, as engagement researchers have defined it, includes many similarities to ego-driven aspects of intrinsic motivation and having a sense of calling is thought to be selfless and prosocial by nature.

Job Performance. The construct of calling is composed of a desire to engage in prosocial behavior, a sense of meaning or purpose for one's life, and includes a summons from beyond the self. Very few studies have explicitly examined the relationship between calling and job performance; however, Hall and Chandler (2005) make a convincing argument for why a positive relationship should exist between these variables. The logic behind there argument is as follows: If an individual perceives a calling it is deeply connected to his or her sense of self, then they should strive to exceed performance expectations as a means for bettering themselves (e.g., self-actualization). When an employee is positively reinforced for increased job performance, then they are likely to internalize this as part of his or her self-esteem, thus, creating a cyclical pattern of increased performance. In a recent dissertation aimed at investigating the role of calling as a moderator of the relationship between perceived overqualification and job performance, Lobene and Meade (2013) found evidence that calling does play a significant role in performance. More specifically, this research suggests performance 
wanes for employees who feel that they are overqualified for their current position and who have a strong calling work orientation. As previously noted, researchers have explored the relationship between motivation and job performance and evidence suggests that the increased commitment to helping people leads to greater performance and persistence at work (Grant, 2008a; Thompson \& Bunderson, 2003). However, the relationship between prosocial motivation and job performance has not been found across all empirical studies perhaps because prosocial motivation is multi-dimensional and the influence of specific dimensions could be confounding this relationship (Alonso \& Lewis, 2001; Grant, 2008a). In their study of prosocial motivation, Grant (2008a) found that fundraising performance was not significantly related to prosocial motivation; however, the interplay of intrinsic motivation and prosocial motivation strengthened this relationship with performance. Researchers have also found a connection between prosocial motivation and resiliency to stress, that perceiving an impact from helping others can actually protect an individual against exhaustion (Grant, 2007). As a result, it has been predicted that this resiliency leads to increased performance on the job (Grant \& Sonnentag, 2010). When the relationship between prosocial impact and supervisory ratings of performance was tested directly, the correlation was non-significant; however, the indirect effect through emotional exhaustion was supported. Therefore, if taken together, these findings suggest that there is at very least an indirect relationship between prosocial motivation and job performance. It can be inferred, therefore, that calling would also be a predictor of job performance because prosocial motivation is such a major component of a sense of calling to one's work. 
Striving to find purpose and meaning in one's life is another major component of a sense of calling. Meaningful work has been investigated with regard to job performance and persistence outcomes. One of the three factors that makes up meaningful work in the job characteristic model (Hackman \& Oldham, 1975), task significance, has been linked to increased job performance (Morgeson \& Humphrey, 2006). The empirical literature that has attempted to consolidate findings of job design and performance has not actually found strong correlations between task significant and job performance outcomes (Fried \& Ferris, 1987; Humphrey, Nahrgang, \& Morgeson, 2007). One of the limitations of these and other similar findings is that they are primarily cross-sectional and correlational study designs; few studies have manipulated perceptions of meaningful work (Grant, 2008b). In their experimental field study research, Grant (2008b) found evidence to support a causal linkage between perception of task significance and increased job performance in three separate samples.

The experience of feeling called or summoned to a particular line of work has been linked to a greater sense of spirituality or a stronger connection to religion (Dik \& Duffy, 2009). Only a few peer-reviewed articles have attempted to measure the correlation between spirituality, religiosity, and job performance; however, a number of dissertations within the past decade have investigated this relationship (Tischler et al., 2002). In one study of leadership effectiveness and spirituality, Zwart (2000) did not find evidence to suggest spirituality was a predictor of transformational leadership. With regard to employee job strain and spirituality, it appears that those individuals who report being more spiritual also report fewer strain complaints (Frew, 2000). Generally speaking, feelings of support (e.g., perceived organizational support) have been positively 
related to work outcomes such as job performance (Rhoades \& Eisenberger, 2002).

Likewise, researchers suggest that individuals who are spiritual or religious report that they feel supported by God, a higher power, and their affiliated religious communities; this has been linked to lower levels of psychological stress and depression (Fiala, Bjorck, \& Gorsuch, 2002; Larson, Milano, \& Lu, 1998; Plante \& Sharma, 2001). Though it appears that the majority of research on spirituality and religiosity in the workplace has focused on health and well-being outcomes, the experience of feeling support from a sense of calling is likely to have a positive affect on job performance outcomes.

Although there are only a few studies to date that have empirically examined the relationship between overall job performance and calling work orientation, it can be predicted on the basis of the aforementioned linkages that a positive relationship should exist. Unlike other work behaviors and outcomes, however, job performance is a complex criterion to measure. Job performance has thought to be comprised of multiple dimensions and there is also evidence to suggest that job performance is best explained by a single factor (Viswesvaran, Schmidt, \& Ones, 2002; Viswesvaran, Schmidt, \& Ones, 2005). One of the most significant predictors of job performance is cognitive or general mental ability, which tends to be determined by both environmental and biological factors (Schmidt \& Hunter, 1996). Within the calling work orientation literature, researchers have questioned the role of education and social economic status as it relates to the adoption of a calling to a certain line of work (Elangovan et al., 2010). The relationship between calling work orientation and job performance behavior is important to explore because it is possible that the strong prosocial drive of an employee with a calling may equip him or her to compensate for shortcomings in terms of general ability. 
It is possible that although they do not maintain the same work orientation, employees who have a career work orientation and value ego needs such as promotions may perform at an equally superior level but for different reasons. Likewise, those employees who maintain a work orientation where they are primarily interested in the monetary reward may perform at a high level. Employees who maintain a calling work orientation evaluate the outcomes of their contributions at work and job performance in terms of their personal calling or mission (Burke, 1991; Lord \& Brown, 2004)

\section{Calling as Identity}

The role that individuals' jobs play in their overall sense of self and worth differ. In every conceptualization of calling work orientation, there is a strong personally defining component, which may be a spiritual or religious identification (Duffy \& Sedlacek, 2007). An individual's view of himself or herself has recently been studied within the realm of organizations and has been measured in the form of core selfevaluations, which includes traits such as self-esteem, self-efficacy, locus of control, and emotional stability (Judge, Locke, Durham, \& Kluger, 1998). The following sub-section will introduce the roles of self-concept and personal identity and how they relate to work orientation and will provide a distinction between spirituality, religiousness, workaholism, and calling constructs.

Personal Identity. Within the field of Social Psychology, self-concept has been conceptualized as a cognitive and affective appraisal process that can be influences by outside forces (Burke, 1991; Lord \& Brown, 2004). Findings from self-concept research suggests that some aspects of the self are more salient and will ultimately lead to corresponding behavior; however, other aspects of the self are activated by specific 
situations (Alexander \& Wiley, 1981; Stryker, 1987). Early theories of the self proposed by Carl Jung and other theorists center on the idea that all people are in a constant journey to discover the authentic self in relation to the world (Jacoby, 1990; Jung, 1933; Whitmont, 1969). Having a sense of calling is strongly related to purpose for one's life; therefore, it should also make up a considerable portion of one's self-concept. In one study of the self and transcendence, researchers found that most respondents tended to overemphasized aspects of the self as compared to aspects of transcendence or spirituality (Lynn, Naughton, \& Vander Veen, 2010). The work roles that are psychologically central to our self-concept are fundamental in predicting behavior that corresponds with our identity (Farmer \& Van Dyne, 2010). Although roles that are in alignment with our selfconcept generally lead to associated behaviors, Farmer and Van Dyne (2010) found that individuals who maintained a helping identity engage in prosocial behaviors even when their defined roles do not support this identity. While some may argue all people have an inherent tendency toward fulfilling self-interests, there are strong social mechanisms driving people's behavior toward others (De Dreu \& Nauta, 2009).

Individuals who endorse a calling to their work also consider their calling a life's purpose and it becomes a significant part of their personal identity. In fact, calling has been defined as, "a central facet of the narrative that a person constructs to make sense of his or her personal history (Bogart, 1994, p.12)." Drawing upon the findings regarding self-concept and identity, therefore, an individual with a specific calling will most likely recognize it as something salient in their self-concept (Stryker, 1987). A calling is also associated with what has been referred to as an other-focus (De Dreu \& Nauta, 2009). Whereas self-concern parallels a more individualistic mentality (i.e., the underlying 
motive is independent from others a group), other-orientation parallels a more collectivistic mentality (i.e., the focus is on group-level processing, social cues, and social consequences; De Dreu \& Nauta, 2009). The concept of calling seems to complement many theories of the self; in fact, researchers have suggested that calling falls nicely within self-discrepancy theory (Elangovan et al., 2010). Within this theory of the self, dissonance occurs when the ideal, actual, and ought selves do not coincide, when there is a discrepancy. This proposition was supported by a case study where some employees reported conflict between internal ideal and the external environment (Kovan \& Dirkx, 2003). Interestingly, however, these employees were able to remain engaged in their work even when experiencing self-discrepancy. Elangovan et al. (2010) posit that the convergence of the three selves occurs when and employee is fulfilling his or her calling. Though personal identity and self-concept play an important role, calling is something that originates from beyond the self. In other words, calling involves something distinct from self-esteem, self-efficacy, and other-orientation, something spiritual in nature.

Spirituality and Religiousness. While calling has been considered a function of prosocial motivation and meaningful work, most definitions also include a summons from beyond the self (Dik \& Duffy, 2009). Historically, this experience of a transcendent calling from beyond the self was almost exclusively referring to a call from God or a higher power. The origin of one's calling, spiritual or secular, is from outside of the self, but the implications of the calling are deeply personal. In fact, Dirkx (2001) describes the importance of spirituality at work as the integration of unconscious desired of the soul coming to fruition in an individual's consciousness. The "nurturing of the soul" and 
connection with spirituality is thought to facilitate a more transformational learning environment. Integrating spirituality and work is critical because work serves the function of connecting behavior, values, and meaning for many employees (Bean, 2000; Tisdell, 2000). The workplace spirituality literature has highlighted the idea that employees bring their entire selves to work and religious identity influences work behaviors; however, the conclusions that can be drawn about how religious belief influence work have been limited (Lynn et al., 2010). Despite the limited empirical evidence, spirituality remains an important area for future research.

Both spirituality and religiosity have been examined with regard to and individual's identity and sense of calling (Steger et al., 2010). There is no consensus across researchers regarding the most appropriate definition of spirituality; however, English \& Gillen (2000) have identified commonalities across definitions: 1) greater depth in life and 2) connection with things greater than oneself. Tischler et al. (2002) have classified spirituality as "personal experience of God, Allah, the Transcendent, the Beyond, the Sacred" and it is a "direct experience of something other than what is normally the focus of daily, material, sensory, or even emotional reality."(p. 207) The distinction between spirituality and religiosity is that someone who identified with a religion adopts a worldview that reflects specific values and social roles (Cavanaugh, 2001).

Only examining calling within the context of spirituality and religiosity is somewhat restrictive and may have negative implications for individuals who may be trying to discern their career decisions (Steger et al., 2010). There is some evidence to suggest that when spirituality is salient, individuals engage in more helping behaviors 
(Lips-Wiersma, \& Mills, 2002). In their study of intrinsic religiousness and meaning in life, Steger et al. (2010) concluded that calling is experienced in a similar way in both a secular and sacred context. The construct of calling was founded in a religious and spiritual tradition; however, these and other findings suggest that calling is independent from religion and spirituality.

Workaholics. The term "workaholism" has been used as a colloquial description in popular press to classify individuals who engage in excessive work involvement, are motivated in their work, and who lack the enjoyment aspect of their work (Aziz \& Zickar, 2006; Spence \& Robbins, 1992). In another definition of workaholism, Mudrack (2006) dismissed the third factor; lack of enjoyment in one's job does not need to be present for workaholism to exist. Workaholism has only recently become a topic of interest among researchers; therefore, the empirical implications of this condition on organizational outcomes are scant (Scott, Moore, \& Miceli, 1997). Similar to the concept of calling, individuals who are workaholics have a certain orientation or mindset toward the work they do; work becomes a significant part of one's self-concept. Unlike individuals who experience a calling, employees do not self-identify as a workaholic because it carries with it negative connotations (Scott et al., 1997).

The difference between work engagement and workaholism is that workaholic employees obsessively think about their work and cannot disengage even when failure to do so may have negative repercussions (e.g., on psychological or physiological health). Employees who are simply engaged in their work are able to recognize their personal limits; however, there may be a fine line between engagement and workaholism (Van Beek, Taris, \& Schaufeli, 2011). Individuals with a specific calling are indeed engaged 
when they perceive their contributions as something that makes a difference in the lives of others. Workaholism is associated with negative organizational and individual outcomes: interpersonal conflict (Mudrack, 2006), job strain, and health problems (Burke, 1999).

Research on calling suggests that individuals who feel called report less stress and depression (Treadgold, 1999) and may be especially resilient against attacks of the self. Similar to those employees who experience work-life enrichment, employees with a calling may derive fulfillment and be better equipped to handle non-work roles even though they commit a considerable amount of time and effort to their work (Grzywacz, 2002). Cardador and Caza (2012) argue that the difference between healthy and unhealthy callings is the ability to remain flexible in how an employee views their identity with work, which allows employees to cope with the changes in the profession, the self, and the organization.

While there is some support that an employee with a calling work orientation may not experience the same aspects of workaholism, other work-life balance research suggest that investments in work roles can become detrimental to other roles and relationships when the investment in work becomes too great (Carlson, Witt, Zivnuska, Kacmar, \& Grzywacz, 2008). It is not uncommon for employees with a calling to invest a considerable amount of time and even sacrifice aspects of the self for the sake of their calling (Bunderson \& Thompson, 2009). In their study of calling conceptualizations, Bunderson and Thompson (2009) differentiate between classic formulations as a personal duty and a contemporary formulation as a focus on personal fulfillment and passion. These researchers found that the benefit of a calling was not without costs. More 
specifically, a calling can also come with feelings of rigid duty, self-sacrifice, and heightened commitment. In other words, like workaholism, calling can be a double-edged sword. It can be wonderfully fulfilling and personally draining (Serow, 1994). A deep sense of calling has been linked to burnout as a result of unrealistic performance expectation of the self and others (Vinje \& Mittelmark, 2007). Workers with a calling orientation may become chronically dissatisfied when they have unmet goals (Hirschi, 2011). Unrealistic expectations that are set by the employee with a calling may create unnecessary stress and interpersonal conflict, which is similar to that experienced by workaholics (Cardador \& Caza, 2012).

\section{Calling as an Attitude}

There is some debate regarding what is and is not considered a job attitude, and some early researchers have even recognized job design and motivation as job attitudes (Lawler \& Hall, 1970). More recently, researchers on job attitudes suggest that a revolution or paradigm shift is underway and the cognitive conceptualization of job attitudes (i.e., Locke, 1969) that was widely accepted is being challenged with more affective perspectives (Judge \& Ilies, 2004). Job satisfaction is the job attitude that is most often measured and is organizational outcome that has been linked to calling work orientation most often (Duffy et al., 2011). The following sub-section will outline the empirical evidence from studies that have examined job satisfaction and establish the link between attitudes and calling work orientation in general.

Job Satisfaction. The focus of most current empirical research on calling work orientation has investigated the relationship between job attitudes such as job satisfaction and calling (Cardador et al., 2011; Duffy et al., 2011). The basic assumption from 
vocational and career counseling literature about calling and job satisfaction is that individuals who feel as sense of calling are aware of the social contributions of their work and this awareness leads to increased job satisfaction (Dik, Duffy, \& Eldridge, 2009). Hall and Chandler (2005) make the profound claim that a calling orientation to one's work leads to "the deepest form of satisfaction or psychological success."(p. 160). Additionally, the research on meaningful work supports the idea that employees who value their work above and beyond the monetary compensation also report greater job satisfaction (Dik et al., 2009). Evaluating job satisfaction within the context of calling is thought to be especially intriguing because how an individual views their work may have a more significant impact on job satisfaction than status or income (Duffy \& Sedlacek, 2007).

As previously noted, sometimes individuals are at a different phase in determining their calling work orientation (Pratt \& Ashforth, 2003). A university student, for example, may desire work that will be fulfilling to his or her personal mission in life (e.g., to be a trauma nurse) and be making strides in that direction. Alternatively, an information technology (IT) specialist may have the required education and training, be working in an organization's technology department, and be searching for new employment opportunities that better fit his or her life's purpose. Both of these examples illustrate the idea that a calling work orientation is a process whereby there are phases of both evaluation and inquiry. The relationship between calling and job satisfaction has been hypothesized to depend largely on the stage in the calling process (e.g., search for calling vs. fulfilling a sense of calling; Duffy \& Sedlacek, 2007). Specifically, those individual who may be actively searching for a work that aligns with their calling tend to experience 
less satisfaction and other negative psychological outcomes. In a qualitative study of employees who either did not answer their calling or who received an additional calling over time, Berg, Grant, and Johnson (2010) found that participants reported dissatisfaction with their current job was the motivating factor for their renewed interest in pursuing their calling. Regarding the participants who reported receiving an additional calling tended to experience less long-term regret and less dissatisfaction (Berg et al., 2010). Comparing the job satisfaction of participants who self-reported a job, career, or calling orientation toward their work, Wrzesniewski et al. (1997) found that participants with a calling orientation had a higher job and life satisfaction even when controlling for variables such as income, education level, and occupational type. Taken together, these findings provide sufficient evidence to suggest that the various stages of calling and orientations an employee maintains do relate to job satisfaction.

Because the majority of empirical studies that have examined calling have adopted a vocational or career counseling focus, job satisfaction is commonly measured. When examining the influence of zest and calling on attitudinal outcomes of job and life satisfaction, Peterson et al. (2009) found positive relationships (Job: $r=.54, p<.001$; Life: $r=.32, p<.001)$. Job satisfaction was measured by Cardador et al. (2011) primarily to control for its affects on organizational attachment; however, they also found positive correlations between calling orientation and job satisfaction $(r=.55, p<.05)$. In another empirical study of calling, job satisfaction, and career commitment, Duffy et al. (2011) report a moderately strong correlation of calling with job satisfaction $(r=.31, p<.01)$ and career commitment mediated this relationship. In a follow-up study, researchers found that the relationship is significant and is moderated by the degree to which the 
called individual feels that they are fulfilling their calling (Duffy, Bott, Allan, Torrey, \& Dik, 2012). In summary, there is a considerable amount of empirical and theoretical evidence in support of the relationship between calling and job satisfaction.

While there is evidence to suggest a positive relationship, there have been some exceptions. For instance, various qualitative investigations suggest that those who have a sense of calling may also maintain a chronic sense of dissatisfaction, which originates from constant salience of the incomplete. In other words, some individuals with a calling have an unrealistic "ought" self and, therefore, feel inadequate (Elangovan et al., 2010). Interestingly, some researchers have evidence that individuals who report a sense of calling also may forego job satisfaction for the sake of others (i.e., self-sacrificing behavior; Dik \& Duffy, 2009; Hardy, 1990). There are some limitations to the aforementioned findings because they are merely correlational studies. Duffy et al. (2011) note this limitation and propose that a reciprocal relationship could exist: job satisfaction may yield a greater sense of calling for employees. As with job performance behavior, job attitudes fluctuate very frequently and are dependent upon many organizational and environmental factors in addition to work orientation. An employee's cognitive evaluation of his or her contribution to others is likely to be influenced by his or her attitude toward work, but not exclusively.

Organizational Commitment and Job Embeddedness. Another job attitude that has been recognized in the organizational literature is organizational commitment, which is comprised of behavioral, cognitive, and affective elements. Organizational commitment has been categorized in terms of three lower order factors: normative, affective, and continuance commitment (Meyer \& Allen, 1991). The affective type 
involves the emotional associated with the aligning of one's personal goals with those of the organization. In other words, an employee develops a positive attachment or bond with their current employment situation. Continuous commitment is primarily a cognitive process of evaluating one's working conditions rather than an emotional state. This type of organizational commitment exists when the negative outcomes of leaving the organization (i.e., voluntary turnover) outweigh the benefits of finding alternative employment (Schleicher, Hansen, \& Fox, 2010). The third factor of organizational commitment, the normative type, is characterized by a self-imposed sense of moral obligation to the organization, perhaps because of perceived organizational support or investments (Meyer \& Allen, 1991). Organizational commitment involves maintaining positive beliefs about organizational goals and values, but not necessarily the organization itself (Cardador et al., 2011). Employees with a calling are likely to be dedicated to the work itself, rather than the place of work (Pratt \& Ashforth, 2003).

In an extensive review of organizational commitment literature, correlations and antecedents, Schleicher, Hansen, and Fox (2010) found that altruism was moderately related to commitment $(\rho=.20)$. The findings by Schleicher, et al. (2010) are intriguing with regard to an employee's calling work orientation because altruism has been described as an attitude or worldview that corresponds with the prosocial motivation. Because altruism is theorized to be a large component of a person's calling orientation, it is also be important to examine how commitment is involved in a person's calling. Although altruism and commitment are related according to the thorough review of literature (Schleicher et al, 2010), the two constructs are conceptually distinct. In fact, the limited research examining both commitment and calling has found a strong link to 
current and future career commitment (Bunderson \& Thompson, 2009; Duffy \& Sedlacek, 2007; Steger et al., 2010). In a more recent empirical study of commitment and calling, Duffy, Dik, and Steger (2011) tested a model; whereby, career commitment was thought to mediate the relationship between calling and other organizational outcomes. The direct effects in their hypothesized model were consistent with prior research: individuals who maintained a calling work orientation were more likely to report organizational commitment. There was partial support for an indirect effect for career commitment as a mediator between calling and organizational commitment. These findings suggest that individuals whose calling align with career goals will display organizational commitment behaviors, and those employees who have a calling but are not committed may be searching for an alternative environment to fulfill their calling (Duffy et al., 2011).

Job embeddedness is similar to commitment and engagement, in that, the primary mechanism involves the forces acting upon an employee to keep them from leaving their organization (Yao, Lee, Mitchell, Burton, \& Sablynski, 2004). Within the organizational commitment literature, normative commitment has been identified as having similarities to job embeddedness because both are negatively related to turnover. A strong link has been identified between calling and commitment to one's career (Bunderson \& Thompson, 2009; Duffy, Dik, \& Steger, 2011; Steger, Pickering, Shin, \& Dik, 2010). Organizational identification, defined as the degree to which an employee sees their job as a part of their self-concept, is similar to job embeddedness (Cardador et al., 2011). With this in mind, researchers posit that employees with a calling work orientation are more likely to experience personal connectedness to their organization $(r=.42, p<.05)$. 
Specifically, researchers on calling have found support that commitment to career acts as a mediator of work outcomes of organizational commitment and withdrawal intentions. With these findings in place, one must be hesitant to make the claim that calling is simply how a person justifies their commitment, embeddedness, and engagement. In calling, engagement, and embeddedness an employee may derive meaning from their work; however, the intentions and motives behind the behavior may differ.

\section{Attitude Formation and Calling as a Process}

Critics may suggest calling is merely an attitude that an individual maintains a mechanism to provide sufficient justification for why and individual has chosen a specific career path. Furthermore, qualitative and empirical research on the construct of calling suggests that an individual's work orientation may shift throughout the lifespan (Davidson \& Caddell, 1994). When examining the role of calling in a college student population, for example, there is evidence that a calling is a process of acknowledging and making career decisions that correspond with that work orientation (Duffy \& Sedlacek, 2010). Because calling is a process that involves both an attitudinal and behavioral response, it is essential to understand the possible antecedents. Within the social psychological literature, researchers have identified three predominant theories to explain the relationship between attitudes and behaviors: self-perception, selfpresentation, and cognitive dissonance (Myers, 2010). The following section will outline the attitude formation process as it related to calling.

Self-Perception Theory. The underlying assumption of self-perception theory, proposed by Bem (1972), is that individuals examine their situation and infer their attitude based on corresponding behaviors. In other words, an employee who engages in 
counterproductive work behaviors (CWB) would infer that his or her attitude (i.e., job satisfaction) must be negative toward the organization. Viewing a sense of calling to work from the perspective of self-perception theory would suggest that individuals whose work situation involves engaging in prosocial behavior or making a difference in the world would infer that they must feel a sense of calling. Empirical research has, in fact, found some support for self-perception theory and prosocial behaviors. For example, employees participating in work for "the greater good" reported a deeper sense of selfidentity, stronger helping values and beliefs (Boggs, 1986; Kovan \& Dirkx, 2000; Scott, 1992). Because the experience of calling has been observed in all types of work, even in jobs that are considered taboo or "dirty," the self-perception theory of why people who feel called also report satisfaction may be insufficient (Ashforth \& Kreiner, 1999). In one study of college students, Duffy et al. (2010) found that the intent to pursue advances academic degrees (i.e., doctorate, medical, or law) was associated with a greater report of a sense of calling than students whose intent was to pursue a bachelor's or master's degree. The pursuit of prestigious or inherently prosocial areas of work such as a professor, physician, or lawyer can contribute to the argument that education level is an antecedent of calling (Davidson \& Caddell, 1994). This finding provides some evidence to suggest that self-perception may influence the report of a calling for some individuals.

Self-Presentation Theory. The self-presentation theory of attitudes and behaviors attempts to explain this relationship in terms of impression management; people have an inherent desire to be perceived as consistent instead of as a hypocrite (Leary, 1994). Therefore, employees who are driven by impression management are more concerned with how their supervisor and co-workers view their behavior and make an 
extra effort to appear in a positive light (Leary \& Kosvalski, 1990). Self-presentation suggests that individuals will modify their behaviors to be in accordance with their previously defined attitudes. With regard to the previous example of the employee who engages in counterproductive work behaviors (CWB), self-presentation theory would assume that the employee developed a negative attitude toward the organization and, in order to be perceived as consistent, the employee would decide to behave in counterproductive ways such as stealing office supplies or withdrawing from work responsibilities. Other conceptualizations of self-perception theory (Grube \& Piliavin, 2000; Piliavin, Grube, \& Callero, 2002) suggest that roles become a part of an individual's self-concept and expectations from the external environment serve to drive future behavior. When considering the influence of self-presentation on the formation of a calling attitude and subsequent satisfaction self-reports, the assumption would be that the attitude existed prior to engaging in prosocial behavior and individuals would report a calling because of a social norm or impression management. This assumption is consistent with the modern theories of calling as something that transcends a specific work situation; however, it cannot account for individuals who experience a calling to their work but do not engage in the corresponding prosocial behavior. Furthermore, discerning the true relationship between calling as an attitude and behavior is complicated by the fact that some vocations or careers expect that individuals express a sense of calling (i.e., religious organizations and professions traditionally considered to involve a calling). Moreover, having a calling to one's work is sometimes initiated because of a family legacy (Dik, Duffy, \& Eldridge, 2009). In Western culture, calling has become an especially desirable characteristic and popular press has taken hold of the concept in 
books using phrases such as "Live your Calling” (Brennfleck \& Brennfleck, 2005;

Cardador, Dane, \& Pratt, 2011). Considering the aforementioned findings, it appears that normative influences may be an antecedent of calling work orientation.

Cognitive Dissonance Theory. Perhaps the most widely studied theory of how attitudes affect behavior, cognitive dissonance, builds upon the assumption that incongruent thoughts between one's behaviors and attitudes cause cognitive tension (Cooper, 1999; Festinger, 1957). There are three major theories of cognitive dissonance: self-consistency, self-affirmation, and the "New Look" theory. The self-standard model of cognitive dissonance theory, which attempts to consolidate the three main dissonance theories, is based on the presumption that individuals engage in a behavior and measure that behavior against some meaningful judgment criteria (Stone \& Cooper, 2001).

Generally speaking, people prefer to view themselves as consistent (i.e., selfconsistency), to highlight the more positive aspects of the self to reduce internal threats to one's self-esteem (i.e., self-affirmation), and to change undesirable behaviors (i.e., the New Look). With the dissonance framework in mind, it is possible to infer that individuals who report a calling do so as a means for justifying a career choice when there is an internal conflict or interest (e.g., a moral obligation or tension). The antecedent of a calling for some employees may the perceived incompatibility of their current work situation with aspects of their self-concept (i.e., self-consistency). Contrary to the motive of truly altruistic and prosocial individuals, the antecedent for someone with a calling work orientation may also be self-serving to bolster his or her self-esteem (i.e., selfaffirmation). When examining how perceived prosocial impact differs across people, Grant and Sonnentag (2010) found evidence to suggest that this perceived impact of their 
behaviors is especially important for those who have negative appraisals of their work tasks and identities (e.g., low core self-evaluations).

In one study of zest (e.g., passion or vigor) and work orientation, researchers analyzed group differences in calling across a variety of occupational types: professional, managerial, administrative, clerical, blue collar, and homemaker (Peterson, Park, Hall, \& Seligman, 2009). Results from this study suggest differences across occupational types exist, but the effect sizes are small. Although the effect sizes were small, occupation accounted for more variance in calling than for other work orientations (i.e., career or job orientations). Findings support the notion that calling, career, and job work orientations span across many occupations. In other words, regardless of the type of occupation, employees may be primarily motivated by monetary incentives, prospects for promotion or status, or to fulfill their life's purpose. In addition to this general finding, Peterson, Park and Seligman (2009) also suggest occupation was a stronger predictor for calling work orientations. Perhaps employees in higher status, professional work are looking to their occupation for validation of a calling, or these employees have sought out their high status occupations to have congruence between their calling and occupation. The formation of a sense of calling is said to originate from beyond the self, yet the few empirical studies that have examined individual differences such as education level and occupation type have yielded findings that suggest otherwise. A more robust approach to calling research would benefit from exploring the full process of acknowledging a sense of calling through the experience of fulfilling a calling. 


\section{CHAPTER THREE - CURRENT STUDY}

The primary purpose of the current study is to develop hypotheses that are derived from the current conceptualization of calling work orientation (Dik \& Duffy, 2009). Most of the extant calling literature has examined the role of work orientation from the employee perspective and has focused on job attitudes such as job satisfaction and commitment (Dik \& Duffy, 2007; Duffy et al., 2010), and there is a gap with regard to the affect of work orientation on job performance. Over the course of several decades, mating theory has been applied when considering employee recruitment and selection functions: employees search for work opportunities where they feel they can utilize their personal skills and abilities; meanwhile, organizations use various techniques to determine whether employees will fill a desired need (Cascio, 1998). Mating theory is the basis of the widely accepted attraction-selection-attrition (ASA) model that suggests only interested individuals apply for a position, only the most qualified are selected, and those employees whose performance is suffering either voluntarily or involuntarily exit the organization (Schneider, 1987; Schneider, Smith, \& Goldstein, 2000). It is important to note, however, that other organizational and individual factors such as discrimination in recruitment and selection procedures also contribute to the ASA model. Another possible cause of voluntary or involuntary turnover related to the ASA model is the Peter Principle, which suggests that individuals may also rise through the ranks in an organization and be employed in a position that is beyond their individual capabilities (Peter \& Hull, 1969). Considering both the ASA model and Peter Principle, it can be inferred that individuals who are currently engaging in work that they consider their calling have most likely found their ideal match. In general, the demographics of the 
current workforce are changing (e.g., an aging and more ethnically diverse workforce) and according to the Bureau of Labor and Statistics (BLS, 2010) the median tenure for U.S. employees is only 4.4 years. In our current economic recession, perhaps individuals are simply satisfied with their current job because if they make a social comparison, job security is more salient. From an organizational perspective, management may feel an ethical responsibility for their employees to be satisfied, but the bottom line for most organizations is usually return on investment (ROI; Sher, 2012). With managers placing so much importance on employee performance, knowing whether an employee's work orientation is predictive of job performance would be invaluable for an organization.

$H_{1 A}$ : Employees who report a calling work orientation perform at a higher level compared to employees who report a career or job orientation.

$H_{I B}$ : There is a positive relationship between calling work orientation and selfreport and other-report job performance.

In recent years, organizations and managers have recognized the importance of measuring performance-related behaviors that transcend those of overall job performance (Miles, Borman, Spector, \& Fox, 2002). On the positive side of this continuum, there are organizational citizenship behaviors (OCB), which are defined as behaviors that contribute to organizational goals above and beyond those, outlined in a formal job description. On the negative side, researchers have defined counterproductive work behaviors (CWB), which may encompass such behaviors as severe as workplace aggression, sabotage, revenge, theft or seemingly innocuous behaviors such as absenteeism or intentionally wasting time at work (Fox, Spector, \& Miles, 1999). When considering the underlying factors related to OCB and CWB, Miles et al. (2002) 
highlighted the importance of appraising individual (e.g., positive/negative affect, neuroticism, locus of control) and environmental (e.g., organizational constraints) factors.

Counterproductive work behaviors (CWB) have been defined as "intentional behavior on the part of an organization member viewed by the organization as contrary to its legitimate interests" (Sackett, 2002, p.5). Many researchers regard CWB as behavioral indicators of a specific facet of job performance (Campbell, McCloy, Oppler, \& Sager, 1993; Sackett, 2002). Some examples of measureable CWB include the following: theft, destruction of property, misusing or wasting time, revealing confidential information, not abiding by safety regulations, inexcusable absenteeism, alcohol or substance use at work, and physical or verbal violence (Gruys, 1999). Although there have been mixed results across studies, meta-analytic exploration of the relationship between CWB and job performance has yielded support for a significant negative correlation (e.g., Viswesvaran, Schmidt, and Ones (1999) found a significant negative observed correlation $(r=-.54)$. Given the relationship between CWB and the empirical support for its use in predicting job performance, the following hypothesis is offered.

$H_{I C}$ : Employees who report a calling work orientation conduct fewer counterproductive work behaviors (CWB) compared to employees who report a career or job orientation.

$H_{I D}$ : There is a negative correlation between calling work orientation and counter-productive work behaviors (CWB).

As described above, organizational citizenship behaviors (OCB) are those that are not formally outlined by an employee's job description, but that are "above and beyond" what is expected in the workplace. An organization cannot function optimally if their 
employees merely perform the tasks outlined in the job description. Katz and Kahn (1966, p. 338) describe that OCB are "vital to organizational survival and effectiveness." In fact, the term OCB emerged as a method to link affective states associated with job satisfaction to factors important to organizational effectiveness (Motowidlo, 2000). Some of the behaviors that were originally associated with organizational citizenship included what we now consider prosocial behaviors such as volunteering, following rules, or coming up with innovative solutions to organizational problems (Borman \& Motowidlo, 1993; Motowidlo, 2000). These OCB have been attributed to organizational success and performance in several different ways: 1) increasing employees and manager productivity; 2) managing resources more efficiently; 3) increasing interdepartmental or intergroup cooperation; and 4) increasing organizational attractiveness, and providing more organizational flexibility during times of change and growth (Podsakoff, MacKenzie, Paine, \& Bacharach, 2000).

There seems to be a fairly consistent link between OCB and outcomes of job performance according to the aforementioned findings. A considerable amount of research has also explored the antecedents and individual differences that may foster OCB in employees. For example, in a more recent study of OCB, Mayfield and Taber (2009) found that students with a prosocial self-concept were more likely to engage in OCB in a university setting $(r=.16, p<.05)$. In a similar study, Grant (2010) found that employees who perceived their work as having a prosocial impact helped to shift their focus away from self-serving activities to focus outward on others. Additionally, Grant found evidence to suggest employees with a perceived prosocial impact were protected 
from becoming emotionally exhausted and were able to contribute more in terms of job performance.

$H_{I E}$ : Employees who report a calling work orientation engage in more organizational citizenship behaviors (OCB) compared to employees who report a career or job orientation.

$H_{I F}:$ There is a positive relationship between calling work orientation and organizational citizenship behaviors (OCB).

In one of the most influential articles outlining utility and validity of job performance criteria, Schmidt and Hunter (1998) found that general mental ability or cognitive ability is the best predictor of job performance across jobs. Another factor that has consistently been found to predict job performance is the personality variable of conscientiousness (Barrick \& Mount, 1991; corrected $r=.26$ ). One of the aims of the current study will be to determine whether the degree to which an employee has a sense of calling to their work is predictive of performance above and beyond general mental ability and conscientiousness.

$\mathrm{H}_{2}$ : Calling work orientation is incrementally predictive of job performance above and beyond general mental ability and conscientiousness.

The definition of calling that has recently been adopted by the majority of researchers in this area includes three major components: prosocial motivation; meaningful work; and summon to the work from beyond the self (Dik \& Duffy, 2009). One of the challenges of this conceptualization is that summon from beyond the self has been difficult to quantify and researchers have resorted to measuring aspects of religiosity and spirituality (Duffy, 2006). The combination of all three factors are thought to interact 
to form an individual's work orientation and that employees who maintain a different orientation (i.e., a career or job orientation) can be prosocially motivated, but not called. As a means of investigating whether calling work orientation does indeed involve the interplay of these three components, the incremental validity of a sense of calling in predicting job performance above and beyond the sub-components (i.e., prosocial motivation, meaningful work, and spirituality) will be tested. Likewise, the incremental validity of a sense of calling in predicting job satisfaction and work engagement will be examined above and beyond the sub-components of calling.

$H_{3}$ : Calling work orientation is predictive of job performance above and beyond prosocial motivation, meaningful work, and spirituality

$H_{4}$ : Calling work orientation is predictive of job satisfaction above and beyond prosocial motivation, meaningful work, and spirituality

$H_{5}$ : Calling work orientation is predictive of work engagement above and beyond prosocial motivation, meaningful work, and spirituality

As mentioned above, individuals may have a sense of calling, be in the process of discerning a calling, or not have a calling at all (Duffy \& Sedlacek, 2007). Additionally, an individual who reports having a calling may or may not perceive their work as fulfilling that calling. Given these various stages in the work orientation process, the changing nature of current jobs, and the continual process of evaluation on the part of the employee, it is essential to understand the role of the organization in this process. Perceived career opportunity is a relatively new consideration for organizational researchers as has been defined in terms of the degree to which career goals align with the prospect or opportunity that the organization provides for attaining those career 
aspirations (Kraimer, Seibert, Wayne, Liden, \& Bravo, 2011). Regardless of whether they are studying work orientation or perceived career opportunity, researchers recognize that the ever-changing work environment makes an employee's appraisal of his or her work more complicated. If one were to consider these findings together, this suggests that those individuals who maintain a calling work orientation and who report having sufficient perceived career opportunity may be especially equipped to experience job satisfaction and job performance.

$\mathrm{H}_{6}$ : Perceived career opportunity (PCO) moderates the relationship between calling work orientation and job performance.

$H_{7}$ : Perceived career opportunity (PCO) moderates the relationship between calling work orientation and job satisfaction.

$H_{8}:$ Perceived career opportunity (PCO) moderates the relationship between calling work orientation and work engagement.

There may also be individual differences that affect the relationship between work orientation and organizational outcomes. One such individual difference is core selfevaluations, which has been conceptualized as the lens through which we view our world and the people around us. Core self-evaluations are defined by a set of four personality traits that are theoretically underlying an individual's perception of their surroundings and which guide their evaluation process overall (Judge et al., 1998). The four facets of the core self-evaluation factor are generalized self-efficacy, self-esteem, emotional stability, and internal locus of control. Taken together, an individual who is high on core self-evaluations would appraise himself or herself as worthy (i.e., self-esteem) and capable of attaining their goals (i.e., self-efficacy). Furthermore, these individuals would 
attribute their successes to internal or dispositional factors (i.e., internal locus of control) and are generally comfortable dealing with emotional situations without getting too depressed, anxious, or angry, as a result leading to increased job satisfaction and job performance (Judge \& Bono, 2001). One of the major gaps in the work orientation literature has been in the empirical examination of individual differences as they relate to work outcomes. One exception to this lack of individual difference inquiry has been the study of self-efficacy as it relates to calling orientation and various outcomes. In one study by Domene (2012), researchers found support for the mediating role of selfefficacy between undergraduate students' sense of calling and perceptions of career outcomes. A similar study by Duffy et al. (2011), found that self-efficacy fully mediated the relationship between presence of a calling and academic satisfaction for undergraduate students. While these results do provide some evidence to suggest individual difference contribute to overall perceptions of work, they do not account for how they affect performance and attitudinal outcomes for a work sample. To fill the gap in the literature, core self-evaluations will be examined as a possible moderator of the relationship between calling work orientation and outcomes of job satisfaction, job performance, and work engagement. Considering the underlying theories of work orientation and core self-evaluations, several inferences can be drawn. When an individual has a calling work orientation and feels confident and capable of his or her abilities and has a solid sense of self, they are likely to be even more satisfied with their work, will be more engaged, and will perform at a higher level. Another aim of the current model, therefore, will be to examine the possible moderating effect of the 
organization by measuring perceived career opportunity and the individual by measuring core self-evaluations.

$H_{9:}$ Core self-evaluations (CSE) moderate the relationship between calling work orientation and job performance.

$H_{10}$ : Core self-evaluations (CSE) moderate the relationship between calling work orientation and job satisfaction.

$H_{11}$ : Core self-evaluations (CSE) moderate the relationship between calling work orientation and work engagement. 


\section{CHAPTER FOUR - METHOD}

\section{Participants - Pilot Sample}

Prior to collecting data for the current dissertation, the scales identified for the study were pilot tested on a sample of working students. Participants were recruited from Florida International University’s SONA research hosting website. Eligibility requirements for the pilot sample included being currently employed at least part-time and at least 18 years of age (to provide informed consent). Data were collected from 520 $(\mathrm{M}$ age $=22.2$ years, $\mathrm{SD}=4.76)$ working students. The majority of participants were women $(80.6 \%)$ and the ethnic background of participants was as follows: Hispanic (75.6\%); White/Caucasian (9.2\%); Black/African American (9.0\%); Asian (2.3\%); and other (3.8\%). Most participants reported working part-time, between 15 and 40 hours per week (58.1\%), and fewer students reported working full-time, over 40 hours per week $(16.0 \%)$. Previous research reports that students are about equally likely to have a calling, career, or job work orientation; however, only about $10.6 \%$ of students reported that their work was a calling. Instead, most students reported their current work as merely a job $(67.3 \%)$ to meet their financial obligations (see Tables 1 and 2 for a full breakdown of pilot sample demographics).

\section{Procedure - Pilot Sample}

Students signed-in to access their SONA systems account at which time they were redirected to the online survey materials hosted by Qualtrics. A brief description with enough information for students to make an informed decision whether or not they would like to participate was provided prior to the online consent form. Participants completed survey items including calling work orientation, job satisfaction, job performance, work 
engagement, spirituality, meaningful work, prosocial motivation, core self-evaluations, and perceived career opportunity. Students then read about the aims of the study and electronically provided consent. Following the consent, participants indicated the degree to which they agreed or disagreed with each statement. Once participants completed the scale portion of the survey on the first session, they were asked a series of demographic questions that included age, gender, ethnicity, hours worked per week, and type of work. Upon completion of the study, participants received research credit toward a psychology course.

\section{Participants - Work Sample}

The work sample of participants were full- or part-time employees recruited from Amazon's Mechanical Turk website who were at least 18 years of age (to provide informed consent). Amazon Mechanical Turk allows employees to create an account and be paid to take part in research studies. Researchers are able to create a separate account through Amazon Mechanical Turk where they can recruit eligible participants by posting an advertisement for their study. As with other recruitment techniques, there have been critics who question the reliability of data collected from Amazon Mechanical Turk. Recent studies aimed at determining the reliability and validity of data collected on Mechanical Turk have found samples to be diverse and reliable (see Buhrmester, Kwang, \& Gosling, 2011; Mason \& Suri, 2012; Paolacci, Chandler, \& Ipeirotis, 2010). Additionally, we chose this option as participants' responses could remain anonymous thus reducing response distortion, and employee data are relatively context free (e.g., multiple organizations and occupations) versus data from a single or small number of organizations. On the basis of an a priori analysis of power with the anticipated number 
of predictors and an anticipated medium effect size determined by using the Cohen $\mathrm{f}$ squared estimations, a sample of at least 500 participants would yield sufficient power for the hierarchical regression analyses (Soper, 2012).

Data were collected from $520(M$ Age $=32.2$ years, $S D=1.0)$ employees from both the United States $(N=287)$ and non-US countries $(N=228)$. The majority of participants were men (58.5\%). In terms of ethnicity, the current sample was comprised of 47.1\% White/Caucasian, 42.9\% Asian/Indian, 3.8\% Black/African American, 2.3\% Hispanic, 1.9\% Multi-Racial, 0.4\% Afro-Caribbean, 0.2\% Pacific Islander, $0.2 \%$ Native American, and $1.0 \%$ other. With regard to education level, most participants had earned a Bachelors' degree (45.8\%). About $93.3 \%$ of participants reported having at least some post-secondary education (i.e., some college). Because the construct of calling involves a spiritual component, religious affiliation was measured as a study demographic. The average number of hours worked per week for the work sample was 41.2 hours. The occupational tenure for this sample was 6.35 years and the organizational tenure was 4.81 years (see Tables 3 through 6 for a breakdown of the work sample demographics). Another demographic measured in the current sample was occupational type. Theoretically, it is thought that employees from all occupations are equally likely to report a calling, career, or job work orientation. To investigate this assumption, a breakdown of occupation type by calling, career, and job is provided (see Table 7 for a this breakdown). 


\section{Procedure - Work Sample}

Participants signed-on to Amazon Mechanical Turk at which time they were redirected to the online survey materials hosted by Qualtrics. A brief description with enough information for employees to make an informed decision whether or not they would like to participate was provided prior to the online consent form. Participants completed survey items including calling work orientation, prosocial motivation, meaningful work, job performance, job satisfaction, work engagement, spirituality, OCB, CWB, conscientiousness, core self-evaluations, perceived career opportunity, and numeracy scales. Before the survey, participants read about what the study would entail and electronically provided consent. Following the consent, participants indicated the degree to which each statement is true for them or filled in numerical responses for numeracy scale items. Once participants completed the scale portion of the survey, they were asked a series of demographic questions that included age, gender, ethnicity, religion/spirituality, education, job tenure, job title, and type of work. Participants were asked whether they would mind having a supervisor rate their job performance. Emails were sent to participants with directions on how to have their supervisor rate their job performance. To ensure participant confidentiality, employee email addresses were not linked to any of the scales for individual analysis. Only aggregated, group-level data were analyzed. Upon completion of the study, participants received payment of one dollar through Amazon Mechanical Turk.

\section{Materials}

Work Orientation. To categorize work orientation as calling, career, or job, participants read three statements and selected the one that best describes their attitude 
toward their work. These three work orientation statements were developed by Davidson and Caddell (1994) and utilized for the current study (see Appendix A for items).

Calling Scale. The 12-item Calling Scale developed by Dobrow and Tosti-Kharas (2011) was used in the current study to measure the degree to which participants feel called, in addition to the categorical classification that was obtained using the statements described above. In four separate samples, scale developers found that internal consistency reliability scores were very good: high school students pursuing music $(\alpha=$ $.88)$, high school students pursuing performing arts or writing $(\alpha=.90)$, undergraduate and graduate business students $(\alpha=.90)$, and professional managers $(\alpha=.94)$. Across their four samples, the inter-item correlations were sufficient and ranged from .41 to .73 (Mean $r=.63$ ). An exploratory factor analysis (EFA) was conducted on the various samples and test developers found that two factors emerged for the high school musicians and high school performing artists; however, a Scree test was conducted and all four samples revealed a single factor structure (Dobrow \& Tosti-Kharas, 2011). On the basis of the theoretical underpinnings of the calling construct, scale developers conducted a confirmatory factor analysis (CFA) to determine the fit of a model whereby all 12 items loaded on one factor. Fit index results suggest that the model fit was adequate (Comparative Fit Index $=.90 ;$ Standardized Root-Squared Mean Residual $=.06)$. To examine the convergent validity of this newly developed calling scale, researchers administered it alongside three other established scales: Calling Orientation Scale (Wrzesniewski et al., 1997), Neoclassical Calling Scale (Bunderson \& Thompson, 2009), and 2-item Calling Scale (Duffy \& Sedlacek, 2007). As anticipated, the 12-items were significantly related to the Calling Orientation scale for samples $1(r=.19), 3(r=.27)$, 
and $4(r=.61)$ and were significantly related to the Neoclassical Calling Scale $(r=.59)$ and the 2-item Self-Defined Calling Scale $(r=.48)$ for sample 4. Multiple measures of calling work orientation were not measures in sample 2 of this validation study. A sample item for the scale is "The first thing that I often think about when describing myself to others is that I am a [insert job title]" (see Appendix A for items). Participants responded to statements on a 5-point Likert scale $(1=$ Strongly Disagree, $2=$ Disagree, $3=$ Neutral, 4 = Agree, 5 = Strongly Agree)

Work Engagement Scale. The 9-item short version of the original 17-item Utrecht Work Engagement Scale (UWES) developed by Schaufeli, Salanova, GonzalezRoma, and Bakker (2002) was used for the current study (cf.; Schaufeli, Bakker, \& Salanova, 2006). In the original validation of the UWES, researchers found that all three subscales had adequate internal consistency reliability for an employee sample: vigor ( $\alpha$ $=.80)$, dedication $(\alpha=.91)$, and absorption $(\alpha=.75)$. To establish convergent and discriminant validity, researchers simultaneously administered the scale along with theoretically similar (i.e., other engagement scales) and dissimilar (i.e., burnout and exhaustion scales). As anticipated, all three subscales of the UWES were negatively correlated with exhaustion and cynicism (Schaufeli et al., 2002). To determine the integrity of the three-factor model that has its basis in theory, researchers conducted a confirmatory factor analysis (CFI) with two different models: a one-factor model to support the presumption that engagement is one variable and a three-factor model to suggest that the three subscales are related, yet distinct. The fit for the three-factor model was significantly better than the fit of the one-factor model. While the original validation of the 17-item UWES has demonstrated adequate psychometric properties, researchers 
were interested in the cross-cultural integrity of the scale and whether a shortened version could be developed. In their study of the UWES across 10 different countries, Schaufeli et al. (2006) conducted another confirmatory factor analysis on this dataset and found three vigor, two dedication, and three absorption items could be omitted while maintaining adequate reliability, validity, and model fit. A sample item for the vigor subscale of the UWES is "At work, I feel bursting with energy." For the dedication subscale, the following is an example of an item: "I am proud of the work that I do." Lastly, for the absorption scale, the following is an item: "I get carried away when I am working" (see Appendix A for items). Participants responded to statements on a 5-point Likert scale $(1=$ Strongly Disagree, $2=$ Disagree, $3=$ Neutral, $4=$ Agree, $5=$ Strongly Agree).

Job Satisfaction Scale. The Hackman and Oldham (1975) 3-item general scale was used to assess job satisfaction for the comparative job analysis sample. The internal consistency reliability for the validation study was adequate at .76. A sample item from the scale is "I am generally satisfied with the kind of tasks I do at my job." Participants responded to statements on a 5 -point Likert scale $(1=$ Strongly Disagree, $2=$ Disagree, 3

= Neutral, 4 = Agree, 5 = Strongly Agree .

Job Performance. Three items modified from the original 7-item scale of Job Performance was used to measure self-report and supervisory- or peer-report job performance (Motowidlo \& Van Scotter, 1994). The scale was developed to tap into several dimensions of job performance that are generalizable across various professions or careers. When computed for the validation sample, the internal consistency reliability for the scale was high $(\alpha=.96)$. For the supervisory or peer rating, the prompt for each of 
these items was the same: “This subordinate's overall job performance", each rating required individuals to choose the appropriate corresponding anchors. For the self-report performance, employees were prompted with the following: "My own overall job performance." An example of the first item's anchors might range from 1-2 (does not meet standards for job performance) to 3-5 (meets standards for job performance) to 6-7 (exceeds standards for job performance). (See Appendix A for items).

Organizational Citizenship Behaviors. The 20-item OCB-Checklist was used to measure how often employees engaged in behaviors above and beyond those explicitly stated in their job description. The original Organizational Citizenship Behavior Checklist (OCB-C) consisted of 42 items that were designed to assess the frequency of behaviors performed by employees, but has since been refined and shortened to 20 items (Fox, Spector, Goh, Bruursema, \& Kessler, 2011). The items tap into organizationaldirected as well as individual-directed (e.g., co-worker) types of organizational citizenship behaviors (i.e., OCB-O and OCB-I). The internal consistency reliability for the validation study was very high $(\alpha=.94)$. In terms of convergence, self-report responses to the 20 -item OCB-C correlated with co-worker ratings $(r=.29, \mathrm{p}<.01)$. Sample items include "Took time to advise, coach, or mentor a co-worker" and "Offered suggestions to improve how work is done." Participants responded using a Likert-Type scale including the following scale points: $1=$ Never; $2=$ Once or twice; $3=$ Once or twice per month; 4 = Once or twice per week; $5=$ Everyday.

Counterproductive Work Behaviors. The 32-item CWB-Checklist was used to measure how often employees engaged in behaviors that are considered deviant or maladaptive within the organization (Spector, Fox, Penney, Bruursema, Goh, \& Kessler, 
2006). This 32 -item version may be broken down into subscales of abuse, production deviance, sabotage, theft, and withdrawal behaviors. The validation study for the scale found the internal consistency reliabilities for the five subscales to be moderately high: abuse $(\alpha=.85)$; production deviance $(\alpha=.63)$; sabotage $(\alpha=.55)$; theft $(\alpha=.63)$; and withdrawal behaviors $(\alpha=.64)$. A sample items from each scale include: Abuse) "Insulted someone about their job performance;" Production Deviance) "Purposely did your work incorrectly;" Sabotage) "Purposely wasted your employer's materials/supplied;" Theft) "Took supplies or tools home without permission;" and Withdrawal Behaviors) "Stayed home from work and said you were sick when you weren't." Participants responded using a Likert-Type scale including the following scale points: $1=$ Never $; 2=$ Once or twice; $3=$ Once or twice per month; $4=$ Once or twice per week; 5 = Everyday.

Cognitive Ability. The 3-item General Numeracy Scale and an adapted version of the 7-item Expanded Numeracy Scale was used to test cognitive ability (Lipkus, Samsa \& Rimer, 2001). The seven additional items in the expanded version was altered to make the question content general instead of specific to a medical population. The internal consistency reliability for the 3-item General Numeracy Scale across the three validation samples were .63, .61, and .57. For the Expanded Numeracy Scale, the internal consistency reliability estimates were $.74, .70$, and .75 . When they conducted a factor structure analysis of the scale items, researchers concluded that items load onto a single factor and the second factor that emerged was due to common measurement variance (Lipkus, Samsa \& Rimer, 2001). Additionally, in a separate study of how the Expanded Numeracy Scale correlates with the Wonderlic cognitive ability test, researchers found a 
strong relationship between these measures $(r=.41$; Brooks \& Pui, 2010). A sample item from the scale is "Imagine that we rolled a fair, six-sided die 1,000 times. Out of the 1,000 rolls, how many times do you think the die would come up even (i.e., 2, 4, or 6)?”.

Conscientiousness Scale. The 10-item Conscientiousness Scale from the International Personality Item Pool (IPIP - Five Factors) was used for the current study (Goldberg, 1999). Sample items include "I am always prepared" and "I pay attention to details." Participants responded to statements on a 5-point Likert scale $(1=$ Strongly Disagree, 2 = Disagree, $3=$ Neutral, $4=$ Agree, $5=$ Strongly Agree $)$.

Meaningful Work. One of the most widely known assessments of meaningful work was conceptualized and developed by Hackman and Oldham (1975) as part of their Job Characteristics Model (JCM). For the purpose of the current study, therefore, the 4item experienced meaningfulness of the work subscale of the Job Diagnostic Survey was used. The scale asked participants to answer two items about their own perceived meaningfulness at work and two similar items reflecting on how other people with the same position or job perceive there to be meaning in what they do. The internal consistency reliability of the meaningful work subscale within the Job Diagnostic Survey was relatively high $(\alpha=.76)$. With regard to convergent validity, the meaningful work subscale was positively correlated with internal motivation $(r=.64)$, general satisfaction $(r=.64)$, and growth satisfaction $(r=.64)$. Although it was not a significant correlation, meaningful work was negatively related to absenteeism as was expected (Hackman \& Oldham, 1976). A sample item from the scale is the following: "The work I do on this job is meaningful to me.” Participants responded to statements on a 5-point Likert scale $(1=$ Strongly Disagree, 2 = Disagree, 3 = Neutral, 4 = Agree, 5 = Strongly Agree $)$. 
Prosocial Motivation Scale. An adapted version of the Self-Regulation Scale by Ryan and Connell (1989) was used to measure prosocial motivation (Grant, 2008a). The 4-item scale that has been used in a number of prosocial motivation studies in recent years has a high internal consistency reliability $(\alpha=.90)$. A sample item from the scale is "I am motivated because I want to help others through my work. Participants responded to statements on a 5-point Likert scale $(1=$ Strongly Disagree, $2=$ Disagree, $3=$ Neutral , $4=$ Agree, $5=$ Strongly Agree .

Spirituality. The 6-item Intrinsic Spirituality Scale was used for the purpose of the current study (Hodge, 2003). One of the strengths of the Intrinsic Spirituality scale is that it is not specific to a certain religion and is applicable even for non-theistic populations. For the validation sample, the internal consistency reliability for the 6-item scale was strong $(\alpha=.96)$. To test the concurrent validity of the Intrinsic Spirituality Scale, researchers administered it alongside a measure of intrinsic religion (which is theoretically similar) and the correlation was significant $(r=.91)$. Additionally, structural equation modeling was used to evaluate validity and reliability of this measure. The fit of the tested model was adequate and validity evidence suggests that this measure performs well in accordance with the existing theory. One sample item from the scale is the following: "When I think of things that help me to grow and mature as a person, my spirituality ( $0=$ Has no effect on my personal growth; $10=$ Is absolutely the most important factor in my personal growth)." (See Appendix A for items).

Perceived Career Opportunity. The 3-item Perceived Career Opportunity (PCO) scale developed and validated by Kraimer, Seibert, Wayne, Liden, and Bravo (2011) was used for the current study. When establishing convergent validity in their 
validation study, Kraimer et al. (2011) predicted that perceived career opportunity would be conceptually similar to perceived organizational support (POS), satisfaction with promotion, and career plateau. Three factors emerged when the authors factor analyzed these three scales together: the first consisted of the POS items and one satisfaction with promotion item; the second contained the career plateau items and remaining promotion items; and the third factor consisted of all three perceived career opportunity (PCO) items. The internal consistency reliability for this 3 -item scale was sufficiently high $(\alpha=$ .85). One sample item from the scale is the following: "There are career opportunities within my company/organization that are attractive to me." (See Appendix A for scale items). Participants responded to statements on a 5-point Likert scale ( $1=$ Strongly Disagree, $2=$ Disagree, $3=$ Neutral, $4=$ Agree, $5=$ Strongly Agree $)$.

Core Self-Evaluation Scale. The 12-item Core Self-Evaluation Scale (CSES) was used in the current study (Judge, Erez, Bono, \& Thoresen, 2003). In an initial validation study, Judge et al. (2003) found that the internal consistency reliability estimates for subscale scores were all above .80 and an average coefficient alpha of .84 . The CSES scale has demonstrated adequate convergent and discriminant validity: there was only a moderate correlation with the Big-Five personality characteristics as anticipated and strong correlations with self-esteem, generalized self-efficacy, and locus of control measures (Judge et al., 2003). Participants responded to the statements on a Likert scale (1=Strongly Disagree, 2= Disagree, 3= Neutral, 4= Agree, 5= Strongly Agree). The following is a sample item from the scale: "I am capable of coping with most of my problems" (see Appendix A for items). 


\section{Analysis}

To test the hypothesis that participants identifying their work as calling, career, or job would differ in terms of performance, organizational citizenship behaviors, and counterproductive behaviors, three analyses of variance (ANOVA) were conducted (i.e., Hypotheses 1a, 1c, and 1e). A Pearson product-moment correlation coefficient was conducted to determine the relationship between calling work orientation, self-report performance, other-report performance, organizational citizenship behaviors, and counter-productive work behaviors (i.e., Hypotheses 1b, 1d, and 1f). For Hypothesis 2, a hierarchical regression was conducted to determine whether a sense of calling is incrementally predictive of job performance above and beyond cognitive ability, the best predictor of performance (Hunter \& Schmidt, 1998). For the incremental validity hypotheses (i.e., Hypotheses 3-5), hierarchical regression analysis was used to determine if sense of calling is incrementally predictive of job performance above and beyond the covariates of calling (i.e., prosocial motivation, meaningful work, and spirituality). Likewise, a hierarchical regression was used to determine if sense of calling is incrementally predictive of job satisfaction and work engagement above and beyond the covariates of calling.

To test the predicted relationships, a series of hierarchical regression analyses were conducted (Aiken \& West, 1991; Cohen \& Cohen, 1983). Moderated regression was used to determine the effect of moderating variables (i.e., perceived career opportunity; PCO, and core self-evaluations; CSE) on the predictor-criterion relationships (Saunders, 1956; Zedeck, 1971). The partial regression coefficient was examined to estimate the moderating effects (McClelland \& Judd, 1993). Furthermore, it has been 
suggested that hierarchical regression be used to test whether the interaction is reliably different from zero when controlling for the individual terms (Aiken \& West, 1991; Cohen \& Cohen, 1983). One criticism of moderated regression analysis, however, has been that it only differentiates between subgroups because of measurement error (Zedeck, 1971). To minimize the negative effects of measurement error, corrections were made to the scale scores for the predictor variables. Specifically, the means were subtracted from scale scores to provide standardization prior to before being entered into the hierarchical regression (i.e., centering the variables).

Before testing hypotheses $\mathrm{H}_{6}$ through $\mathrm{H}_{11}$, scale scores were centered (i.e., by subtracting the scale mean from each individual mean) to provide standardization prior to moderation regression. The centered calling work orientation scores were entered at step one, the centered perceived career opportunity (PCO) scores were entered at step two, and the interaction term between the centered calling and perceived career opportunity variables (i.e., Calling X PCO) was entered in step three. The beta weights were used to determine the directionality and strength of the relationship between calling and performance, satisfaction, and engagement outcomes. Consistent with the suggestions of Cohen and Cohen (1983), these same steps were taken when conducting the moderated regression to test whether the relationship between calling and performance, satisfaction, and engagement varies as a function of core self-evaluations (hypotheses $\mathrm{H}_{9}$ through $\left.\mathrm{H}_{11}\right)$. 


\section{CHAPTER FIVE - RESULTS}

\section{Pilot Study - Results}

The primary purpose of the pilot study was to examine the relationships among study variables and determine whether additional variables should be included in the work sample. Some of the hypotheses presented above were not tested in the pilot study because those variables were added upon evaluation of pilot data. The hypotheses that were tested in the pilot study were as follows: Hypothesis 1a, 1b, and Hypotheses 3-11. When comparing the self-report job performance of participants who categorize their work as a calling, career, or job, the ANOVA results suggest there was a significant difference between groups, $F(2,504)=8.89, p<.001)$. Tukey post-hoc comparisons of the three groups indicate that students with a calling orientation $(M=6.11, S D=.83)$ were more likely to report more high job performance compared to employees with a job orientation. $(M=5.70, S D=.93)$. There were, however, no differences between the mean job performance rating for students with a calling work orientation and students with a career work orientation $(M=6.02, S D=.79)$. For Hypothesis $1 \mathrm{~b}$, the bivariate correlation between calling work orientation and job performance for the working students was positive and significant $(r=.27, p<.001)$. Collectively, these finding provided some evidence to suggest employees who view their work as personally fulfilling will be more likely to perform at a higher level (see Table 8 for the complete correlation table for the pilot sample).

According to Dik and Duffy's (2009) definition of calling work orientation, there are three theoretical covariates that must be present in order for an employee to express his or her calling: 1) prosocial motivation; 2) meaning or purpose at work; and 3) a 
spiritual summons from beyond the self. With the Dik and Duffy (2009) definition in mind, Hypotheses 3 through 5 were developed to determine whether calling was predictive above and beyond these underlying factors. Specifically, it was predicted in Hypothesis 3 that calling work orientation would be predictive of job performance beyond these covariates. A hierarchical regression was conducted with prosocial motivation, meaningful work, and spirituality entered into step one and calling entered into step two. Results provide evidence to suggest calling orientation was predictive of job performance above and beyond the covariates (see Table 9 for a hierarchical regression summary). The hierarchical multiple regression revealed that in step one, prosocial motivation, meaningful work, and spirituality contributed significantly to the regression model, $F(3,515)=16.63, p<.001)$ and accounted for $8.8 \%$ of the variation in job performance. Introducing the calling work orientation variable explained an additional $0.9 \%$ of variation in job performance and the change in $R^{2}$ was significant, $F$ $(4,514)=13.81, p<.001$. Likewise, calling was incrementally predictive of job satisfaction (Hypothesis 4) and work engagement (Hypothesis 5) above and beyond the covariates of prosocial motivation, meaningful work, and spirituality (see Tables 10 and 11 for hierarchical regression summaries). The hierarchical multiple regression revealed that in step one, prosocial motivation, meaningful work, and spirituality contributed significantly to the regression model, $F(3,509)=160.84, p<.001)$ and accounted for $48.7 \%$ of the variation in job satisfaction. Including the calling work orientation variable in step two explained an additional $9.0 \%$ of variation in job satisfaction and the change in $R^{2}$ was significant, $F(4,508)=173.34, p<.001$. Finally, hierarchical regression analysis for work showed that prosocial motivation, meaningful work, and spirituality were 
significantly predictive of work engagement, $F(3,516)=212.18, p<.001)$ and accounted for $55.2 \%$ of the variance. After adding the calling work orientation variable in step two, the regression model explained an additional $15.2 \%$ of variation in work engagement and the change in $R^{2}$ was significant, $F(4,515)=306.14, p<.001$.

Perceived career opportunity, described as an employee's perception of whether his or her work provides an opportunity to meet his or her professional aspirations, was predicted to moderate the relationship between calling work orientation and work outcomes of performance, satisfaction, and engagement (Hypotheses 6 through 8). The relationship between calling orientation and job performance was not significantly moderated by perceived career opportunity (PCO). There was a main effect for calling work orientation, $F(1,517)=41.65, p<.001$, which explained about $7.5 \%$ of the variance in job performance, but no main effect for perceived career opportunity, $F(2$, $516)=20.80, p=N S$ (see Table 12 for the moderated regression summary). There was no support for Hypothesis 7 . There was a main effect for calling orientation $F(1,511)=$ $490.23, p<.001$, which explained about $49.0 \%$ of the variance in job satisfaction. The main effect for perceived career opportunity was also significant $F(2,510)=257.66, p<$ .001 and explained an additional $1.3 \%$ of variance. The interaction effect, however, was not significant (i.e., calling orientation X PCO) $F(3,509)=176.21, p=$ NS, but explained an additional $0.7 \%$ of variance (see Table 13 for the moderated regression summary). There was also support for Hypothesis 8; the relationship between calling orientation and work engagement was moderated by perceived career opportunity (see Table 14 for moderated regression summary). There was a main effects for calling orientation $F(1$, $518)=933.59, p<.001$, which explained about $64.3 \%$ of variance in work engagement. 
The main effect for perceived career opportunity was significant $F(2,517)=479.12, p<$ .001 , and explained an additional $0.6 \%$ of the variance. Lastly, there was a significant interaction effect $F(3,516)=335.93, p<.05$, which explained about $1.2 \%$ of the variance in work engagement (see Table 14 for the moderated regression summary).

There are many possible individual differences that may affect the relationship between calling work orientation and work-related outcomes. In particular, core selfevaluations consist of an individual's perceptions of self-esteem, self-efficacy, locus of control, and emotional stability. It was predicted that employees with a calling work orientation and who also score high on core self-evaluations may be particularly equipped to perform at a higher level, be more satisfied with their work, and be more engaged. Hypothesis 9 was not supported; core self-evaluations did not moderate the relationship between calling work orientation and job performance (see Table 15 for a moderation summary). The main effect for calling orientation was significant $F(1,517)=41.65, p<$ .001 and predicted about $7.5 \%$ of variance in job performance. The main effect for core self-evaluation was also significant $F(2,516)=41.75, p<.001$ and predicted another $6.5 \%$ of the variance. The interaction effect between calling and core self-evaluations was not a significant predictor of job performance $F(3,515)=28.09, p=N S$. These findings suggests that there is no difference in performance for individuals with a calling based on global perceptions of the self and one's environment. Hypothesis 10 not was supported; the main effect for calling work orientation $F(1,511)=490.23, p<.001$ was significant and explained about $49 \%$ of the variance in job satisfaction. The main effect for core selfevaluations $F(2,510)=267.02, p<.001$ on job satisfaction was also significant and predicted about $2.2 \%$ of the variance. The interaction effect was not significant $F(3,509)$ 
$=177.66, p=N S$ (see Table 16 for moderation summary). Finally, there was no support for Hypothesis 11: core self-evaluations did not moderate the relationship between calling orientation and work engagement. Results suggest that there was main effect for work orientation $F(1,518)=933.59, p<.001$, which explained about $64.3 \%$ of the variance for work engagement. There main effect for core self-evaluations was also significant $F(2,517)=519.83, p<.001$ and explained an additional $2.4 \%$ of the variance. The interaction effect was not significant $F(2,516)=346.96, p=N S$ (see Table 17 for moderation summary).

\section{Work Sample - Results}

Before testing the proposed hypotheses that follow, a one-way analysis of variance (ANOVA) was conducted to determine whether employees who reported a calling, career, or job orientation on the Davidson and Caddell (1994) work orientation paragraphs differed on the newly standardized Dobrow (2011) scale. The aim of the ANOVA was to provide additional justification that the Dobrow scale does, in fact, differentiate between employees with various types of work orientations. Employees with different work orientations reported different levels of calling on the Dobrow scale, $F(2$, $513)=117.27, p<.001$. Tukey post-hoc comparisons of the three groups indicate that employees with a calling orientation according to the Davidson and Caddell categories $(M=3.95, S D=.50)$ were more likely to report a greater calling on the Dobrow scale compared to employees with a career orientation $(M=3.59, S D=.67)$. Employees with a calling work orientation were also more likely to report greater calling on the Dobrow scale compared to employees with a job orientation $(M=2.76, S D=.83)$. These findings 
suggest that the Dobrow (2011) scale used for the following analyses does effectively differentiate between work orientations.

Comparing the self-report job performance of participants who categorize their work as a calling, career, or job, ANOVA results suggest there was a significant difference between groups, $F(2,513)=3.80, p<.05)$. Tukey post-hoc comparisons of the three groups indicate that employees with a calling orientation $(M=5.76, S D=.80)$ were more likely to report more high job performance compared to employees with a job orientation. $(M=5.46, S D=.93)$. There were, however, no differences between the mean job performance rating for employees with a calling work orientation and employees with a career work orientation $(M=5.56, S D=.85)$. These findings only partially support Hypothesis 1a because it was predicted that employees with a calling work orientation would differ from both employees with a job and career work orientation. For otherreport performance, the between group difference for employees reporting a calling, career, or job was not significant $F(2,56)=0.61, p=.94$ but there may have not been enough power for the analysis because few employees agreed to have their supervisor rate their performance. The ANOVA conducted to examine the between-group means for counterproductive work behaviors $(\mathrm{CWB})$ was non-significant $F(2,513)=1.92, \mathrm{p}=.15$. Therefore, there was no support for Hypothesis 1c. Regarding Organizational Citizenship Behaviors (Hypothesis 1e), results to suggest between group differences $F(2,512)=$ $10.83, p<.001$. Employees with a calling work orientation reported engaging in more positive behaviors not explicitly described in the job description $(M=3.25, S D=.82)$ compared to employees who reported a job work orientation $(M=2.85, S D=.73)$. The between group difference for employees with a calling work orientation and career 
orientation was not significant $(M=3.10, S D=.76)$. These results only partially support Hypothesis 1e, that employees with a calling work orientation would report significantly more OCB as compared to employees with a career and job work orientation.

Hypotheses $1 \mathrm{~b}, 1 \mathrm{~d}$, and $1 \mathrm{f}$ were developed to examine calling work orientation as it relates to various aspects of performance (i.e., self-report performance, other-report performance, organizational citizenship, and counter productive work behaviors). Previous studies and theory suggest that those employees who experience a calling are more committed to their work and see it as fulfilling a sense of purpose, so it was predicted that individuals with a calling to their current work would be more likely to perform at a higher level compared to employees with a lesser investment in their work (i.e., a career or job orientation). Hypothesis $1 \mathrm{~b}$ was fully supported; results suggest that both self-report and other-report performance were positively related to calling work orientation, $(r=.33, p<.001$ and $r=.36, p<.01)$ respectively. Counterproductive work behaviors (CWB) are consistently negative predictors of work performance, so it would it was predicted that employees with a calling to their work would be much less likely to engage in these detrimental and deviant behaviors. Hypothesis 1d was not supported; results suggest there is no significant relationship between calling work orientation and counterproductive work behaviors (CWB) (see Table 18 for correlation coefficients). Like counterproductive behaviors, organizational citizenship behaviors have also been found to be a good predictor of job performance. Organizational citizenship behaviors, defined as prosocial behaviors that go above and beyond what is expected in the job description, should be positively related to calling work orientation. Individuals with a calling work orientation are likely to engage in positive behaviors because they 
personally identify with the tasks and derive personal meaning from the work that they do. Hypothesis $1 \mathrm{f}$ was supported; there is sufficient evidence to suggest calling work orientation is positively related to organizational citizenship behaviors (OCB), $r=.44, p<.001$

Hypothesis 2 developed to examine the predictive ability of calling above and beyond two of the most predictive criteria for job performance (i.e., cognitive ability and conscientiousness). To test Hypothesis 2, a hierarchical regression was used; whereby, conscientiousness and cognitive ability were entered in step one and calling work orientation was entered in step two. Hypothesis 2 was supported. The hierarchical multiple regression revealed that in step one, conscientiousness and numeracy contributed significantly to the regression model, $F(2,515)=112.32, p<.001$ and accounted for $30.4 \%$ of the variation in job performance. Introducing the calling work orientation variable explained an additional $3.6 \%$ of variation in job performance and the change in $R^{2}$ was significant, $F(3,514)=88.29, p<.001$. Therefore, results suggest calling work orientation was incrementally predictive of job performance above and beyond conscientiousness and cognitive ability (see Table 19 for hierarchical regression summary).

The main objective for Hypothesis 3 through Hypothesis 5 was to explore the covariates of the generally accepted definition of calling work orientation which includes the following: 1) prosocial motivation; 2) purpose and meaningfulness of work; and 3) a transcendent summon related to spirituality. To test these hypotheses, a series of hierarchical regressions were conducted, whereby, prosocial motivation, meaningful work, and spirituality were entered into step one and calling work orientation was entered 
into step two. The dependent variables that were examined included job performance (H4), job satisfaction (H5), and work engagement (H6). For Hypothesis 3, results suggest that calling work orientation was incrementally predictive of job performance above and beyond the covariates of meaningful work, prosocial motivation, and spirituality. In step one, the covariates explained a significant $15.2 \%$ of the variance in job performance $F(3,516)=30.73, p<.001$. In step two, entering calling work orientation helped to explain an additional $0.9 \%$, which was also significant $F(4,515)=24.60, p<.05$ (see Table 20 for hierarchical regression summary). Additionally, there was support for Hypothesis 4, suggesting calling work orientation was incrementally predictive of job satisfaction above and beyond the covariates of meaningful work, prosocial motivation, and spirituality. In step one, the covariates explained a significant $43.2 \%$ of the variance in job satisfaction $F(3,516)=130.77, p<.001$. In step two, entering calling work orientation helped to explain an additional $8.9 \%$, which was significant $F(4,515)=$ $140.15, p<.001$ (see Table 21 for hierarchical regression summary). Lastly, there was support for Hypothesis 5, that calling work orientation was incrementally predictive of work engagement above and beyond meaningful work, prosocial motivation, and spirituality. In step one, the covariates explained a significant $54.9 \%$ of the variance in work engagement $F(3,516)=209.54, p<.001$. In step two, entering calling work orientation helped to explain an additional $18.5 \%$, which was significant $F(4,515)=$ $355.35, p<.001$ (see Table 22 for hierarchical regression summary).

In addition to analyzing the covariates of calling work orientation using the Dobrow (2011) scale, participants were asked to report whether they viewed their work as a calling, career, or job based on the Davidson and Caddell (1994) paragraphs. A one- 
way ANOVA was conducted to determine whether participants with a calling, career, or job reported different amounts of prosocial motivation. With regard to prosocial motivation, employees with different work orientations reported different preferences for prosocial work, $F(2,513)=30.96, p<.001$. Tukey post-hoc comparisons of the three groups indicate that employees with a calling orientation $(M=4.27, S D=.55)$ were more likely to report higher preferences for prosocial work compared to employees with a career orientation. $(M=3.83, S D=.83)$. The Tukey post-hoc analysis also provided evidence to suggest employees with a calling orientation were significantly more likely to report a higher preference for prosocial work compared to employees with a job orientation $(M=3.48, S D=.91)$. Taken together, these findings suggest that individuals with a calling work orientation do, in fact, have a greater preference to engage in prosocial work compared to employees with a career or job orientation.

To further explore the covariates of calling work orientation, a one-way ANOVA was conducted to determine whether participants with a calling, career, or job reported different levels of meaningful work. To determine whether employees reporting a calling, career, or job orientation differ in their perceptions of meaningful work, a one-way ANOVA was conducted. Results suggest that there are indeed differences across these three groups $F(2,513)=46.23, p<.001$. However, Tukey post-hoc analysis suggests that employees with a calling work orientation do not differ from employees with a career orientation with regard to meaningful work. Employees with a calling work orientation $(M=4.06, S D=.73)$ did, however, report more meaning in their work compared to employees with a job orientation $(M=3.29, S D=.86)$. These findings provide some support for meaningful work as a covariate of calling. It is possible, for example, that 
meaningfulness is important for both employees with a calling and a career work orientation.

The final covariate of calling work orientation according to the definition put forth by Dik and Duffy (2009) is spirituality. For spirituality perceptions, employees with different work orientations reported significantly more importance of spirituality in their lives, $F(2,513)=20.69, p<.001$. Tukey post-hoc comparisons of the three groups indicate that employees with a calling orientation $(M=4.40, S D=1.07)$ were more likely to report more importance of spirituality in their lives compared to employees with a career orientation. $(M=3.56, S D=1.59)$. The Tukey post-hoc analysis also provided evidence to suggest employees with a calling orientation were significantly more likely to report a greater importance of spirituality compared to employees with a job orientation $(M=3.20, S D=.1 .59)$. These findings provide additional support for spirituality as a covariate of calling work orientation.

Perceived career opportunity has been defined as the degree to which career goals align with the prospect or opportunity that the organization provides for attaining those career aspirations (Kraimer, Seibert, Wayne, Liden, \& Bravo, 2011). When considering an employee's work orientation, it is reasonable to predict the opportunities present in the organization linked to career aspirations would influence whether an employee is willing to perform at a higher level, be satisfied with their work, and become immersed and engaged at work. Hypotheses 6 through 8 were developed to examine whether perceived career opportunity moderates the relationship between calling work orientation and outcomes of performance, satisfaction, and work engagement. Those individuals who view their work as a calling and who have ample opportunity to meet their career 
aspirations are thought to be especially equipped to perform well, be satisfied, and be engaged. Moderated regression results support Hypothesis 6; there was a significant main effect for calling work orientation $F(1,517)=64.83, p<.001$ which explained about $11.1 \%$ of the variance in job performance but not for perceived career opportunity (PCO) $F(2,516)=33.76, p=$ NS. The interaction effect (Calling X PCO) was a significant predictor of job performance $F(3,515)=25.55$ and explained an additional $1.4 \%$ of variance (see Table 23 for beta weights and r-squared values). These findings suggest that calling is positively related to job performance and perceived career opportunities influence the magnitude of that relationship. Results from the moderated regression for Hypothesis 7 were not significant. There was a significant main effects for calling work orientation $F(1,517)=378.20, p<.001$, which explained about $42.2 \%$ of the variance in job satisfaction. The main effect for PCO was also significant $F(2,516)=214.50, p<$ .001 , explaining about $3.1 \%$ of the variance on job satisfaction. The interaction effect (i.e., calling orientation X PCO), however, was not significant $F(2,513)=144.41, p=$ NS (see Table 24 for beta weights and r-squared values). Results provide evidence to suggest calling work orientation and perceived career opportunities are important in predicting job satisfaction, but $\mathrm{PCO}$ is not affecting the magnitude of that relationship. Moderated regression results support Hypothesis 8: perceived career opportunities moderated the relationship between calling work orientation and work engagement. There was a significant main effect for calling work orientation $F(1,517)=1070.42, p<$ .001 , which explained about $67.4 \%$ of the variance in work engagement. The main effect for PCO was also significant $F(2,516)=563.68, p<.001$, explaining about $1.2 \%$ of the variance on work orientation. Lastly, the interaction between calling work orientation and 
perceived career opportunity was significant $F(3,515)=381.25, p<.01$, explaining a significant $0.4 \%$ of the variance (see Table 25 for moderation summary). The main effects for calling work orientation and PCO were both significant, and the interaction effect (i.e., calling orientation X PCO) was also significant for work engagement. These results suggests those individuals with a calling and who perceive their works as an opportunity to fulfill their aspirations are more likely to be engaged at work.

Considering the function of core self-evaluations (CSE) as the way individuals view themselves and their capabilities in all situations, Hypotheses 9, 10, and 11 examine the influence of core self-evaluations on the relationship between calling work orientation and outcomes of performance, satisfaction and work engagement. Moderated regression results support Hypothesis 9. There was a significant main effects for calling work orientation $F(1,516)=65.03, p<.001$, which explained about $11.2 \%$ of the variance in job performance. The main effect for core self-evaluations was also significant $F(2,515)$ $=88.36, p<.001$, explaining an additional $14.4 \%$ of the variance. Lastly, the interaction effect was significant (i.e., calling orientation X CSES) $F(3,514)=60.51, p<.01$, explaining a significant $0.6 \%$ of the variance. These findings suggest that employees with a calling to and have a positive view of themselves and their environment are more likely to perform at a higher level (see Table 26 for beta weights and r-squared values).

Hypothesis 10 predicted that CSE would moderate the relationship between calling work orientation and job satisfaction. The moderated regression analysis for Hypothesis 10 was not significant. The main effect for calling work orientation was significant $F(1,516)=$ $377.48, p<.001$, which explained approximately $42.2 \%$ of the variance in job satisfaction. The main effect for core self-evaluations (CSES) was also significant $F(2$, 
$515)=270.92, p<.001$, explaining an additional $9.0 \%$ of the variance. The interaction effect (i.e., calling work orientation X CSES), however, was not significant for job satisfaction $F(3,514)=181.96, p=$ NS (see Table 27 for beta weights and $\mathrm{r}$-squared values). Hypothesis 11 was developed to test whether CSES would moderate the relationship between calling work orientation and work engagement. Results support Hypothesis 11 . There was a significant main effect for calling work orientation $F(1,516)$ $=1068.39, p<.001$, which explained about $67.4 \%$ of the variance. The main effect for CSES was also significant $F(2,515)=640.17, p<.001$, predicting an additional $3.9 \%$ of the variance in work engagement. Lastly, the interaction between calling work orientation and CSE was significant $F(3,514)=441.07, p<.01$, accounting for about $0.7 \%$ of the variance (see Table 28 for moderation summary). These results support the claim that employees who personally identify themselves with their line of work and who have a positive view of themselves and their environment are even more likely to become engaged in their work. For Perceived Career Opportunity (PCO) as a moderator of the relationship between calling work orientation and job performance, the simple slope for the employee sample $1 \mathrm{SD}$ below the mean was .19 and the simple slope for employees 1 SD above the mean was .40 (see Figure 1 for interaction graph). For PCO as a moderator of the relationship between work orientation and work engagement, the simple slope for the working student sample $1 \mathrm{SD}$ below the mean was .80 and the simple slope for working students $1 \mathrm{SD}$ above the mean was .60 (see Figure 2 for interaction graph). For PCO as a moderator of the relationship between work orientation and work engagement, the simple slope for the employee sample $1 \mathrm{SD}$ below the mean was .75 and the simple slope for working students $1 \mathrm{SD}$ above the mean was .65 (see Figure 3 for interaction 
graph). For Core Self-Evaluations (CSE) as a moderator of the relationship between calling work orientation and job performance, the simple slope for the employee sample 1 SD below the mean was .12 and the simple slope for employees 1 SD above the mean was .24 (see Figure 4 for interaction graph). For Core Self-Evaluations (CSE) as a moderator of the relationship between calling work orientation and work engagement, the simple slope for the employee sample $1 \mathrm{SD}$ below the mean was .76 and the simple slope for employees $1 \mathrm{SD}$ above the mean was .64 (see Figure 5 for interaction graph). 


\section{CHAPTER SIX - DISCUSSION}

One of the primary objectives of the current study was to investigate the relationship between work orientation and performance outcomes such as self-report performance, other-report performance, organizational citizenship behaviors, and counterproductive work behaviors. Prior to the current dissertation, the majority of work orientations studies had focused primarily on job attitudes as work-related outcomes. Understanding the relationships between work orientation and aspects of job performance may be invaluable to organizations because more efficient and productive employees can lead to increased organizational profitability. As part of the first objective, therefore, it was predicted that calling work orientation would be incrementally predictive of job performance above and beyond two consistently good predictors of job performance, conscientiousness and numerical ability. Another significant objective of the current study was to examine the covariates of calling work orientation (i.e., prosocial motivation, meaningful work, and spirituality) in addition to the main construct of work orientation. Empirically testing the covariates of the calling work orientation construct is an important contribution of the current study because the construct of calling has evolved over time and has taken on new meaning. It wasn't until recently, in fact, that a validated measure of calling work orientation had been developed because the operational definition had yet to be clarified (Dobrow, et al., 2011; Dik, et al., 2012). The final objective of the current study was to explore the possible moderating effect that perceived career opportunity and core self-evaluations might have on the relationship between calling work orientation and work outcomes of performance, satisfaction, and work engagement. The following chapter will reexamine each of the core study 
objectives by reviewing and interpreting the results, discussing theoretical implications, offering practical applications, highlighting possible limitations, and providing avenues for future research in the area of work orientation.

\section{Work Orientation and Job Performance}

The relationship between calling work orientation and both self-report and other report performance was significant for the employee sample, but using the categorical measure of work orientation, the between-group difference in performance for those with a calling and those with a career orientation was only partially supported. The same pattern of findings was evident for the working student sample: there was a significant correlation between self-report performance and calling work orientation, but betweengroup differences were only partially supported. Employees with a calling work orientation reported greater job performance as compared to employees with a job work orientation, but there were no group differences for employees with a calling or career work orientation. One way to explain these mixed results is that employees may be motivated to perform at a high level for many reasons. In the case of employees with a calling, for example, the motivating mechanism is most likely the desire to make a difference on the world and leave a positive footprint in the lives of people their work touches. Perhaps intrinsic and extrinsic motivations are equally linked to overall job performance, and employees with a career orientation are likely to be motivated by both internal and external factors because their work serves the function of fulfilling their ego needs (e.g., status, promotions, influence, etc.). In partial support of these differences in motivation, past research examining the presence of calling work orientation has found only weak to moderate correlations with intrinsic $(r=.27, p<.01)$ and extrinsic $(r=.12$, 
$p<.05$ ) motivation, respectively (Dik et al., 2012). In the case of employees with a job work orientation, they performed at a lower level as compared to employees with a career or calling orientation. When the primary motivation to work is for a paycheck, it is possible that employees are experiencing a sense of continuous commitment (i.e., persisting on the job because there are no other alternatives in the job market) instead of a more emotionally connected sense of affective commitment.

One possible implication of the fact that employees with a job work orientation do not report performing at a high level compared to others is that they will ultimately be detrimental to organizational productivity overall. Perhaps, employees with a job orientation are forced to cognitively regulate their behavior and emotions within the workplace. Drawing from the job design theories of motivation, such as motivationhygiene theory, researchers suggest that the environment does significantly affect motivational potential (Hackman \& Oldham, 1976). Social psychological researchers have found evidence to suggest tasks that require self-regulation or self-control are more depleting of motivation and there is only a finite amount of energy that can be expended on self-regulatory behaviors (Baumeister, Heatherton, \& Tice, 1994; Muraven, Gagne, \& Rosman, 2008). Researchers in the area of self-regulation have studied the affect of inhibiting behavior, emotion, and cognition in a broad range of tasks and settings, as well as its affect on subsequent performance. In the workplace, research has examined emotional labor, which specifically involves the emotional control of employees on the job (Converse \& DeShon, 2009). In one dissertation examining surface and deep acting associated with emotional labor (Yugo, 2009), researchers found support that employees with a calling work orientation are better equipped to handle emotional demands and 
utilized more effective emotional labor strategies. Given these findings and those from previous research, it seems that employees with a job work orientation experience the deleterious effects of having to self-regulate their emotions and behaviors at work more than employees with other work orientations.

Another possible explanation for the non-significant difference between career and calling orientations may be that performance rating are contingent upon more than concrete, inherent ability factors. While there is no empirical evidence to suggest employees with a calling, career, or job orientation should be more or less intelligent or skilled, it is possible that employees with a calling work orientation invest more energy into developing skills that are clearly linked to their perceived purpose. Work motivation may be the differentiating factor when it comes to any differences in performance because motivation describes "energy, direction, persistence, and equifinality" (Ryan \& Deci, 2000). Findings do, however, support the idea that employees with a calling engage in more positive work behaviors not explicitly outlines in their job description (i.e., OCB) compared to employees reporting a job work orientation. The relationship between OCB and calling work orientation is particularly important considering the claim that OCB are "vital to organizational survival and effectiveness" (Katz \& Kahn, 1966, p. 338). There were no between-group differences for employees reporting a calling or career work orientation, so perhaps both groups see the inherent value of exceeding expectations in achieving their unique goals of work, fulfillment of self-actualization or ego needs, respectively.

While the linkages between calling work orientation and various aspects of job performance do provide some insight, it is also possible that the relationship could be 
reversed or even reciprocal. According to self-perception theory (Bem, 1972), employees may do more than what is expected of them in the workplace and perform to their optimal potential, recognize that they are exerting a considerable amount of effort, and then develop an attitude regarding their work behaviors. If self-perception were the case, employees would be more likely to attribute their exertion to the fact that their work has a deeper purpose in their lives. Combining assumptions of self-perception theory and social comparison theory, one way to explain why employees with a job work orientation may have developed that attitude toward their work is that they have engaged in upward comparisons with higher performing individuals and believe that they are somehow incapable of meeting those unrealistic expectations. In one study of self-perception and attitude formation, researchers found that internal self-knowledge is required in the form of sensory data to form accurate attitudes (Tybout \& Scott, 1983). Taken in the context of the current study, these findings suggest that perhaps accurate performance feedback (i.e., sensory data) would aid employees in the development of their work orientation. Given the fact that all employees regardless of their work orientation engage in the cognitive evaluation of their current work situation, it makes sense that frequent and accurate performance feedback would influence perceptions. If an employee performs a behavior that may be perceived as prosocial and receives positive feedback to affirm that behavior, it is possible that he or she will begin to view their work as a calling. Although there are still some unanswered questions regarding performance and work orientation, these findings do provide some clarity and illustrate the practical importance of various work orientations. 
Finding a positive relationship between an employee's view of their work (i.e., work orientation) and his or her job performance has a number of practical implications. While the current study found that there is not as much of a difference between calling work and career work orientations, the results to demonstrate a significant difference between calling and job orientations. In addition to differences between calling and job orientations, results from the hierarchical regression revealed that calling work orientation was predictive of job performance above and beyond conscientiousness and numerical ability, two predictors that are typically associated with job performance (Schmidt \& Hunter, 1998). From a practical standpoint, therefore, employers should begin to recognize the importance of the role work plays in their employees' lives. Highly qualified employees who feel like they have a calling to their work many not feel that their current position is fulfilling. If employees are viewing their work as not fulfilling of a deeper purpose, then managers should seriously consider the possible benefits of altering an employee's work responsibilities or tasks (i.e., through job redesign; Berg et al., 2010) to accommodate for an unanswered calling. Perhaps these minor changes in the work tasks can reduce feelings of boredom, thus, preventing costly voluntary turnover of qualified employees (Bolman \& Deal, 1991). Although there are obvious challenges, hiring managers should consider ways to assess applicants' views of their current occupation and the reasons why employment in the position they are applying for would fulfill a sense of purpose. Unlike some employment predictors, work orientation is likely to be more dynamic, constantly changing as employees re-evaluate their employment situation. Therefore, it would be a challenge to assess work orientation 
during the selection processes because applicants would still be cognitively evaluating the prospective job (i.e., search for calling phase; Dik, Eldridge, Steger, \& Duffy, 2012).

Although the aforementioned findings regarding job performance provide direction for future work orientation research, they are not without limitation. One limitation of the current study was that only self-reported data were collected from working student and employee samples, with the exception of supervisor, peer, or coworker ratings of job performance for the employee sample. According to past research, organizational records and subjective evaluations are the two primary sources of performance data; organizational records are thought to be a more valid and reliable source of performance data because they are "observable, countable, discrete outcomes," such as absenteeism or individual sales records (Viswesvaran, 2001, p. 111). While welldesigned instruments have been developed and a validated measure was used for the current study, perhaps the use of more objective organizational records would have lead to more conclusive results. Though precautions to reduce response distortion were taken (i.e., anonymity of participants, responses were not linked to work performance, etc.), it is possible that employees and working students inflated their self-report performance ratings. In fact, many studies have found evidence to suggest evaluations of oneself may be especially biased by social desirability and there may only be a moderate relationship to objective performance (e.g., Alder, Thomas, \& Castrp, 2005; Johns, 1994).

When critically evaluating research designs that involve self-report questionnaires, another possible limitation is common method variance (Burton-Jones 2009; Reio, 2010). Defined as, "systematic error variance shared among variances measured with and introduced as a function of the same method and/or source 
(Richardson, Simmering, \& Sturman, 2009, p. 763)," common method variance has been found to either inflate or deflate correlations among study variables (Campbell \& Fiske, 1959). There continues to be a debate surrounding the issue of common method variance because researchers have not been able to agree on the extent to which the bias influences relationships among study variables (Reio, 2010). Richardson et al. (2009) states that there are several possible statistical corrections that can be made to accommodate for common method variance that include using partial correlations to control for common method. Alternatively, future studies of work orientation and work outcomes should consider collecting various sources of data such as performance reviews from a supervisor, direct observation of employee engagement at work, or even customer/client satisfaction survey results. Diversifying the source of data collected would control for the possible biases that are associated with common method variance.

As many researchers have found, responses on self-report measures are sometimes fraught with problems: social desirability, memory effects, and unreliability of recall (Crockett, Schulenberg, \& Petersen, 1987; Cronbach, 1970). From a cognitive perspective, models have been developed that describe the complex process associated with having to complete self-report surveys. In one of the most comprehensive models, Tourangeau, Rips, and Rasinski's (2000) posit that there are four stages involved in survey responses: comprehension, retrieval, judgment, and response. The first stage, comprehension, involves the evaluation of whether the content is logical, identifiable, and understandable. The retrieval stage requires an individual to recall information, memories, and infer any missing information. When a memory is incomplete, the individual moves to the third stage, which involves judgment or the assessment of the 
integration of memories. Finally, based on the response options provided on the survey, an individual moves to the fourth stage, which may involve slightly altering the memory to fit the response choices. The self-report job performance scale utilized in the current study may have been especially difficult to answer because it asked participants to compare their own job performance to the performance of other employees at the same level. Also the organizational citizenship and counterproductive work behavior checklists required employees to recall how often they engaged in specific behaviors in the workplace that are not always very common. In fact, there has been a debate regarding the low base rate of counterproductive behaviors and workplace deviance (Slora, 1989). As a result, employees may have modified their responses because they had difficulty recalling the information. Social desirability is also a concern with regard to the current study because past research on the self-serving bias in the workplace suggests that between 86 and 90 percent of employees report superior performance compared to their average peers (French, 1986; Headey \& Wearing, 1987).

These findings and limitations regarding the role of work orientation on job performance, organizational citizenship behaviors, and counterproductive behaviors provide many avenues for future research. First and foremost, future studies of work orientation and job performance should aim to measure performance using organizational records or direct observations instead of self-report or subjective evaluations (Viswesvaran, 2001). Another important distinction that should be made with regard to performance and work orientation is the differences between maximum and typical performance for employees with a calling, career, or job orientation. Recent metaanalysis findings suggest that there is a moderately strong relationship between maximum 
and typical performance $(\rho=.42)$, but the two constructs are clearly distinct (Beus \& Whitman, 2012). Furthermore, Beus and Whitman (2012) found that task complexity as well as the type of performance measure utilized both moderated the relationship between maximum and typical performance. With these findings in mind, researchers should consider adopting longitudinal or multi-wave research designs to control for differences in typical and maximum performance (Bliese, Chan, \& Ployhart, 2007; Ployhart \& Vandenberg, 2010). Also, when it comes to individual differences in maximum performance, general mental ability has been found to account for a considerable amount of variation between employees (Witt \& Spitzmuller, 2007). Therefore, future studies of job performance and work orientation should control for and examine general mental ability and other individual differences that may account for job performance.

As noted above, it is possible that employees' work orientation may be related to whether they perceive their work tasks as requiring self-regulation or not. On the basis of the current findings, it is possible that employees with a job work orientation may have to self-regulate or engage in more emotional labor compared to employees who view their work as either a calling or career. Past research has also found support for the hypothesis that employees with a calling work orientation experience are better equipped to deal with stressors and are less likely to become emotionally exhausted (Treadgold, 1999), which could be explained by the self-regulation theories proposed by Baumeister et al. (2007). Therefore, a future avenue for research would be to develop a testable model involving emotional labor, self-regulation, work orientation, and job performance. Additionally, future research should examine the influence of having to self-regulate as the result of work orientation and the impact self-regulation may have on OCB. The 
fundamental principle underlying OCB suggests that employees engage in positive or productive behaviors that are not explicitly stated in the job description. If an employee has a finite amount of energy to use and self-regulation requires more energy that nonregulation tasks, then employees with a calling should presumably have more physical stamina to engage in OCB (Organ, 1997).

The construct of work orientation is relatively dynamic and employees may be in various phases of answering a calling: search or discernment, acquiring skills to fulfill a calling, or currently employed in a position that is fulfilling a sense of calling (Dik et al., 2012). Considering each of these phases of the process comes with certain challenges and obstacles to overcome, an interesting area for future research should examine the relationship of various phases of calling orientation as they relate to work performance. Employees who feel that they have the potential to move through the ranks in an organization to ultimately fulfill a calling may be even more likely to perform at a higher level; whereas, employees who view their work as currently fulfilling a sense of calling may be complacent and not overexert themselves in terms of performance. Likewise, researchers have found evidence that some individuals actually pursue their life's purpose outside of the work domain and use their leisure time to fulfill a sense of calling (Berg, et al., 2010). Future studies of work orientation should control for the possibility that employees may be fulfilling a greater sense of purpose outside of the workplace. Perhaps the between-group differences for employees who reported a career would have differed from those who reported a calling work orientation. 


\section{Covariates of Calling Work Orientation}

The definition of calling work orientation is multi-faceted and has been operationally defined using three covariates of prosocial motivation, spirituality, and meaningful work (Dik \& Duffy, 2009). The second overarching objective of the current study was to examine whether the complete construct of calling work orientation (i.e., as measured by the Dobrow scale) was predictive of job satisfaction, job performance, and work engagement above and beyond the three covariates. Results from both the student pilot sample and the employee sample demonstrate that calling work orientation was indeed incrementally predictive of job satisfaction, job performance, and work engagement beyond the covariates. To investigate the research question regarding the covariates of calling work orientation further in the employee sample, the categorical measure of work orientation (i.e., Davidson \& Caddell Paragraphs) were used as the independent variable of an ANOVA with covariates of prosocial motivation, spirituality, and meaningful work as the dependent variables. Overall, these findings support the idea that individuals with a calling work orientation have a preference for prosocial work and tend to report being more spiritual as compared to employees with a career or job work orientation. The third covariate, meaningful work, was not as conclusive with regard to between-group differences. In particular, employees with a calling work orientation were

more likely to view their work as meaningful as compared to employees with a job work orientation, but there were no between-group differences with the group that reported having a career work orientation.

The main implication of these findings on the work orientation literature is that they do provide evidence that the covariates identified by Dik and Duffy (2009) does help 
to differentiate between work orientations. Given the fact that the operational definition of calling work orientation has transformed from a Judeo-Christian context to be more widely accepted, it has been a challenge to identify all the facets of the calling construct (Elangovan et al., 2010). The current study extends the literature by providing empirical evidence for covariates that were primarily identified through qualitative inquiry. Furthermore, these findings may benefit future research endeavors aimed at developing even more comprehensive measures of work orientation, which may be especially important as organization begin to adopt work orientation as predictors of job performance, job satisfaction, organizational citizenship behaviors, and many other organizational outcomes. While the findings regarding the covariates of calling work orientation are beneficial, they were not entirely conclusive.

According to these findings, it is possible that the operational definition including three covariates developed by Dik and Duffy (2009) is incomplete. Perhaps there are other facets of the calling work orientation construct that have yet to be identified. While the three covariates do encompass the vast majority of qualitative descriptions of a calling (e.g., Bigham, 2008; Duffy, Foley, Roque-Bodgan, Reid-Marks, Dik, Castano, \& Adams, 2012), other researchers have identified other factors that could be particularly critical to some employees' calling. Conklin (2012), for example, conducted a phenomenological study where six factors emerged including a connection to nature, counterfactual thinking about one's career choices, changes in social identity resulting from a work role, changes in self-perception, feelings of comfort and completeness, and a perception of an urgent mission. Another qualitative study of perceptions of calling work orientation found a theme of person-occupation or person-job fit; whereby, students who 
viewed their work as a calling felt that their unique strengths and interests made them equipped to perform well in their calling and would lead to overall well-being (Hunter et al., 2010). In fact, even unpleasant, difficult, or unexpected personal or global events have been identified as possible predictors of a person's calling (Terranova, 2006).

Likewise, the neo-classical conceptualization of calling utilized by many researchers does involve an aspect of self-sacrifice, which can also be viewed as unpleasant and difficult (Bunderson \& Thompson, 2009).

Another explanation for why the overarching construct of calling work orientation was predictive above and beyond the covariates is because the Dobrow and Tosti-Kharas (2011) scale used to measure calling work orientation may actually be measuring aspects of the workplace beyond the scope of work orientation. Specifically, the correlation between calling work orientation (i.e., measures by the Dobrow \& Tosti-Kharas scale) was strongly correlated with work engagement for the student and employee samples, $r=$ .80 and $r=.82$, respectively. It was expected that work engagement would be significantly related to calling work orientation because the construct of calling includes dimensions such as meaningfulness, person-environmental fit, prosocial motivation, and transcendent purpose (Hagmaier \& Abele, 2012). The deep sense of purpose, dedication, and investment in work tends to parallel the characteristics of work engagement (i.e., vigor, dedication, and absorption; Dobrow \& Tosti-Kharas, 2011). A series of factor analyses were conducted in the validation of the Dobrow and Tosti-Kharas scale to establish convergent validity, and findings suggest calling work orientation was related but distinct from work engagement. When two constructs are too highly correlated, however, they may not be distinct (Campbell \& Fiske, 1959). According to Berry, Ones, 
and Sackett (2007), "it is difficult to point to one value as this threshold, but we posit that when the correlation between two constructs approaches values commonly agreed on as acceptable for reliability coefficients (e.g., $r=.70$ and higher), the distinctiveness of the two constructs becomes questionable“" (pg. 411).

With these limitations in mind and heeding the advice of Berry et al. (2007), a post hoc exploratory factor analysis was conducted on the items from the Dobrow and Tosti-Kharas (2011) calling work orientation scale and the Utrecht Work Engagement Scale (UWES). The standard procedure for conducting a factor analysis on theoretically correlated variables is to perform an oblique rotation, so a Direct Oblimin rotation was used in SPSS for the post hoc analysis. For the employee sample, two factors emerged and the pattern matrix showed that the highest loading items on the first factor included all of the UWES items and two items from the Calling Work Orientation scale. The specific calling work orientation items that loaded onto the engagement factor included "Engaging in my work tasks gives me immense personal satisfaction" and "I am passionate about the tasks I engage in at work." As expected, the component correlation matrix revealed that the two emergent factors were indeed significantly correlated $(r=$ .71). Similarly to the employee sample, two factors emerged from the data for the working student sample. The pattern matrix revealed that the highest loading items for the first factor included all of the engagement items along with the same two items from the Calling Work Orientation scale mentioned above. The two calling work orientation items that consistently loaded onto the engagement factor are not specific to the operational definition of calling. Receiving immense personal satisfaction from work can result from a number of relevant work experiences. According to the Job Characteristic 
Model (Hackman \& Oldham, 1975), for example, immense job satisfaction can be affected by the job itself through perceived significant tasks, completing projects in their entirety, and being able to use a variety of skills on the job. Likewise, having passion for work tasks is not exclusive to a calling work orientation but may also occur when an employee views his or her work as a career. The concept of passion at work can be interpreted within the realm of work orientation as synonymous with meaningfulness and perhaps most closely parallels the dedication and absorption aspects of work engagement.

Even though many of the previous limitations of measuring work orientation have been lifted as researchers have developed and validated new scales, the current findings suggest that there is still significant overlap between constructs. One avenue for future research should focus on empirically testing the differences between calling work orientation and similar constructs. One possible research method that could be employed to further explore the differences between calling and engagement constructs would be to measure both variables simultaneously and collect various sources of data such as selfreport and direct observation (i.e., multi-trait multi-method; Campbell \& Fiske, 1959). While there is some evidence to suggest employees who have a calling work orientation are more engaged at work, future research should investigate the possibility of individual differences such as contentiousness, agreeableness, positive affect, and other personality factors may moderate the relationship. Lastly with regard to engagement and work orientation, future research should consider measuring these variables in tandem over time. Adopting a longitudinal design and experience sampling methodology would allow researchers to determine whether fluctuations in engagement are contingent upon the cognitive evaluations associated with the development of a work orientation. 
The current study found that calling work orientation was predictive of job satisfaction, performance, and engagement above and beyond the covariates of prosocial motivation, spirituality, and meaningful work. One of the explanations of these findings is that the operational definition of calling work orientation may not be all-inclusive. Future research should measure other covariates in conjunction with the commonly accepted ones. In particular, researchers should consider the role of person-environment fit (i.e., P-E fit), preference for self-sacrifice, and perhaps even a connection to nature in the perception of calling work orientation (i.e., variables identified in the qualitative studies mentioned above). Another interesting finding from the current study was that there were no differences in work meaningfulness between employees with a calling and career work orientation. Drawing upon the self-discrepancy theory described by Elangovan et al. (2010), it is possible that some of the covariates associated with a traditional calling may not fall within an employee's self-perception. In other words, identifying one's work as a calling may take precedence over the fulfillment of certain personal aspirations. Furthermore, researchers have found that meaningful work is a subjective experience which involves multiple dimensions including current positive emotions at work, the prospect for deriving future meaning from work, and engaging in tasks for "the greater good" (Steger, Dik, \& Duffy, 2012). Future research should examine the possibility that employees with a calling work orientation may intentionally forego personally meaningful experiences for the "greater good" and the psychological impact the decision to do so may have on an individual. 


\section{Perceived Career Opportunity as a Moderator}

The hypotheses pertaining to perceived career opportunity as a moderator were based upon the presumption that employees may be employed in work that is not currently providing an avenue to fulfill a calling. First, it was predicted that the magnitude of the relationship between reported calling work orientation and job performance would differ for employees who have ample opportunities to grow in their current workplace. For the working student sample, perceived career opportunity did not affect the relationship between calling work orientation and job performance. The main effect for perceived career opportunity was not significant, indicating that students may not have felt it was important for their current employer to provide opportunities to advance. One possibility explanation for these findings, therefore, is that students are at a transitory point in their lives. Investing a considerable amount of time and effort in their current job may not have the same perceived benefits because students know they will be entering the job market once they graduate with a terminal degree. It might be expected that full-time employees are settled in their current workplace and profession, and the moderated regression would reveal different trends. For the employee sample, there was also a main effect for calling work orientation but no main effect for perceived career opportunity. There was a significant interactions effect (Calling X PCO) on job performance. The significant moderation of PCO on the relationship between calling work orientation and job performance suggests that having opportunities for advancement in ones calling does increase the magnitude of the relationship between work orientation and job performance. As expected, the magnitude of the relationship between calling work orientation and job performance was stronger for employees reporting perceived 
career opportunities. When employees are given opportunities in the workplace that correspond with their life's purpose and calling, then they are even more likely to report increased job performance. Taken together, these findings suggest that perhaps there are other more salient motivating factors influencing the decision to persist and perform in one's current work in addition to perceived career opportunity. Another possible explanation for these mixed findings may be that full-time employees with a calling work orientation may assume responsibility for their own fulfillment of that calling rather than rely on the possibilities that are available in the immediate work environment.

In addition to examining the influence of perceived career opportunity on job performance, it was predicted that perceived career opportunity would moderate the relationship between calling work orientation and job satisfaction. As noted above, researchers have traditionally conceptualized job attitudes in terms of cognitive evaluations but a shift is underway to recognize additional affective perspectives (Judge \& Ilies, 2004; LeBreton, Binning, Adorno, \& Melcher, 2004). Having the opportunity to progress in an organization and make growth on a personal level is likely to impact employees both on a cognitive and affective level. It was predicted, therefore, that employees who report a calling work orientation and who perceive opportunity for growth in their calling would be especially satisfied with their work. According to the self-discrepancy theory of calling work orientation, Elangovan et al. (2010) would suggest that perceived opportunity in the workplace would pave the way for creating the alignment of ideal and ought selves, which is likely to explain why Hall and Chandler (2005) consider calling “the deepest form of satisfaction or psychological success.”(p. 
160). There was no support for perceived career opportunity as a moderator for either the working student or full-time employee samples.

One explanation for the lack of support for Hypothesis 7 is that the current job market and unemployment rate. Professionals are currently facing many different challenges in the workplace and may feel that they must continue in their current job because alternatives are not available in the market. According to the most recent US Bureau of Labor and Statistics unemployment report, people aged 20 to 24 are having a very difficult time fining employment (i.e., $13.1 \%$ unemployment) and so are people ranging from 25 to 34 year old (i.e., 7.2\% unemployment; BLS, June 2013). Because the labor market is difficult, it may be especially important for employees with a calling work orientation to find a workplace where they view a potential for professional growth and when employees' needs are met in the organization, they are more likely to be satisfied. It is also possible that individuals who are currently employed feel privileged when comparing themselves to their peers who are struggling to find employment. Regardless, future research should consider controlling for the external job market when developing studies related to work orientation, for the external market is likely to influence employees' perceptions of their current employment. Another possible explanation for the lack of significant findings can be drawn from the attitude formation and modification theories. The lack of perceived career opportunities may trigger employees to modify attitudes or behaviors at work to deal with frustration associated with a lack of opportunities (i.e., cognitive dissonance reductions strategies; Cooper, 1999; Festinger, 1957). 
Perceived career opportunity was also predicted to moderate the relationship between calling work orientation and work engagement. Hypothesis 8 was developed according to the idea that employees with a strong calling to their work would be even more likely to be dedicated to, get immerse in, and have energy to engage in their work. As expected, perceived career opportunity did moderate the relationship between calling work orientation and work engagement for both the student and employee samples. What was not expected, however, was that the magnitude of the relationship between calling work orientation and engagement was stronger for participants scoring one standard deviation below the mean on the perceived career opportunity scale compared to participants scoring one standard deviation above the mean. These findings may suggest that fewer career opportunities are associated with greater work engagement. One explanation for the counterintuitive findings may be the case is that employees who have a calling sometimes perceive their work as self-sacrificing (Bunderson \& Thompson, 2009). In other words, employees with a calling may forego certain opportunities for personal growth in the workplace because they perceive their work as benefiting the greater good. Another possibility is that individuals may adjust their work orientation and perceive a calling when they do not have adequate justification (i.e., insufficient justification) to explain to themselves why they are engaged at work.

Employers should be cautious when trying to apply the above findings to the workplace. First of all, if interpreted incorrectly, they may suggest that providing career opportunities for personal growth are irrelevant and do not contribute to desired performance outcomes. Furthermore, these findings suggest that a lack perceived career opportunities may not necessarily be detrimental to an employee's job satisfaction when 
that employee reports having a calling work orientation. The non-significant findings raise the question, are employees with a calling to their work going to remain loyal to the organization despite personal dissatisfaction? Employers should be advised not to take advantage of an employee with a calling work orientation and provide them with equal opportunities for personal advancement and growth. In the original study using the career opportunity scale, researchers found support for the idea that a lack of desired career paths is positively related to organizational turnover and a search for alternative employment (Kraimer et al., 2011). Since retention of qualified and experienced employees is associated with fewer organizational costs, employers should provide ample opportunities for employees to advance in their current line of work, regardless of the employees' work orientation (Morrell, et al., 2001).

While perceived career opportunity does moderate some of the hypothesized relationship and the findings were replicated across both student and employee samples, there are always possible limitations. Although Multiple Moderated Regression (i.e., MMR) is the standard strategy for assessing moderation with continuous variables (Aiken \& West, 1991; Stone-Romero \& Anderson, 1994), researchers have criticized the MMR technique (Aguinis \& Stone-Romero, 1997). Researchers have criticized the traditional MMR technique stating that factors such as sample size, unreliability of measures, intercorrelations of predictor variables and population magnitude can increase the likelihood of Type II error (Dunlap \& Kemery, 1988; Stone-Romero \& Anderson, 1994). The two samples that were collected for the current study do provide some evidence for the moderating effects of perceived career opportunity, but arguably the samples are rather heterogeneous. More specifically, both of the samples included well-educated 
individuals (i.e., most having earned or who were pursuing a Bachelor's Degree) and who were probably from the middle or upper middle social classes. Individuals from lower socioeconomic groups, "are expected-and they need-to 'go to work,' and so they take the jobs that are available." (Dawis, 1996, p. 230). As a result, they may be less likely to perceive their work as a calling or career as compared to individuals from higher socioeconomic groups. Another possible limitation of the current study, therefore, may be that the moderated regression analyses are subject to range restriction for the two samples. If more diverse samples were collected, therefore, it is possible that the relationships examined in the current study could be even stronger.

Despite these limitations, the current findings regarding perceived career opportunity do provide some directions for future research. One important avenue for investigation would be to determine how an employee develops his or her perception of career opportunity. In other words, future research should explore whether employees with different work orientations make different attributions in the workplace that help them sustain a high job performance and become engaged in their work. It is possible, for example, that employees whose work is merely a source of income (i.e., a job work orientation) do not perceive career opportunities because they do not desire advancement in that area of work. Likewise, the findings from the current study are based on regression analyses and causality of relationships cannot be assumed. Therefore, employees who view opportunities for growth and advancement in their current work may modify their work orientation to reduce cognitive dissonance. Future research should examine the possibility that a calling work orientation may be the result of incongruent attitudes and behaviors. If quantitative evidence were found for the incongruent attitude 
argument, then findings would explain why some employees will remain in a job that they do not particularly enjoy but feel "called" to do and why employees with a calling are sometimes at higher risk for burnout (Cardador \& Caza, 2012; Hartnet \& Kline, 2005; Sherman, 2004).

The construct of perceived career opportunity is not something that may be obvious at the onset of a job, but is something that evolves and transforms over time (Kraimer et al., 2011). Considering the dynamicity of perceived career opportunity, it is recommended that future research utilize experimental and longitudinal designs to determine the true affect of perceived career opportunity on the relationship between work orientation and job outcomes. Measuring all of these variables in tandem would allow researchers to determine how fluctuations in the criterion are reflected in the predictors. Likewise, adopting an experimental design would answer the question whether perceived career opportunity is the cause of job satisfaction, job performance, or work engagement. Furthermore, it was predicted that antecedents of perceived career opportunity such as self-efficacy, resiliency, or career strategies might also influence organizational outcomes (Kraimer et al., 2011). In the future, therefore, researchers should consider testing multiple moderator and mediator models to obtain a more comprehensive view of how variables are interacting. As stated above, one of the limitations of using the Multiple Moderation Regression (MMR) in the current study is that it is subject to Type II error. While precautions were taken to reduce the chance of error, some of the null findings may actually be significant if a larger sample size were used. To combat possible limitations, researchers should consider using simulated analyses such as the Monte Carlo technique (Aguinis \& Stone-Romero, 1997). The final 
limitation of the moderated regression analysis was that the sample was relatively heterogeneous, most being well-educated professionals. Another avenue for future research would be to examine the affect of perceived career opportunity and work orientation on employees with high and low education levels and various socioeconomic classes.

\section{Core Self-Evaluations as a Moderator}

Core self-evaluations are a set of four personality traits (i.e., generalized selfefficacy, self-esteem, internal locus of control, and emotional stability) that are said to govern the way an individual views his or her immediate environment and all aspects of his or her life (Judge, Locke, \& Durham, 1997). Employees with a high core selfevaluation value themselves as individuals, feel worthy of success, attribute successes to their own accord, and maintain their composure even in challenging emotional situations; while employees with low core self-evaluations feel unworthy of success, attribute success to luck or external factors, and are easily agitated in challenging emotional situations. It was hypothesized, therefore, that employees with a calling work orientation and who reported high core self-evaluations would be better equipped to perform at a higher level, be more satisfied with their job, and be more engaged while at work. In other words, it was predicted that core self-evaluations would moderate the relationship between calling work orientation and work outcomes. Previous research that found support for a moderating effect of core self-evaluations on the relationship between calling and life satisfaction (Duffy, Allan, \& Bott, 2012), but the goal of the current study was to extend these findings to work outcomes. 
Arguably one of the most important workplace outcomes is job performance, so the first hypothesis was designed to test whether core self-evaluations moderated the relationship between work orientation and performance. For the working student sample, the main effects for core self-evaluations and calling work orientation were significant but the interaction was not. However, the moderated regression for the full-time employee sample was fully supported; both direct and interaction effects were significant. When considering the magnitude of the correlation for employees scoring one standard deviation above and below the mean on core self-evaluations, findings suggest those employees with a calling and who have a more positive outlook (i.e., high CSE) are more likely to perform at a higher level at work. As expected, these results suggest the relationship between work orientation and job performance is stronger for employees who are confident in their own abilities and who have positive feelings of self-worth. The differences that were observed between student and employee samples may be because of to the fact that students are in a different phase of their work lives; they may be in the process of discerning a calling to a particular profession or cause. There is some empirical evidence to support differences; in that, a smaller proportion of individuals from the student sample reported a calling work orientation as compared to the proportion from the work sample.

The second hypothesis regarding core self-evaluations as a moderator examined the relationship between calling work orientation and job satisfaction. It was predicted that employees with a calling and who with high core self-evaluations would be more likely to report job satisfaction in comparison to employees with low core self-evaluation. There was no support for core self-evaluations as a moderator of the relationship between 
calling work orientation and job satisfaction either the working student or employee sample. In other words, there is no difference in job satisfaction for employees who report a calling work orientation based on their perceptions of their self-worth (i.e., selfesteem), and feelings of competence (i.e., self-efficacy). The significant main effect suggests that calling work orientation is predictive of job satisfaction, so employees with that view of their work are more likely to report being satisfied. The lack of a significant moderating effect for core self-evaluations, therefore, may be because even employees with negative self-perceptions who have a calling derive satisfaction from their work. As with many organizational constructs, job satisfaction is multi-faceted and involves the evaluation of a number of work and non-work factors. One factor in particular that has been identified as influencing reports of job satisfaction is positive affect (Connolly \& Viswesvaran, 2000; Judge \& Ilies, 2004). Combining these findings, perhaps employees with a calling derive positive affective feelings from the anticipated contribution of their work rather more egoistic sources of positive affect. Employees with a calling may believe, "I am not worthy of the things I have and I am not the best at what I do, but I am still satisfied because what I do is important for the greater good." Stated differently, it is possible that perceptions of core self-evaluations are relative, shifting based on the social comparison an individual is making.

Core self-evaluations were also hypothesized to moderate the relationship between calling work orientation and work engagement. It was expected that employees with a calling and who have positive core self-evaluations would be more likely to report getting immersed in their work, being dedicated to their job, and having energy and vigor for completing work tasks. Findings from the working student sample provided support 
for the main effects of calling work orientation and core self-evaluations, but no interaction effect. In comparison, however, there was significant moderation for the employee sample. Together, these findings provide some evidence that core selfevaluation is an individual difference that does affect the magnitude of the relationship between work orientation and engagement. Contrary to what was expected, the relationship between calling work orientation and work engagement was stronger for employees reporting low core self-evaluations. These results suggest that the relationship between calling work orientation and engagement was stronger for employees with low self-worth and negative appraisals of the self. One explanation for these unexpected findings is that employees with a calling work orientation and negative self-appraisals may become more engaged in their work to justify their calling. One of the characteristics of a calling work orientation is that the employee adopts their work role into their selfconcept (Stryker \& Serpe, 1994). As has been found in the prosocial behavior literature, it is possible that employees with a calling work orientation were especially engaged in their work in an attempt to boost or maintain their feelings of self-worth (Brown \& Smart, 1991; Tesser, 2000).

While a number of research studies have found significant support for core selfevaluations as a predictor of job-related outcomes, there has been some question regarding the psychometric properties of the core self-evaluation construct (Johnson, Rosen, \& Levy, 2008). Judge et al. (1997) developed the concept of core self-evaluation and studies have confirmed the factor loading of the four personality traits (Judge, Bono, $\&$ Thoresen, 2003). One of the main criticisms of core self-evaluation is that the four personality traits (i.e., self-esteem, self-efficacy, locus of control, and emotional stability) 
may be causal indicators (Johnson et al., 2008). Stated differently, the personality traits may be more than just intercorrelated, one may cause another trait to be more prominent or pronounced. Similarly, it is possible that core self-evaluations may be both an antecedent and outcome of the cognitive appraisal process used to develop ones work orientation. In other words, causal relationships cannot be inferred when correlational or multiple regression statistical techniques are utilized. Future studies should consider measuring core self-evaluations at multiple times during an employees tenure, including during times of career transition, promotion, or job redesign aimed at increasing calling work orientation.

One aspect of core self-evaluations that is particularly interesting to consider within the realm of calling work orientation is locus of control. Locus of control is defined by the amount of control individuals perceive they have over their external environment (Rotter, 1966). Individuals who score high on internal locus of control tend to perceive their environment as changeable and they can control the outcomes of situations (Spector, 1982). Individuals with an internal locus of control also value reward systems and contingent rewards for performance because they make an association between a stimulus, response, and outcome in their external environment. One of the main components of a true calling is that it originates from beyond the self (Dik \& Duffy, 2009), which is more likely to correspond with an external locus of control. If an individual believed that he or she was put on the earth to be a teacher, for example, they would be convinced it was fate instead of self-determinism. Attributing successes in an individual's work life to an intelligent designer, Allah, God, or fate of the universe may not carry with it the same outcomes as an external locus of control in the traditional 
sense. It is possible that the transcendent and spiritual aspects associated with a calling may buffer the "out of control" feelings employees feel in the workplace.

In addition to some concerns with the conceptualization of core self-evaluation, it is important to note the possible limitations associated with the measurement of job performance and job satisfaction constructs. As noted above, cross-sectional and selfreport data are subject to response biases and distortions. Both job performance and job satisfaction involve the cognitive and affective evaluation of multiple workplace factors (Judge \& Ilies, 2004; Viswesvaran, 2001). One of the limitations of the current study, therefore, was that only overall job satisfaction and performance were measured. It is possible that core self-evaluations would moderate the relationship between calling work orientation and some dimensions of job performance and satisfaction instead of global measures of these constructs. Future research should consider using a multi-dimensional scale of job satisfaction, along with a scale of trait affect to account for cognitive and emotional determinants of satisfaction.

While the current study did find some important results regarding the influence of core self-evaluation on the relationship between work orientation and work outcomes, there is more work to be done. In particular, future research should investigate other individual differences such as resiliency, flexibility, coping mechanisms, emotional intelligence, or creativity that may moderate these relationships. One study of work orientation and emotional labor found that employees with a calling were better equipped to deal with situations that require self-regulation (Yugo, 2009). Considering both of these findings, perhaps employees with a work orientation have developed strategies to more effectively deal with stressors in the workplace (e.g., role ambiguity, role conflict, 
etc.). Therefore, the work orientation literature may benefit from testing a multiple moderator-mediator model that includes some of the linkages discussed above. Utilizing structural equation modeling, would allow for an interpretation of the goodness of fit for more complete models including work orientation.

\section{Concluding Remarks}

The primary aim of the current dissertation was to review the current work orientation literature, compare and contrast calling work orientation with similar organizational constructs, empirically examine the covariates of calling work orientation, and investigate two possible moderators of the relationship between calling work orientation and work-related outcomes. Another objective of the current study was to explore the role of work orientation in employee performance. In partial fulfillment of that aim, hierarchical regression findings suggest calling work orientation was predictive of overall job performance above and beyond two common predictors of performance, conscientiousness and numerical ability. The results for the covariate analyses provided evidence that prosocial motivation, meaningful work, and spirituality do play a significant role in the development of an employees' work orientation. Finally, the moderation effect for perceived career opportunities and core self-evaluations were somewhat mixed. Although there was limited support for some of the study hypotheses, the findings do provide information pertaining to the complexity of work orientation as a construct. The most notable findings were that perceived career opportunities moderated the relationship between calling work orientation and job performance for the employee sample, and that core self-evaluations moderated the relationship between calling work 
orientation and job performance, and that core self-evaluations moderated the relationship between calling work orientation and work engagement. 
Table 1. Pilot Sample Gender and Ethnicity Summary

\begin{tabular}{lcc}
\hline Gender & Frequency & Percent \\
\cline { 2 - 3 } Male & 96 & $18.5 \%$ \\
Female & 419 & $80.6 \%$ \\
Not Specified & 5 & $1.0 \%$ \\
Ethnicity & & \\
White/Caucasian & 48 & $9.2 \%$ \\
Black/African American & 47 & $9.0 \%$ \\
Hispanic & 393 & $75.6 \%$ \\
Asian/Indian & 12 & $2.3 \%$ \\
Other & 20 & $3.8 \%$ \\
\hline
\end{tabular}


Table 2. Pilot Sample - O*Net Occupation Categorization Summary

\begin{tabular}{lcc}
\hline Agriculture, Food, and Natural Resources & 23 & $4.4 \%$ \\
Architecture and Construction & 0 & $0.0 \%$ \\
Art, Audio/Video Technology, and Communications & 9 & $1.7 \%$ \\
Business, Management, and Administration & 69 & $13.3 \%$ \\
Education and Training & 73 & $14.0 \%$ \\
Finance & 14 & $2.7 \%$ \\
Government and Public Administration & 10 & $1.9 \%$ \\
Health Sciences & 62 & $11.9 \%$ \\
Hospitality and Tourism & 48 & $9.2 \%$ \\
Human Sciences & 22 & $4.2 \%$ \\
Information Technology & 9 & $1.7 \%$ \\
Law, Public Safety, Corrections, and Security & 26 & $5.0 \%$ \\
Manufacturing & 3 & $0.6 \%$ \\
Marketing, Sales and Service & 141 & $27.1 \%$ \\
Science, Technology, Engineering, and Mathematics & 7 & $1.3 \%$ \\
Transportation, Distribution, and Linguistics & 4 & $0.8 \%$ \\
\hline
\end{tabular}


Table 3. Work Sample Gender and Ethnicity Summary

\begin{tabular}{lcc}
\hline Gender & Frequency & Percent \\
\cline { 2 - 3 } Male & 304 & $58.5 \%$ \\
Female & 214 & $41.2 \%$ \\
Not Specified & 2 & $0.4 \%$ \\
Ethnicity & & \\
White/Caucasian & 245 & $47.1 \%$ \\
Black/African American & 20 & $3.8 \%$ \\
Afro-Caribbean & 2 & $0.4 \%$ \\
Pacific Islander & 1 & $0.2 \%$ \\
Hispanic & 12 & $2.3 \%$ \\
Native American & 1 & $0.2 \%$ \\
Asian/Indian & 223 & $42.9 \%$ \\
Multi-Racial & 10 & $1.9 \%$ \\
Other & 5 & $1.0 \%$ \\
\hline
\end{tabular}


Table 4. Work Sample - Level of Education Summary

\begin{tabular}{lcc}
\hline Level of Education & Frequency & Percent \\
\cline { 2 - 3 } Some High School & 1 & $0.2 \%$ \\
High School Diploma/GED & 33 & $6.3 \%$ \\
Some College & 92 & $17.1 \%$ \\
Associates Degree & 48 & $9.2 \%$ \\
Bachelors Degree & 238 & $45.8 \%$ \\
Masters Degree & 90 & $17.3 \%$ \\
Specialist Degree & 7 & $1.3 \%$ \\
Doctoral Degree & 8 & $1.5 \%$ \\
Post-Doctoral Degree & 2 & $0.4 \%$ \\
\hline
\end{tabular}


Table 5. Work Sample - Religion and Spirituality Summary

\begin{tabular}{lcc}
\hline Religion/Spirituality & Frequency & Percent \\
\cline { 2 - 3 } Christianity - Catholic & 77 & $14.8 \%$ \\
Christianity - Protestant & 104 & $20.0 \%$ \\
Mormonism & 5 & $1.0 \%$ \\
Judaism & 11 & $2.1 \%$ \\
Islam & 23 & $4.4 \%$ \\
Buddhism & 6 & $1.2 \%$ \\
Hinduism & 144 & $27.7 \%$ \\
Jainism & 2 & $0.4 \%$ \\
Sikhism & 1 & $0.2 \%$ \\
Taoism & 3 & $0.6 \%$ \\
Agnostic & 54 & $10.6 \%$ \\
Atheist & $55 \%$ \\
Other & $54 \%$ \\
\hline
\end{tabular}


Table 6. Work Sample - O*Net Occupation Categorization Summary

\begin{tabular}{lcc}
\hline Agriculture, Food, and Natural Resources & 11 & $2.1 \%$ \\
Architecture and Construction & 17 & $3.3 \%$ \\
Art, Audio/Video Technology, and Communications & 34 & $6.5 \%$ \\
Business, Management, and Administration & 68 & $13.1 \%$ \\
Education and Training & 63 & $12.1 \%$ \\
Finance & 33 & $6.3 \%$ \\
Government and Public Administration & 18 & $3.5 \%$ \\
Health Sciences & 29 & $5.6 \%$ \\
Hospitality and Tourism & 15 & $2.9 \%$ \\
Human Sciences & 8 & $1.5 \%$ \\
Information Technology & 80 & $15.4 \%$ \\
Law, Public Safety, Corrections, and Security & 13 & $2.5 \%$ \\
Manufacturing & 23 & $4.4 \%$ \\
Marketing, Sales and Service & 54 & $10.4 \%$ \\
Science, Technology, Engineering, and Mathematics & 35 & $6.7 \%$ \\
Transportation, Distribution, and Linguistics & 19 & $3.7 \%$ \\
\hline
\end{tabular}




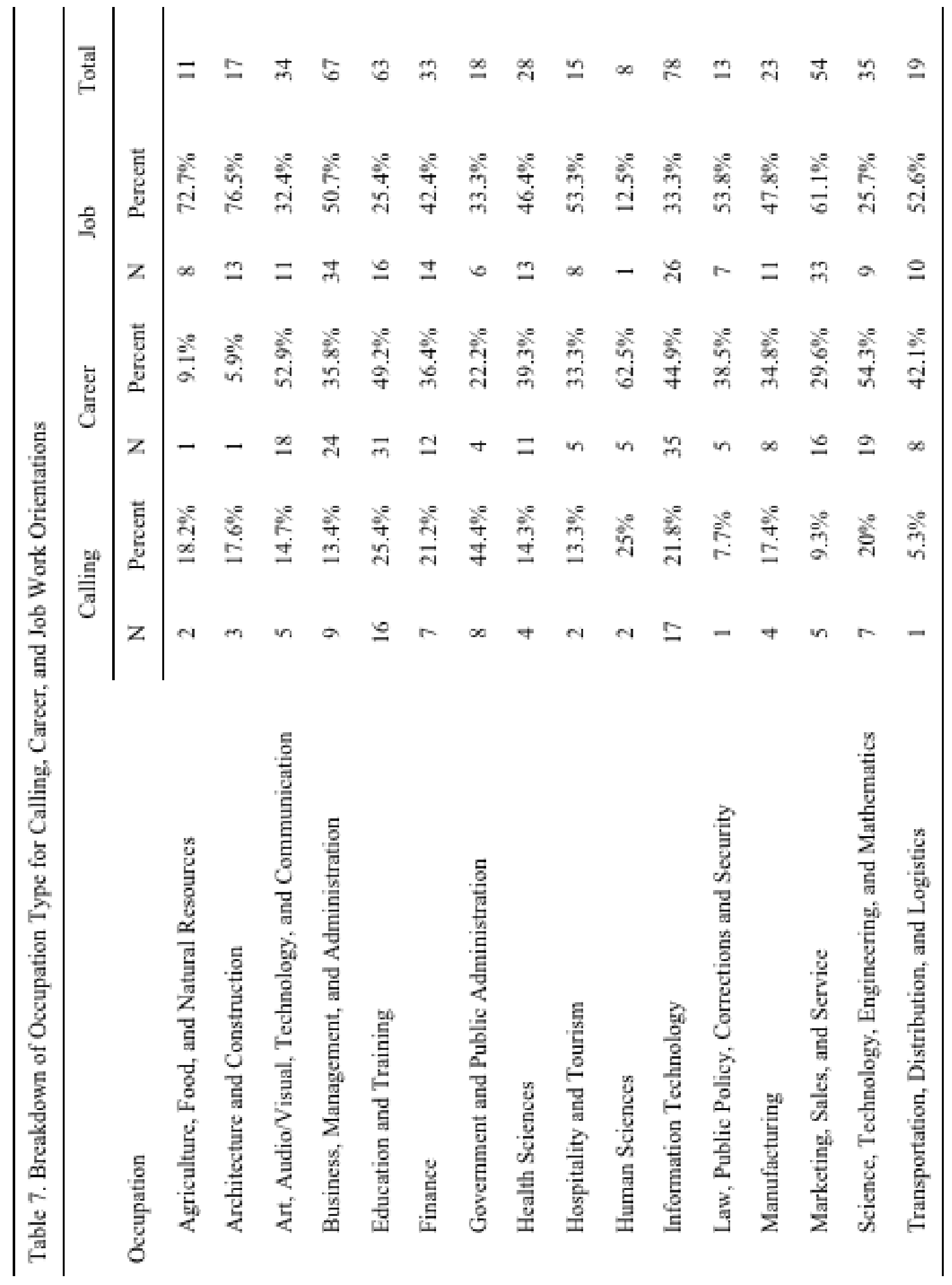




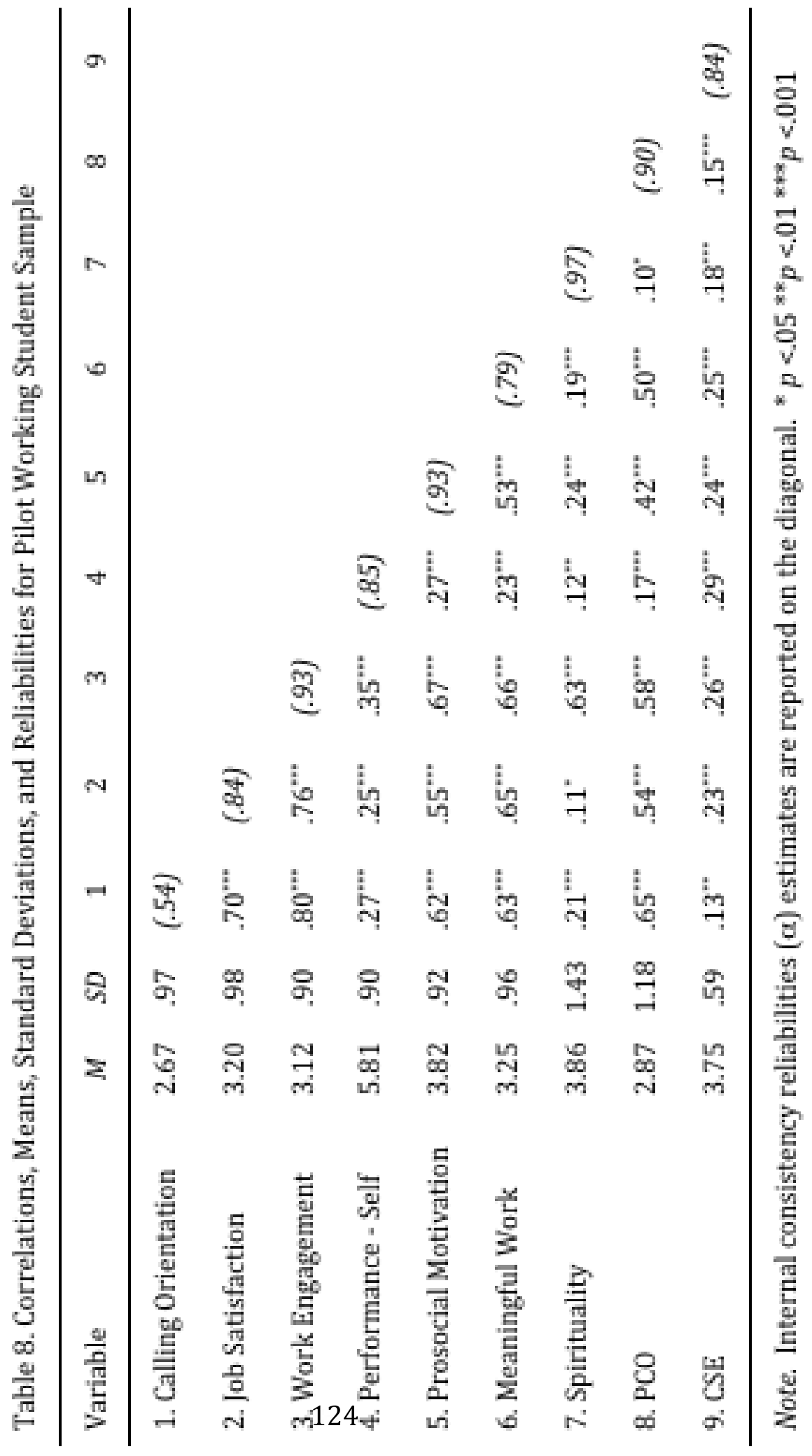


Table 9. Hierarchical Regression for Job Performance, Calling, and Covariates -Pilot

Job Performance

$\underline{\beta} \stackrel{\mathrm{R}^{2}}{\Delta \mathrm{R}^{2}} \stackrel{\mathrm{F}}{ }$

Step One

$\begin{array}{lllll}\text { Prosocial Motivation } & .20^{* * *} & .088 & .088^{* * *} & 16.63^{* * *} \\ \text { Spirituality } & .06 & & \\ \text { Meaningful Work } & .12^{* *} & & \end{array}$

Step Two

\begin{tabular}{lcccc} 
Prosocial Motivation & $.14^{* *}$ & .097 & $.009^{*}$ & $13.81^{* * *}$ \\
Spirituality & .05 & & \\
Meaningful Work & .06 & & \\
Calling Orientation & $.13^{*}$ & \\
\hline
\end{tabular}

Note. ${ }^{*} p<.05 * * p<.01 * * * p<.001$ 
Table 10. Hierarchical Regression for Job Satisfaction, Calling, and Covariates - Pilot

\begin{tabular}{|c|c|c|c|c|}
\hline & \multicolumn{4}{|c|}{ Job Satisfaction } \\
\hline & $\beta$ & $\mathrm{R}^{2}$ & $\Delta \mathrm{R}^{2}$ & $\mathrm{~F}$ \\
\hline \multicolumn{5}{|l|}{ Step One } \\
\hline Prosocial Motivation & $.29^{* * *}$ & .487 & $.487^{* * *}$ & $160.84^{* * *}$ \\
\hline Spirituality & -.05 & & & \\
\hline Meaningful Work & $.51^{* * *}$ & & & \\
\hline \multicolumn{5}{|l|}{ Step Two } \\
\hline Prosocial Motivation & $.13^{* * *}$ & .577 & $.090^{* * *}$ & $173.34^{* * *}$ \\
\hline Spirituality & $-.07^{*}$ & & & \\
\hline Meaningful Work & $.33^{* * *}$ & & & \\
\hline Calling Orientation & $.43^{* * *}$ & & & \\
\hline
\end{tabular}

Note. ${ }^{*} p<.05 * * p<.01 * * * p<.001$ 
Table 11. Hierarchical Regression for Engagement, Calling, and Covariates - Pilot

\begin{tabular}{|c|c|c|c|c|}
\hline & \multicolumn{4}{|c|}{ Work Engagement } \\
\hline & $\beta$ & $\mathrm{R}^{2}$ & $\Delta \mathrm{R}^{2}$ & $\mathrm{~F}$ \\
\hline \multicolumn{5}{|l|}{ Step One } \\
\hline Prosocial Motivation & $.46^{* * *}$ & .552 & $.552^{* * *}$ & $212.18^{* * *}$ \\
\hline Spirituality & .01 & & & \\
\hline Meaningful Work & $.39^{* * *}$ & & & \\
\hline \multicolumn{5}{|l|}{ Step Two } \\
\hline Prosocial Motivation & $.24^{* * *}$ & .704 & $.152^{* * *}$ & $306.14^{* * *}$ \\
\hline Spirituality & -.01 & & & \\
\hline Meaningful Work & $.16^{* * *}$ & & & \\
\hline Calling Orientation & $.56^{* * *}$ & & & \\
\hline
\end{tabular}

Note. ${ }^{*} p<.05 * * p<.01 * * * p<.001$ 
Table 12. Moderated Regression for Calling, Performance, and Career Opportunity - Pilot

\begin{tabular}{|c|c|c|c|c|}
\hline & \multicolumn{4}{|c|}{ Job Performance } \\
\hline & $\beta$ & $\mathrm{R}^{2}$ & $\Delta \mathrm{R}^{2}$ & $\mathrm{~F}$ \\
\hline \multicolumn{5}{|l|}{ Step One } \\
\hline Calling Orientation & $.27^{* * *}$ & .075 & $.075^{* * *}$ & $41.65^{* * *}$ \\
\hline \multicolumn{5}{|l|}{ Step Two } \\
\hline Calling Orientation & $.28^{* * *}$ & .075 & .000 & $20.80^{* * *}$ \\
\hline Perceived Career Opportunities (PCO) & -.01 & & & \\
\hline \multicolumn{5}{|l|}{ Step Three } \\
\hline Calling Orientation & $.28^{* * *}$ & .075 & .000 & $13.93^{* * *}$ \\
\hline Perceived Career Opportunities (PCO) & -.01 & & & \\
\hline Calling X PCO & .02 & & & \\
\hline
\end{tabular}

Note. ${ }^{*} p<.05 * * p<.01 * * * p<.001$ 
Table 13. Moderated Regression for Calling, Satisfaction, and Career Opportunity - Pilot

\begin{tabular}{|c|c|c|c|c|}
\hline & \multicolumn{4}{|c|}{ Job Satisfaction } \\
\hline & $\beta$ & $\mathrm{R}^{2}$ & $\Delta \mathrm{R}^{2}$ & $\mathrm{~F}$ \\
\hline \multicolumn{5}{|l|}{ Step One } \\
\hline Calling Orientation & $.70^{* * *}$ & .490 & $.490^{* * *}$ & $490.23^{* * *}$ \\
\hline \multicolumn{5}{|l|}{ Step Two } \\
\hline Calling Orientation & $.60^{* * *}$ & .503 & $.013^{* * *}$ & $257.66^{* * *}$ \\
\hline Perceived Career Opportunities (PCO) & $.15^{* * *}$ & & & \\
\hline \multicolumn{5}{|l|}{ Step Three } \\
\hline Calling Orientation & $.62^{* * *}$ & .509 & $.007^{* *}$ & $176.21^{* * *}$ \\
\hline Perceived Career Opportunities (PCO) & $.14^{* * *}$ & & & \\
\hline Calling X PCO & -.08 & & & \\
\hline
\end{tabular}

Note. ${ }^{*} p<.05 * * p<.01 * * * p<.001$ 
Table 14. Moderated Regression for Calling, Engagement, and Career Opportunity - Pilot

\begin{tabular}{|c|c|c|c|c|}
\hline & \multicolumn{4}{|c|}{ Work Engagement } \\
\hline & $\beta$ & $\mathrm{R}^{2}$ & $\Delta \mathrm{R}^{2}$ & $\mathrm{~F}$ \\
\hline \multicolumn{5}{|l|}{ Step One } \\
\hline Calling Orientation & $.80^{* * *}$ & .643 & $.643^{* * *}$ & $933.59^{* * *}$ \\
\hline \multicolumn{5}{|l|}{ Step Two } \\
\hline Calling Orientation & $.73^{* * *}$ & .650 & $.006^{* * *}$ & $479.12^{* * *}$ \\
\hline Perceived Career Opportunities (PCO) & $.11^{* *}$ & & & \\
\hline \multicolumn{5}{|l|}{ Step Three } \\
\hline Calling Orientation & $.75^{* * *}$ & .661 & $.012^{*}$ & $335.93^{* * *}$ \\
\hline Perceived Career Opportunities (PCO) & $.10^{* *}$ & & & \\
\hline Calling X PCO & $-.11^{* * *}$ & & & \\
\hline
\end{tabular}

Note. ${ }^{*} p<.05 * * p<.01 * * * p<.001$ 
Table 15. Moderated Regression for Calling, Performance, and Core Self-Evaluations - Pilot

\begin{tabular}{|c|c|c|c|c|}
\hline & \multicolumn{4}{|c|}{ Job Performance } \\
\hline & $\beta$ & $\mathrm{R}^{2}$ & $\Delta \mathrm{R}^{2}$ & $\mathrm{~F}$ \\
\hline \multicolumn{5}{|l|}{ Step One } \\
\hline Calling Orientation & $.27^{* * *}$ & .075 & $.075^{* * *}$ & $41.65^{* * *}$ \\
\hline \multicolumn{5}{|l|}{ Step Two } \\
\hline Calling Orientation & $.24^{* * *}$ & .139 & $.065^{* * *}$ & $41.75^{* * *}$ \\
\hline Core Self-Evaluations (CSE) & $.26^{* * *}$ & & & \\
\hline \multicolumn{5}{|l|}{ Step Three } \\
\hline Calling Orientation & $.24^{* * *}$ & .141 & .001 & $28.09^{* * *}$ \\
\hline Core Self-Evaluations (CSE) & $.26^{* * *}$ & & & \\
\hline Calling X CSE & .04 & & & \\
\hline
\end{tabular}

Note. ${ }^{*} p<.05 * * p<.01{ }^{* * *} p<.001$ 
Table 16. Moderated Regression for Calling, Satisfaction, and Core Self-Evaluations - Pilot

\begin{tabular}{|c|c|c|c|c|}
\hline & \multicolumn{4}{|c|}{ Job Satisfaction } \\
\hline & $\beta$ & $\mathrm{R}^{2}$ & $\Delta \mathrm{R}^{2}$ & $\mathrm{~F}$ \\
\hline \multicolumn{5}{|l|}{ Step One } \\
\hline Calling Orientation & $.70^{* * *}$ & .490 & $.490^{* * *}$ & $490.23^{* * *}$ \\
\hline \multicolumn{5}{|l|}{ Step Two } \\
\hline Calling Orientation & $.68^{* * *}$ & .512 & $.022^{* * *}$ & $267.02^{* * *}$ \\
\hline Core Self-Evaluations (CSE) & $.15^{* * *}$ & & & \\
\hline \multicolumn{5}{|l|}{ Step Three } \\
\hline Calling Orientation & $.68^{* * *}$ & .512 & .000 & $177.66^{* * *}$ \\
\hline Core Self-Evaluations (CSE) & $.15^{* * *}$ & & & \\
\hline Calling X CSE & -.00 & & & \\
\hline
\end{tabular}

Note. ${ }^{*} p<.05 * * p<.01 * * * p<.001$ 
Table 17. Moderated Regression for Calling, Engagement, and Core Self-Evaluations - Pilot

\begin{tabular}{|c|c|c|c|c|}
\hline & \multicolumn{4}{|c|}{ Work Engagement } \\
\hline & $\beta$ & $\mathrm{R}^{2}$ & $\Delta \mathrm{R}^{2}$ & $\mathrm{~F}$ \\
\hline \multicolumn{5}{|l|}{ Step One } \\
\hline Calling Orientation & $.80^{* * *}$ & .643 & $.643^{* * *}$ & $933.59^{* * *}$ \\
\hline \multicolumn{5}{|l|}{ Step Two } \\
\hline Calling Orientation & $.78^{* * *}$ & .667 & $.024^{* * *}$ & $518.83^{* * *}$ \\
\hline Core Self-Evaluations (CSE) & $.16^{* * *}$ & & & \\
\hline \multicolumn{5}{|l|}{ Step Three } \\
\hline Calling Orientation & $.78^{* * *}$ & .669 & .001 & $346.96^{* * *}$ \\
\hline Core Self-Evaluations (CSE) & $.16^{* * *}$ & & & \\
\hline Calling X CSE & -.03 & & & \\
\hline
\end{tabular}

Note. ${ }^{*} p<.05 * * p<.01 * * * p<.001$ 


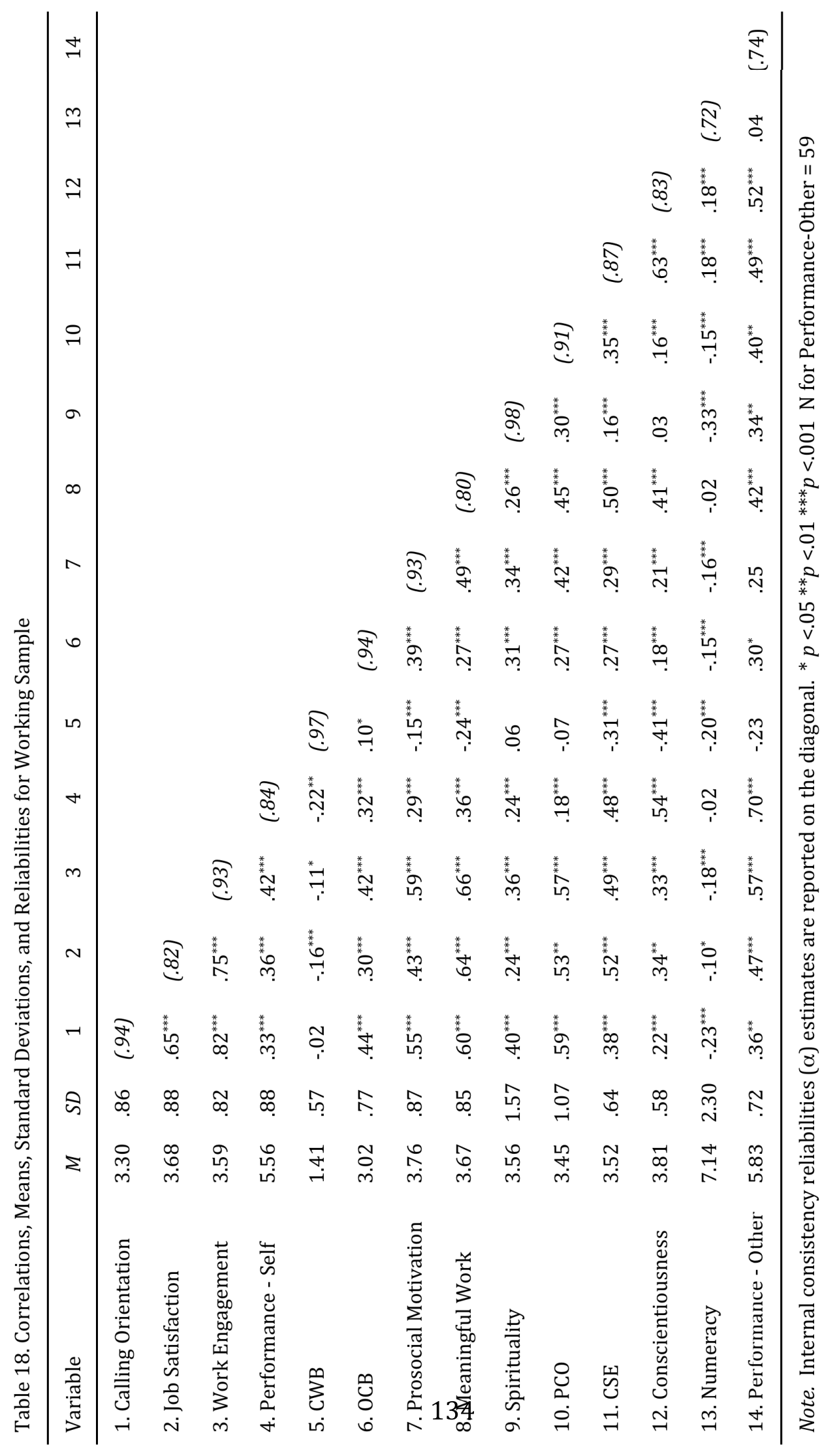


Table 19. Incremental Validity for Numeracy, Conscientiousness, and Calling

\begin{tabular}{|c|c|c|c|c|}
\hline & \multicolumn{4}{|c|}{ Job Performance } \\
\hline & $\beta$ & $\mathrm{R}^{2}$ & $\Delta \mathrm{R}^{2}$ & $\mathrm{~F}$ \\
\hline \multicolumn{5}{|l|}{ Step One } \\
\hline Conscientiousness & $.56^{* * *}$ & .304 & $.304^{* * *}$ & $112.32^{* * *}$ \\
\hline Numeracy (Mental Ability) & $-.12^{* * *}$ & & & \\
\hline \multicolumn{5}{|l|}{ Step Two } \\
\hline Conscientiousness & $.55^{* * *}$ & .340 & $.036^{* * *}$ & $88.29^{* * *}$ \\
\hline Numeracy (Mental Ability) & -.06 & & & \\
\hline Calling Orientation & $.20^{* * *}$ & & & \\
\hline
\end{tabular}

Note. ${ }^{*} p<.05 * * p<.01 * * * p<.001$ 
Table 20. Hierarchical Regression for Performance, Calling, and Covariates - Work

\begin{tabular}{|c|c|c|c|c|}
\hline & \multicolumn{4}{|c|}{ Job Performance } \\
\hline & $\beta$ & $\mathrm{R}^{2}$ & $\Delta \mathrm{R}^{2}$ & $\mathrm{~F}$ \\
\hline \multicolumn{5}{|l|}{ Step One } \\
\hline Prosocial Motivation & $.13^{* *}$ & .152 & $.152^{* * *}$ & $30.73^{* * *}$ \\
\hline Spirituality & .06 & & & \\
\hline Meaningful Work & $.29^{* * *}$ & & & \\
\hline \multicolumn{5}{|l|}{ Step Two } \\
\hline Prosocial Motivation & .09 & .160 & $.009^{*}$ & $24.60^{* * *}$ \\
\hline Spirituality & .03 & & & \\
\hline Meaningful Work & $.23^{* * *}$ & & & \\
\hline Calling Orientation & $.13^{*}$ & & & \\
\hline
\end{tabular}


Table 21. Hierarchical Regression for Job Satisfaction, Calling, and Covariates - Work

\begin{tabular}{|c|c|c|c|c|}
\hline & \multicolumn{4}{|c|}{ Job Satisfaction } \\
\hline & $\beta$ & $\mathrm{R}^{2}$ & $\Delta \mathrm{R}^{2}$ & $\mathrm{~F}$ \\
\hline \multicolumn{5}{|l|}{ Step One } \\
\hline Prosocial Motivation & $.14^{* * *}$ & .432 & $.432^{* * *}$ & $130.77^{* * *}$ \\
\hline Spirituality & .06 & & & \\
\hline Meaningful Work & $.56^{* * *}$ & & & \\
\hline \multicolumn{5}{|l|}{ Step Two } \\
\hline Prosocial Motivation & .02 & .521 & $.089^{* * *}$ & $140.15^{* * *}$ \\
\hline Spirituality & -.02 & & & \\
\hline Meaningful Work & $.39^{* * *}$ & & & \\
\hline Calling Orientation & $.42^{* * *}$ & & & \\
\hline
\end{tabular}

Note. ${ }^{*} p<.05 * * p<.01 * * * p<.001$ 
Table 22. Hierarchical Regression for Engagement, Calling, and Covariates - Work

\begin{tabular}{|c|c|c|c|c|}
\hline & \multicolumn{4}{|c|}{ Work Engagement } \\
\hline & $\beta$ & $\mathrm{R}^{2}$ & $\Delta \mathrm{R}^{2}$ & $\mathrm{~F}$ \\
\hline \multicolumn{5}{|l|}{ Step One } \\
\hline Prosocial Motivation & $.32^{* * *}$ & .549 & $.549^{* * *}$ & $209.54^{* * *}$ \\
\hline Spirituality & $.13^{* * *}$ & & & \\
\hline Meaningful Work & $.48^{* * *}$ & & & \\
\hline \multicolumn{5}{|l|}{ Step Two } \\
\hline Prosocial Motivation & $.15^{* * *}$ & .734 & $.185^{* * *}$ & $355.35^{* * *}$ \\
\hline Spirituality & .01 & & & \\
\hline Meaningful Work & $.23^{* * *}$ & & & \\
\hline Calling Orientation & $.60^{* * *}$ & & & \\
\hline
\end{tabular}

Note. $* p<.05 * * p<.01 * * * p<.001$ 
Table 23. Moderated Regression for Calling, Performance, and Career Opportunity - Work

\begin{tabular}{|c|c|c|c|c|}
\hline & \multicolumn{4}{|c|}{ Job Performance } \\
\hline & $\beta$ & $\mathrm{R}^{2}$ & $\Delta \mathrm{R}^{2}$ & $\mathrm{~F}$ \\
\hline \multicolumn{5}{|l|}{ Step One } \\
\hline Calling Orientation & $.33^{* * *}$ & .111 & $.111^{* * *}$ & $64.83^{* * *}$ \\
\hline \multicolumn{5}{|l|}{ Step Two } \\
\hline Calling Orientation & $.29^{* * *}$ & .116 & .004 & $33.76^{* * *}$ \\
\hline Perceived Career Opportunities (PCO) & .08 & & & \\
\hline \multicolumn{5}{|l|}{ Step Three } \\
\hline Calling Orientation & $.29^{* * *}$ & .130 & $.014^{* *}$ & $25.55^{* * *}$ \\
\hline Perceived Career Opportunities (PCO) & $.11^{*}$ & & & \\
\hline Calling X PCO & $.12^{* *}$ & & & \\
\hline
\end{tabular}

Note. $* p<.05 * * p<.01 * * * p<.001$ 
Table 24. Moderated Regression for Calling, Satisfaction, and Career Opportunity - Work

\begin{tabular}{|c|c|c|c|c|}
\hline & \multicolumn{4}{|c|}{ Job Satisfaction } \\
\hline & $\beta$ & $\mathrm{R}^{2}$ & $\Delta \mathrm{R}^{2}$ & $\mathrm{~F}$ \\
\hline \multicolumn{5}{|l|}{ Step One } \\
\hline Calling Orientation & $.65^{* * *}$ & .422 & $.422^{* * *}$ & $378.20^{* * *}$ \\
\hline \multicolumn{5}{|l|}{ Step Two } \\
\hline Calling Orientation & $.52^{* * *}$ & .454 & $.031^{* * *}$ & $214.495^{* * *}$ \\
\hline Perceived Career Opportunities (PCO) & $.22^{* * *}$ & & & \\
\hline \multicolumn{5}{|l|}{ Step Three } \\
\hline Calling Orientation & $.52^{* * *}$ & .457 & .003 & $144.43^{* * *}$ \\
\hline Perceived Career Opportunities (PCO) & $.21^{* * *}$ & & & \\
\hline Calling X PCO & -.06 & & & \\
\hline
\end{tabular}

Note. ${ }^{*} p<.05 * * p<.01 * * * p<.001$ 
Table 25. Moderated Regression for Calling, Engagement, and Career Opportunity - Work

\begin{tabular}{|c|c|c|c|c|}
\hline & \multicolumn{4}{|c|}{ Work Engagement } \\
\hline & $\beta$ & $\mathrm{R}^{2}$ & $\Delta \mathrm{R}^{2}$ & $\mathrm{~F}$ \\
\hline \multicolumn{5}{|l|}{ Step One } \\
\hline Calling Orientation & $.82^{* * *}$ & 674 & $.674^{* * *}$ & $1070.42^{* * *}$ \\
\hline \multicolumn{5}{|l|}{ Step Two } \\
\hline Calling Orientation & $.74^{* * *}$ & 686 & $.012^{* * *}$ & $563.68^{* * *}$ \\
\hline Perceived Career Opportunities (PCO) & $.13^{* * *}$ & & & \\
\hline \multicolumn{5}{|l|}{ Step Three } \\
\hline Calling Orientation & $.74^{* * *}$ & 690 & $.004^{*}$ & $381.25^{* * *}$ \\
\hline Perceived Career Opportunities (PCO) & $.12^{* * *}$ & & & \\
\hline Calling X PCO & $-.06^{*}$ & & & \\
\hline
\end{tabular}

Note. ${ }^{*} p<.05 * * p<.01 * * * p<.001$ 
Table 26. Moderated Regression for Calling, Performance, and Core Self-Evaluation - Work

\begin{tabular}{|c|c|c|c|c|}
\hline & \multicolumn{4}{|c|}{ Job Performance } \\
\hline & $\beta$ & $\mathrm{R}^{2}$ & $\Delta \mathrm{R}^{2}$ & $\mathrm{~F}$ \\
\hline \multicolumn{5}{|l|}{ Step One } \\
\hline Calling Orientation & $.34^{* * *}$ & .112 & $.112^{* * *}$ & $65.03^{* * *}$ \\
\hline \multicolumn{5}{|l|}{ Step Two } \\
\hline Calling Orientation & $.18^{* * *}$ & .255 & $.144^{* * *}$ & $88.36^{* * *}$ \\
\hline Core Self-Evaluations (CSE) & $.41^{* * *}$ & & & \\
\hline \multicolumn{5}{|l|}{ Step Three } \\
\hline Calling Orientation & $.18^{* * *}$ & .261 & $.006^{*}$ & $60.51^{* * *}$ \\
\hline Core Self-Evaluations (CSE) & $.41^{* * *}$ & & & \\
\hline Calling X CSE & $.07^{*}$ & & & \\
\hline
\end{tabular}

Note. ${ }^{*} p<.05 * * p<.01 * * * p<.001$ 
Table 27. Moderated Regression for Calling, Satisfaction, and Core Self-Evaluation - Work

\begin{tabular}{|c|c|c|c|c|}
\hline & \multicolumn{4}{|c|}{ Job Satisfaction } \\
\hline & $\beta$ & $\mathrm{R}^{2}$ & $\Delta \mathrm{R}^{2}$ & $\mathrm{~F}$ \\
\hline \multicolumn{5}{|l|}{ Step One } \\
\hline Calling Orientation & $.65^{* * *}$ & .422 & $.422^{* * *}$ & $377.48^{* * *}$ \\
\hline \multicolumn{5}{|l|}{ Step Two } \\
\hline Calling Orientation & $.53^{* * *}$ & .513 & $.090^{* * *}$ & $270.92^{* * *}$ \\
\hline Core Self-Evaluations (CSE) & $.32^{* * *}$ & & & \\
\hline \multicolumn{5}{|l|}{ Step Three } \\
\hline Calling Orientation & $.53^{* * *}$ & .515 & .002 & $181.96^{* * *}$ \\
\hline Core Self-Evaluations (CSE) & $.32^{* * *}$ & & & \\
\hline Calling X CSE & -.05 & & & \\
\hline
\end{tabular}

Note. ${ }^{*} p<.05 * * p<.01 * * * p<.001$ 
Table 28. Moderated Regression for Calling, Engagement, and Core Self-Evaluation - Work

\begin{tabular}{|c|c|c|c|c|}
\hline & \multicolumn{4}{|c|}{ Work Engagement } \\
\hline & $\beta$ & $\mathrm{R}^{2}$ & $\Delta \mathrm{R}^{2}$ & $\mathrm{~F}$ \\
\hline \multicolumn{5}{|l|}{ Step One } \\
\hline Calling Orientation & $.82^{* * *}$ & .674 & $.674^{* * *}$ & $1068.39^{* * *}$ \\
\hline \multicolumn{5}{|l|}{ Step Two } \\
\hline Calling Orientation & $.74^{* * *}$ & .713 & $.039^{* * *}$ & $640.174^{* * *}$ \\
\hline Core Self-Evaluations (CSE) & $.21^{* * *}$ & & & \\
\hline \multicolumn{5}{|l|}{ Step Three } \\
\hline Calling Orientation & $.74^{* * *}$ & .720 & $.007^{* * *}$ & $441.07^{* * *}$ \\
\hline Core Self-Evaluations (CSE) & $.21^{* * *}$ & & & \\
\hline Calling X CSE & $-.08^{* * *}$ & & & \\
\hline
\end{tabular}

Note. ${ }^{*} p<.05{ }^{* *} p<.01{ }^{* * *} p<.001$ 
Figure 1. Interaction Graph for Calling, Job Performance, and PCO (Employee)

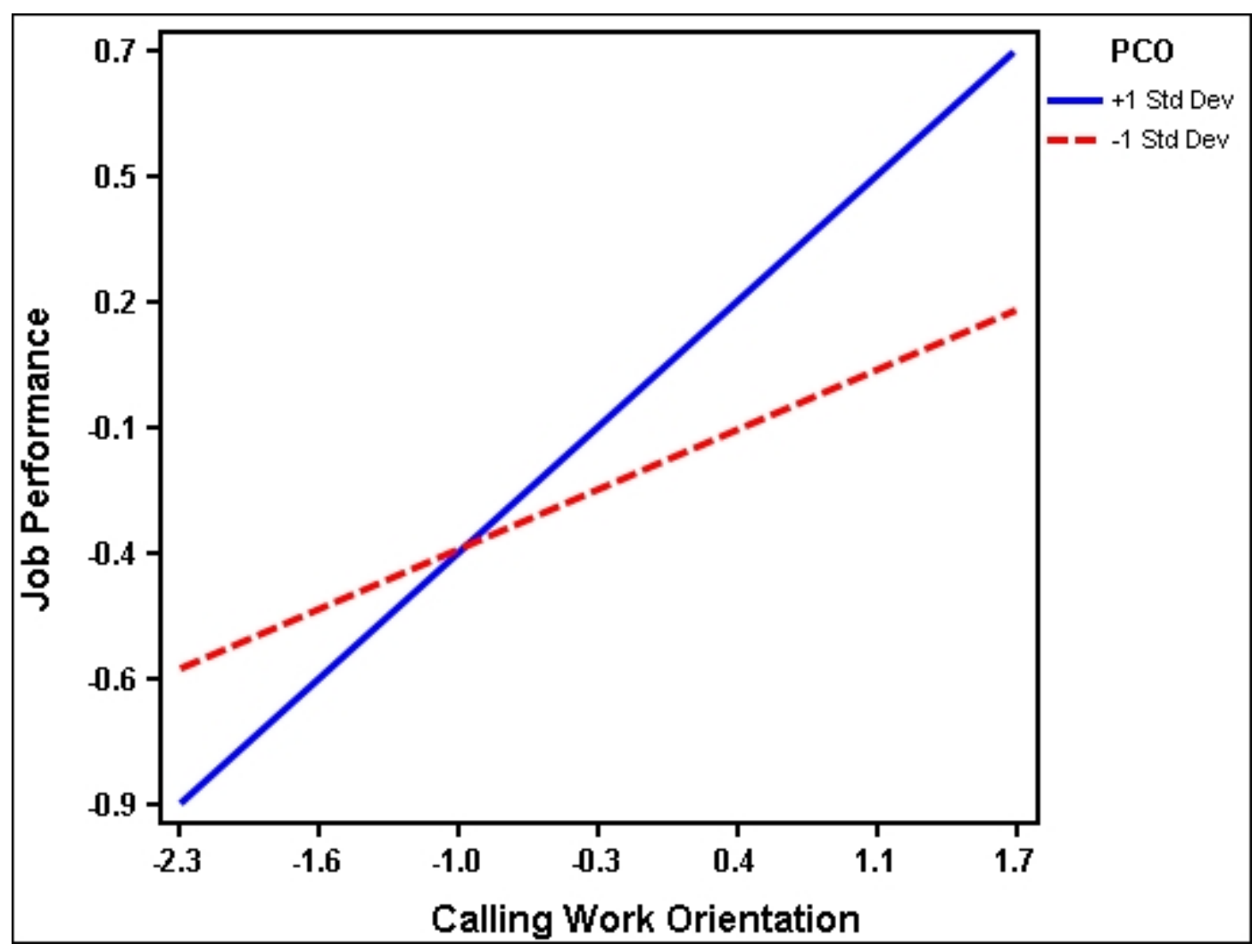


Figure 2. Interaction Graph for Calling, Engagement, and PCO (Working Student)

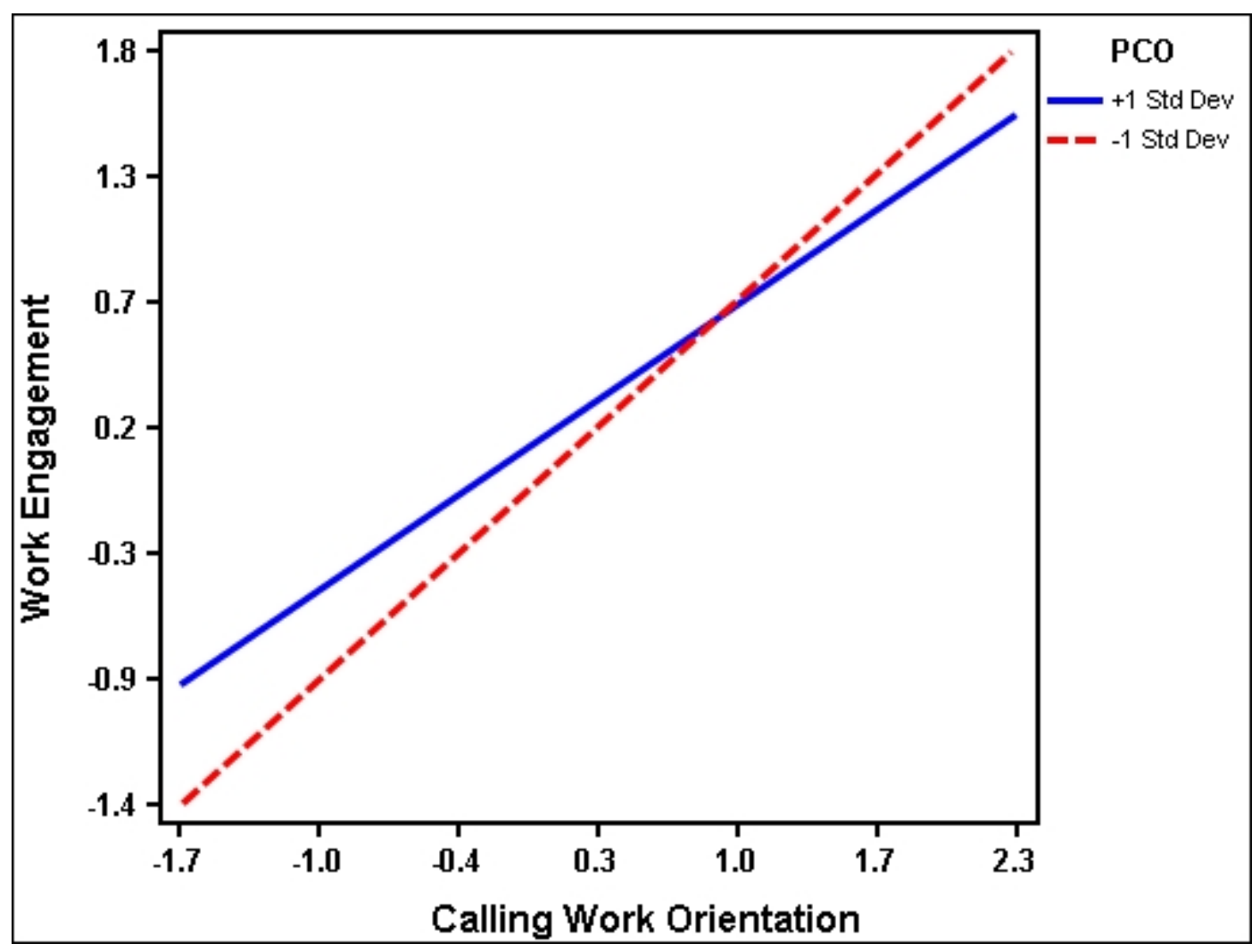


Figure 3. Interaction Graph for Calling, Engagement, and PCO (Employee)

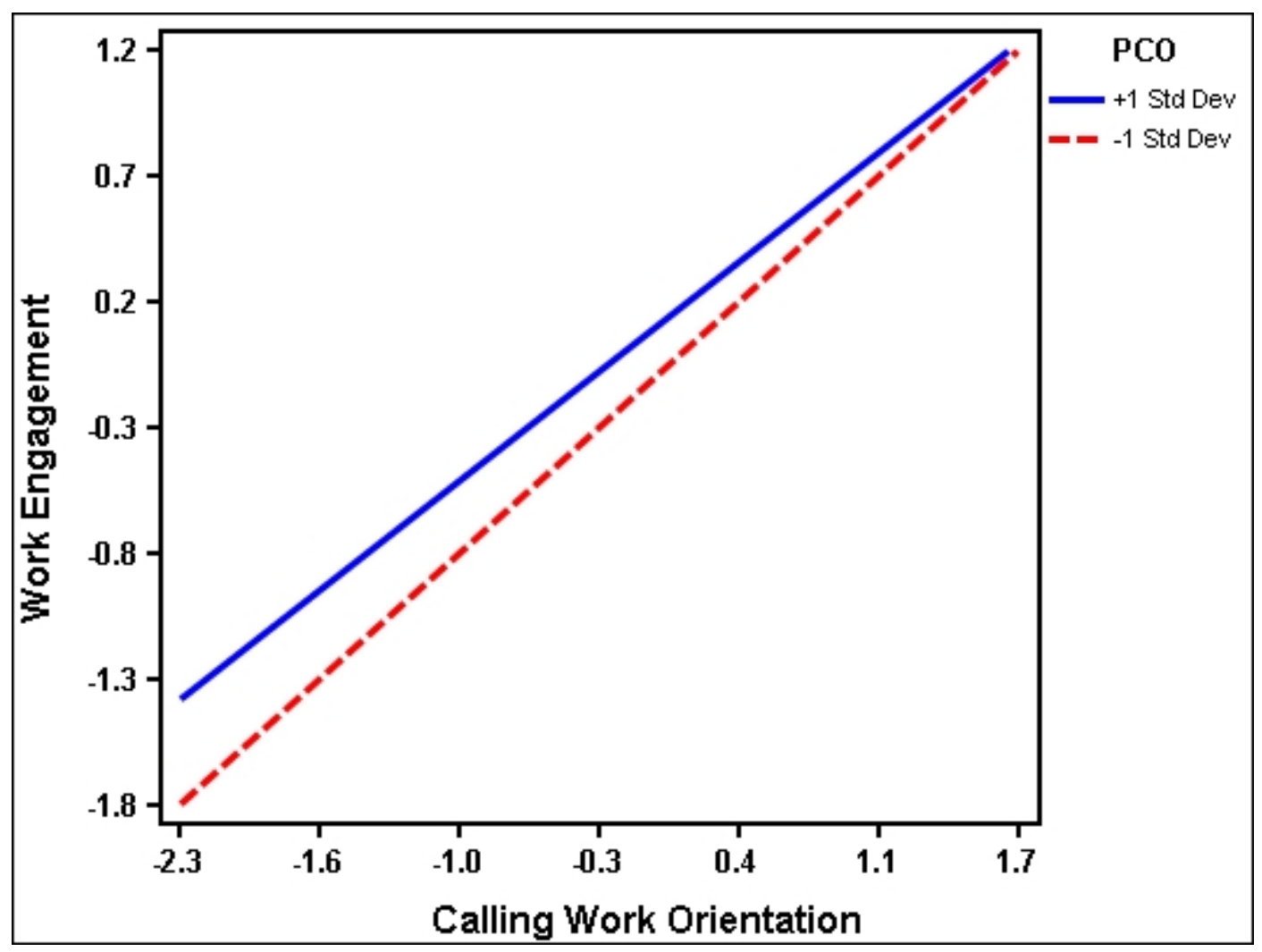


Figure 4. Interaction Graph for Calling, Performance, and CSE (Employee)

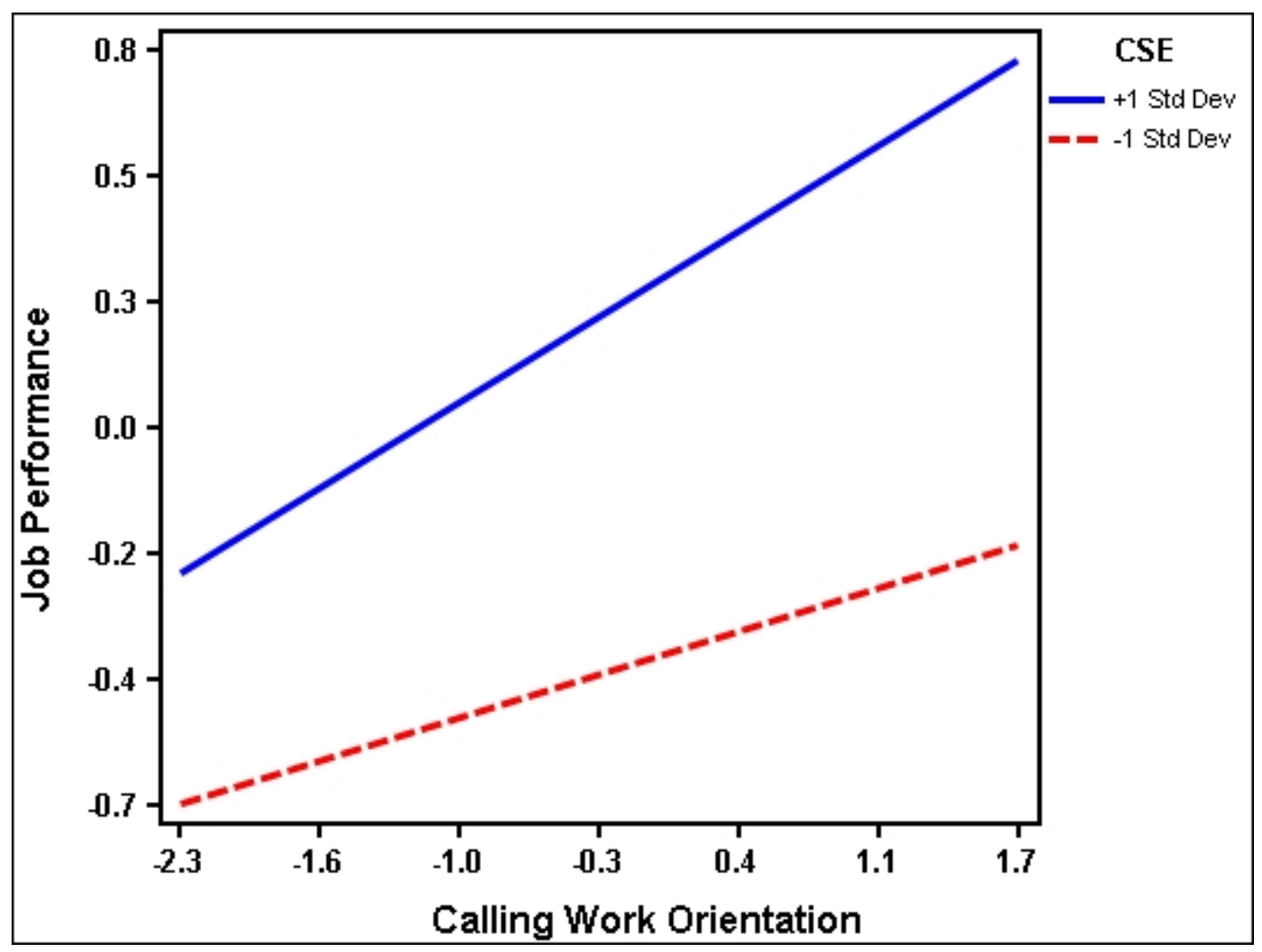


Figure 5. Interaction Graph for Calling, Engagement, and CSE (Employee)

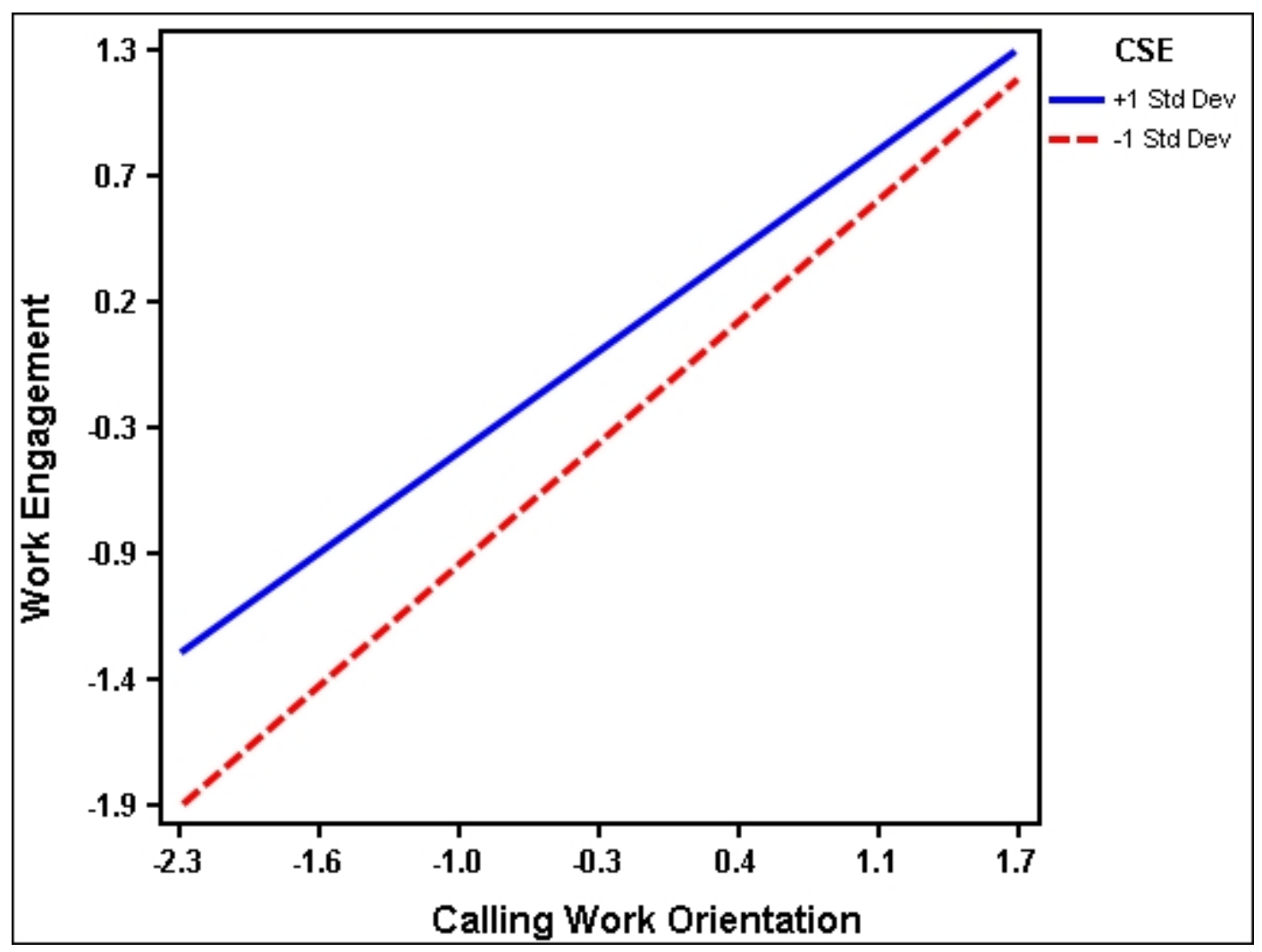




\section{References}

Adams, C. M. (2012). Calling and career counseling with college students: Findings meaning in work and life. Journal of College Counseling, 15, 65-80.

Aguinis, H., \& Stone-Romero, E. F. (1997). Methodological artifacts in multiple regression and their affects on statistical power. Journal of Applied Psychology, 82(1), 192-206.

Aiken, L. S. \& West, S. G. (1991). Multiple regression: Testing and interpreting interactions. Thousand Oaks, CA: Sage Publications, Inc.

Alder, A. B., Thomas, J. L., \& Castro, C. A. (2005). Measuring up: Comparing selfreports with unit records for assessing soldier performance. Military Psychology, 17(1), 3-24.

Alexander. C. N., \& Wiley. M. G. (1981). Situated activity and identity formation. In M. Rosenberg \& R. H. Turner (Eds.), Sociological perspectives on social psychology (pp. 269-289). New York, NY: Basic Books.

Alonso, P., \& Lewis, G. B. (2001). Public service motivation and job performance: Evidence from the public sector. American Review of Public Administration, 31, 363-380.

Amabile, T. M., Hill, K.G., Hennessey, B. A., \& Tighe, E.M. (1994). The work preference inventory: Assessing intrinsic and extrinsic motivational orientations. Journal of Personality and Social Psychology, 66, 950-967. doi: 10.1037/00223514.66.5.950.

Ashforth, B. E., \& Kreiner, G. E. (1999). "How can you do it?" Dirty work and the challenge of constructing a positive identity. Academy of Management Review, 24, 413-434. doi: 10.2307/259134.

Aziz, S., \& Zickar, M. J. (2006). A cluster analysis investigation of workaholism as a syndrome. Journal of Occupational Health Psychology, 11, 52-62. doi: 10.1037/1076-8998.11.1.52.

Barrick, M. R., \& Mount, M. K. (1991). The Big Five personality dimensions and job performance: A meta-analysis. Personnel Psychology, 44, 1-26. doi: 10.1111/j.1744-6570.1991.tb00688.x.

Bateman, T. S. \& Organ, D. W. (1983). Job satisfaction and the good soldier: The relationship between affect and employee "citizenship." Academy of Management Journal, 26, 587-595. 
Batson, C. D. (1998). Altruism and prosocial behavior. In D. Gilbert, S. Fiske, \& G. Lindzey (Eds.), The handbook of social psychology, 4th edition (pp. 282-316). New York: McGraw-Hill.

Batson, C. D., \& Oleson, K. C. (1991). Current status of the empathy-altruism hypothesis. In M. S. Clark (Ed.), Review of personality and social psychology: Prosocial behavior (pp. 62-18). Newbury Park, CA: Sage.

Baumeister, R. F., Heatherton, T. F., \& Tice, D. M. (1994). Losing control: How and why people fail at self-regulation. San Diego, CA: Academic Press.

Baumeister, R. F., Vohs, K. D., \& Tice, D. M. (2007). The strength model of self-control. Current Directions in Psychological Science, 16, 351-355.

Beadle, R. \& Knight, K. (2012). Virtue and meaningful work. Business Ethics Quarterly, 22(2), 433-450. doi: 10.5840/beq201222219.

Bean, W. E. (2000). Community development and adult education: Locating practice in its roots. In L. English \& M. Gillen (Eds.), Addressing the spiritual dimensions of adult learning: What educators can do (pp. 67-76). San Francisco: Jossey-Bass.

Bellah, R. N., Madsen, R., Sullivan, W. M., Swindler, A. \& Tipton, S. M. (1989). Habits of the heart: Individualism and commitment in American life. New York: Harper \& Row.

Bem, D. J. (1972). Self-perception theory. In L. Berkowitz (Ed.), Advances in experimental social psychology. New York, NY: Academic Press.

Berg, J. M., Grant, A. M., \& Johnson, V. (2010). When callings are calling: Crafting work and leisure in pursuit of unanswered occupational callings. Organizational Science, 21, 973-994. doi: 10.1287/orsc.1090.0497.

Berry, C. M., Ones, D. S., \& Sackett, P. R. (2007). Interpersonal deviance, organizational deviance, and their common correlates: A review and meta-analysis. Journal of Applied Psychology, 92(2), 410-424. doi: 10.1037/0021-9010.92.2.410

Berry, L.M. (2003). Employee Selection. Belmont, CA: Thomson Wadsworth

Beus, J. M. \& Whitman, D. S. (2012). The relationship between typical and maximum performance: A meta-analytic examination. Human Performance, 25, 355-376. doi: 10.1080/08959285.2012.721831. 
Bigham, J. T. (2008). Role of spirituality in persons choosing a career in education: Calling as a motivating factor. (Doctoral dissertation). Retrieved from ProQuest. (UMI Microform 3297478).

Bliese, P. D., Chan, D., \& Ployhart, R. E. (2007). Multilevel methods: Future directions in measurement, longitudinal analyses, and nonnormal outcomes. Organizational Research Methods, 10(4), 551-563. doi: 10.1177/1094428107301102

BLS (2010). Labor Force Statistics from the Current Population Survey: Average Employee Tenure Retrieved from Bureau of Labor and Statistics: http://www.bls.gov/web/empsit/cpseea10.htm

BLS (June, 2013). Labor Force Statistics from the Current Population Survey: Unemployment rates by age, sex, and marital status, seasonally adjusted. Retrieved from Bureau of Labor and Statistics: http://www.bls.gov/web/empsit/cpseea10.htm

Bogart, G. (1994). Finding a life's calling. Journal of Humanistic Psychology, 34(4), 637.

Boggs, D. L. (1986). A case study of citizen education and action. Adult Education Quarterly, 37(1), 1-13.

Bolman, L., \& Deal, T. (1991). Reframing organizations. San Francisco: Jossey- Bass.

Borman, W. C., \& Motowidlo, S. J. (1993). Expanding the cri- terion domain to include elements of contextual perfor- mance. In N. Schmitt \& W.C. Borman (Eds.), Personnelse- lection (yp-71-98). San Francisco: Jossey-Bass.

Borman, W. C., \& Motowidlo, S. J. (1997). Task performance and contextual performance: The meaning for personnel selection research. Human Performance, 10, 99-109.

Brennfleck, K., \& Brennfleck, K. M. (2005). Live your calling: A practical guide to finding and fulfilling your mission in life. San Francisco: Jossey-Bass.

Brief, A. P., \& Motowidlo, S. J. (1986). Prosocial organizational behaviors. Academy of Management Review, $U$, 710-725.

Brooks, M. E. \& Pui, S. Y. (2010). Are individual differences in numeracy unique from general mental ability? A closer look at a common measure of numeracy. Individual Difference Research, 8, 257-265. 
Brown, J. D. \& Smart, S. A. (1991). The self and social conduct: Linking selfrepresentation to prosocial behavior. Journal of Personality and Social Psychology, 60(3), 368-375.

Buhrmester, M., Kwang, T., \& Gosling, S. D. (2011). Amazon's Mechanical Turk: A new source of inexpensive, yet high-quality, data? Perspectives on Psychological Science, 6(3), 3-5. doi: 10.1177/1745691610393980.

Bunderson, J.S., \& Thompson, J.A. (2009). The call of the wild: Zookeepers, callings, and the double-edged sword of deeply meaningful work. Administrative Science Quarterly, 54, 32-57. doi:10.2189/asqu.2009.54.1.32.

Burke, P. J. (1991). Identity process and social stress. American Sociological Review, 56, 836-849.

Burke, P. J., \& Reitzes, D. C. (1991). An identity theory approach to commitment. Social Psychology Quarterly, 54, 280-286. doi: 10.2307/2786653.

Burton-Jones, A. (2009). Minimizing method bias through programmatic research. MIS Quarterly, 33, 445-471.

Campbell, D. T., \& Fiske, D. W. (1959). Convergent and discriminant validation by the multitrait-multimethod matrix. Psychological Bulletin, 56, 81-105.

Campbell, J.P., McCloy, R.A., Oppler, S.H. and Sager, C.E. (1993) A theory of performance. In N. Schmitt and W. Borman (eds) Personnel Selection in Organizations. San Francisco: Jossey-Bass.

Cardador, M. T., \& Caza, B. B. (2012). Relational and identity perspectives on healthy versus unhealthy pursuit of callings. Journal of Career Assessment, 20(3), 338353. doi: $10.1177 / 1069072711436162$.

Cardador, M. T., Dane, E., \& Pratt, M. G. (2011). Linking calling orientations to organizational attachment via organizational instrumentality. Journal of Vocational Behavior, 79, 367-378. doi: 10.1016/j.jvb.2011.03.009.

Carlson, D., Witt, L., Zivnuska, S., Kacmar, K., \& Grzywacz, J. (2008). Supervisor appraisal as the link between family-work balance and contextual performance. Journal of Business \& Psychology, 23, 37-49. doi:10.1007/s10869-008-9083-z

Cascio, W.F. (1998). Recruitment. In W.F. Cascio. Applied Psychology in Human Resource Management (5th Ed.). pp. 174-186. Prentice Hall: Upper Saddle River, NJ.

Cavanaugh, G. (2001). Toward a spirituality for the contemporary organization: 
Implications for faith, work, and society. In: Delbecq AL (ed.) Bridging the Gap between Spirituality and Business: Proceedings from the Santa Clara Conference. (pp. 10-42). Santa Clara, CA: Santa Clara University Press

Cohen, J., \& Cohen, P. (1983). Applied multiple regression/correlation analysis for the behavioral sciences (2nd ed.). Hillsdale, NJ: Erlbaum.

Colquitt, J. A., LePine, J.A., \& Noe, R. A. (2000). Toward an integrative theory of training motivation: A meta-analytic path analysis of 20 years of research. Journal of Applied Psychology, 85, 678-707. doi: 10.1037//0021-9010.g5.5.678.

Conklin, T. A. (2012). Work worth doing: A phenomenological study of the experience of discovering and following one's calling. Journal of Management Inquiry, 21(3), 298-317. doi: 10.1177/1056492611414426.

Connolly, J. J., \& Viswesvaran, C. (2000). The role of affectivity in job satisfaction: A meta-analysis. Personality and Individual Differences, 29, 265-281.

Converse, P. D. \& DeShon, R. P. (2009). A tale of two tasks: Reversing the selfregulatory resource depletion effect. Journal of Applied Psychology, 94, 13181324.

Cooper, J. (1999). Unwanted consequences and the self: In search of the motivation for dissonance reduction. In E. Harmon-Jones \& J. Mills (Eds.), Cognitive dissonance: Progress on a pivotal theory in social psychology. Washington, DC: American Psychological Association.

Crockett, L.T., Schulenberg, J. E., \& Petersen, A. C. (1987). Congruence between objective and self-report data in a sample of young adolescents. Journal of Adolescent Research, 2, 383-392.

Cronbach, L. J. (1970). Essential of Psychological Testing ( $3^{\text {rd }}$ Edition). New York: Harper \& Row.

Davidson, J. C., \& Caddell, D. P. (1994). Religion and the meaning of work. Journal for the Scientific Study of Religion, 33, 135-147. doi: 10.2307/1386600.

Dawis, R. V. (1996). Vocational psychology, vocational adjustment, and the workforce: Some familiar and unanticipated consequences. Psychology, Public Policy, and Law, 2(2), 229-248.

De Dreu, C. K. W., \& Nauta, A. (2009). Self-interest and other-orientation in organizational behavior: Implication for job performance, prosocial behavior, and personal initiative. Journal of Applied Psychology, 94, 913-926. doi: $10.1037 / \mathrm{a} 0014494$. 
Dess, G.D. \& Shaw, J.D. (2001). Voluntary turnover, social capital, and organizational performance. Academy of Management Review, 26(3), 446-56.

Dik, B. J., \& Duffy, R. D. (2009). Calling and vocation at work: Definitions and prospects for research and practice. The Counseling Psychologist, 37, 424-450. doi: $10.1177 / 0011000008316430$.

Dik B.J., Duffy, R. D., \& Eldridge, B. M. (2009). Calling and vocation in career counseling: Recommendations for promoting meaningful work. Professional Psychology: Research and Practice, 40, 625-632. doi: 10.1037/a0015547.

Dik, B.J., Eldridge, B.M., Steger, M.F, \& Duffy, R.D. (2012). Development and validation of the calling and vocation questionnaire (CVQ) and brief calling scale (BCS). Journal of Career Assessments, 20(3), 242-263. doi: 10.1177/1069072711434410.

Dirkx, J. (2001). The power of feelings: Emotion, imagination, and the construction of meaning in adult learning. New Directions for Adult and Continuing Education, 89, 63-72.

Dobrow, S. R. (2006). Having a calling: A longitudinal study of young musicians. (unpublished doctoral dissertation). Harvard University.

Dobrow, S. R., \& Tosti-Kharas, J. (2011). Calling: The development of a scale measure. Personnel Psychology, 64, 1001-1049. doi: 10.1111/j.1744-6570.2011.01234.

Domene, J. F. (2012). Calling and career outcome expectations: The mediating role of self-efficacy. Journal of Career Assessment, 20(3), 281-292. doi: $10.1177 / 1069072711434413$.

Duffy, R. D. (2006). Spirituality, religion, and career development: Current status and future directions. The Career Development Quarterly, 55, 52-63. doi: 10.1002/j.2161-0045.2006.tb00004.x.

Duffy, R. D., Allan, B. A., \& Bott, E. M. (2012). Calling and life satisfaction among undergraduate students: Investigating mediators and moderators. Journal of Happiness Studies, 13, 469-479. doi: 10.1007/s10902-011-9274-6.

Duffy, R. D., Bott, E. M., Allan, B. A., Dik, B. J., \& Torrey, C. L. (2012). Perceiving a calling, living a calling, and job satisfaction: Testing a moderated, multiple mediator model. Journal of Counseling Psychology, 59, 50-59. doi: $10.1037 / \mathrm{a} 0026129$. 
Duffy, R.D., Dik, B.J., \& Steger, M.F. (2011). Calling and work-related outcomes: Career commitment as a mediator. Journal of Vocational Behavior, 78, 210-218. doi: $10.1016 /$ j.jvb.2010.09.013.

Duffy, R. D., Foley, P. F., Roque-Bodgan, T. L., Reid-Marks, L., Dik, B. J., Castano, M. C., \& Adams, C. M. (2012). Counseling psychologists who view their careers as a calling: A qualitative study. Journal of Career Assessment, 20(3), 293-308. doi: 10.1177/1069072711436145.

Duffy, R. D., \& Sedlacek, W. E. (2007). The presence of and search for calling: Connections to career development. Journal of Vocational Behavior, 70, 590-601. doi: 10.1016/j.jvb.2007.03.007.

Duffy, R. D., \& Sedlacek, W. E. (2010). The salience of a career calling among college students: Exploring group differences and links to religiousness, life meaning, and life satisfaction. The Career Development Quarterly, 59, 27-41.

Dunlap, W. P., \& Kemery, E. R. (1988). Effects of predictor intercorrelations and reliabilities on moderated multiple regression. Organizational Behavior and Human Decision Processes, 41, 248-258.

Egan, T. (1999). Defining spirituality in the workplace. Spirit at Work Newsletter. Retrieved from http:// www.fourgateways.com/newsletr/art004.htm.

Elangovan, A. R., Pinder, C. C., \& McLean, M. (2010). Callings and organizational behavior. Journal of Vocational Behavior, 76, 428-440. doi: 10.1016/j.jvb.2009.10.009.

English, L. M., \& Gillen, M. A. (Eds.). (2000). Addressing the spiritual dimensions of adult learning: What educators can do. San Francisco: Jossey-Bass.

Farmer, S. M., \& Van Dyne, L. (2010). The idealized self and the situated self as predictors of employee work behaviors. Journal of Applied Psychology, 95, 503516. doi: 10.1037/a0019149.

Festinger, L. (1957). A theory of cognitive dissonance. Stanford, CA: Stanford University Press.

Fiala, W. E., Bjorck, J. P., \& Gorsuch, R. L. (2002). The Religious Support Scale: Construction, validation, and cross-validation. American Journal of Community Psychology, 30(6), 761-786. doi: 10.1023/A:1020264718397.

Finkelstein, M. A., \& Penner, L. A. (2004). Predicting Organizational Citizenship Behavior: Integrating the functional and role identity approaches. Social Behavior and Personality, 32, 383-398. 
Fox, S., Spector, P. E., Goh, A., Bruursema, K., \& Kessler, S. R. (2011). The deviant citizen: Measuring potential positive relations between counterproductive work behaviour and organizational citizenship behaviour. Journal of Occupational and Organizational Psychology, 85, 199-220. doi: 10.1111/j.2044-8325.2011.02032.x

Fox, S., Spector, P.E. and Miles, D. (1999) Counterproductive behavior (CPB) in response to job stressors and organizational justice: The moderator effect of autonomy and emotion traits. Paper presented at the annual conference of the Society for Industrial and Organizational Psychology, Atlanta.

French, J. R. P. (1968). The conceptualization and measure mental health in terms of selfidentity theory, In S. B. Sells (Ed.), The definition and measurement of mental health. Washington, DC: Department of Health, Education, and Welfare.

Frew, E.J. (2000). Stressors, strain and spirituality at work. (published doctoral dissertation) New Mexico State University, Las Cruces, NM: Dissertation Abstracts International.

Fried, Y., \& Ferris, G. R. (1987). The validity of the job characteristics model: A review and meta-analysis. Personnel Psychology, 40, 287-322. doi: 10.1111/j.17446570.1987.tb00605.x.

Goldberg, L. R. (1999). A broad-bandwidth, public domain, personality inventory measuring the lower-level facets of several five-factor models. In I. Mervielde, I. Deary, F. De Fruyt, \& F. Ostendorf (Eds.), Personality Psychology in Europe, Vol. 7 (pp. 7-28). Tilburg, The Netherlands: Tilburg University Press.

Grant, A. M. (2007). Relational job design and the motivation to make a prosocial difference. Academy of Management Review, 32, 393-417. doi: 10.5465/amr.

Grant, A. M. (2008a). Does intrinsic motivation fuel the prosocial fire? Motivational synergy in predicting persistence, performance, and productivity. Journal of Applied Psychology, 93, 48-58. doi: 10.1037/0021-9010.93.1.48.

Grant, A. M. (2008b). The significance of task significance: Job performance effects, relational mechanisms, and boundary conditions. Journal of Applied Psychology, 93, 108-124. doi: 10.1037/0021-9010.93.1.108.

Grant, A. M., \& Mayer, D. M. (2009). Good soldiers and good actors: Prosocial and impression management motives as interactive predictors of citizenship behavior. Journal of Applied Psychology, 94, 900-912.

Grant, A. M., \& Sonnentag, S. (2010). Doing good buffers against feeling bad: Prosocial impact compensates for negative task and self-evaluations. Organizational 
Behavior and Human Decision Processes, 111, 13-22. doi: 10.1016/j.obhdp.2009.07.003.

Greenhaus, J. H., \& Beutell, N. J. (1985). Sources of conflict between work and family roles. Academy of Management Review, 10, 76-88.

Grube, J., \& Piliavin, J. A. (2000). Role identity, organizational experiences, and volunteer experiences. Personality and Social Psychology Bulletin, 26, 11081120 .

Gruys, M.L. (1999) The dimensionality of deviant employee performance in the workplace. Unpublished doctoral dissertation, University of Minnesota.

Grzywacz, J. G. 2002. Toward a theory of work-family facilitation. Paper presented at the 2002 Persons, Processes, and Places: Research on Families, Workplaces and Communities Conference, San Francisco.

Grzywacz, J. G. \& Marks, N. F. (2000). Reconceptualizing the work-family interface: An ecological perspective on the correlates of positive and negative spillover between work and family. Journal of Occupational Health Psychology, 5, 111-126. doi: 10.1037/1076-8998.

Hackman, J.R., \& Oldham, G. R. (1975). Development of the job diagnostic survey. Journal of Applied Psychology, 60, 159-170. doi: 10.1037/ h0076546.

Hackman, J. R., \& Oldham, G. R. (1976). Motivation through design of work: A test of a theory. Organizational Behavior and Human Performance, 16, 250-279.

Halbesleben, J. R. B., \& Wheeler, A. R. (2008). The relative roles of engagement and embeddedness in predicting job performance and intention to leave. Work \& Stress, 22, 242-256. doi: 10.1080/02678370802383962.

Hagmaier, T. \& Abele, A. E. (2012). The multidimensionality of calling: Conceptualization, measurement and a bicultural perspective. Journal of Vocational Behaviors, 81, 39-51. doi: 10.1016/j.jvb.2012.04.001.

Hall, D. T., \& Chandler, D. E. (2005). Psychological success: When the career is a calling. Journal of Organizational Behavior, 26, 155-176. doi: 10.1002/job.301.

Hall, R. E. (1982). The importance of lifetime jobs in the US economy. The American Economic Review, 72(4), 716-724.

Hardy, L. (1990). The fabric of this world: Inquiries into calling, career choice, and the design of human work. Grand Rapids, MI: Eerdmans. 
Hartnett, S., \& Kline, F. (2005). Preventing the fall from the call to teach. The Journal of Christian Faith and Belief, 9, 9-20.

Headey, B., \& Wearing, A. (1987). The sense of relative superiority - central to wellbeing. Social Indicators Research, 20, 497-516.

Hirschi, A. (2011). Callings in career: A typological approach to essential and optional components. Journal of Vocational Behavior, 79, 60-73. doi: 10.1016/j.jvb.2010.11.002.

Hodge, D. R. (2003). The intrinsic spirituality scale: A new six-item instrument for assessing the salience of spirituality as a motivational construct. Journal of Social Service Research, 30, 41-61. doi: 10.1300/J079v30n01_03.

Hui, C., Lam, S. K., \& Law, K. K. S. (2000). Instrumental values of organizational citizenship behavior for promotion: A field quasi-experiment. Journal of Applied Psychology, 85(5), 822-828. doi: 10.1037//0021-9010.85.5.822

Humphrey, S. E., Nahrgang, J. D., \& Morgeson, F. P. (2007). Integrating motivational, social, and contextual work design features: A meta- analytic summary and theoretical extension of the work design literature. Journal of Applied Psychology, 92, 1332-1356.

Hunter, I., Dik, B. J., \& Banning, J. H. (2010). College students' perceptions of calling in work and life: A qualitative analysis. Journal of Vocational Behavior, 76, 178186. doi: 10.1016/j.jvb.2009.10.008.

Jacoby, M. (1990). Individuation and narcissism: The psychology and the self in Jung and Kohut. New York: Routledge.

Johns, G. (1994). How often were you absent? A review of the use of self-reported absence data. Journal of Applied Psychology, 79, 574-591.

Johnson, R. E., Rosen, C. C., \& Levy, P. E. (2008). Getting to the core of core selfevaluations: A review and recommendations. Journal of Organizational Behavior, 29, 391-413.

Judge, T. A. \& Bono, J. E. (2001). Relationship of core self-evaluations traits - selfesteem, generalized self-efficacy, locus of control, and emotional stability - with job satisfaction and performance: A meta-analysis. Journal of Applied Psychology, 86, 80-92. doi: 10.1037//0021-9010.86.1.80.

Judge, T. A., Erez, A., Bono, J. E., \& Thoresen, C. J. (2003). The core self-evaluation scale: Development of a scale. Personnel Psychology, 56, 303-331. 
Judge, T. A. \& Ilies, R. (2004). Affect and job satisfaction: A study of their relationship at work and at home. Journal of Applied Psychology, 89, 661-673. doi: $10.1037 / 0021-9010.89 .4 .661$

Judge, T. A., Locke, E. A., \& Durham, C. C. (1997). The dispositional causes of job satisfaction: A core evaluations approach. Research in Organizational Behavior, $19,151-188$.

Judge, T. A., Locke, E. A., Durham, C. C., \& Kluger, A. N. (1998). Dispositional effects on job and life satisfaction: The role of core evaluations. Journal of Applied Psychology, 83, 17-34. doi: 10.1037/0021-9010.83.1.17.

Jung, C. G. (1933). Modern Man in Search of a Soul. London: Kegan Paul Trench Trubner, Harvest Books (1955 ed.).

Kahn, W. A. (1990). Psychological conditions of personal engagement and disengagement at work. Academy of Management Journal, 33(4), 692-724.

Katz, D. \& Kahn, R. L. (1966). The social psychology of organizations. New York: Wiley Publishing Company.

Katz, D., \& Kahn, R. L. (1978). The social psychology of organizations. New York, NY: Wiley.

Kehr, H. M. (2004). Integrating implicit motives, explicit motives, and perceived abilities: The compensatory model of work motivation and volition. Academy of Management Review, 29, 479-499.

Kovan, J. T. \& Dirkx, J. M. (2003). "Being called awake": The role of transformative learning in the lives of environmental activists. Adult Education Quarterly, 53(2), 99-118. doi: 10.1177/0741713602238906.

Kraimer, M. L., Seibert, S. E., Wayne, S. J., Liden, R. C., \& Bravo, J. (2011). Antecedents and outcomes of organizational support for development: The critical role of career opportunities. Journal of Applied Psychology, 96, 485-500. doi: $10.1037 / \mathrm{a} 0021452$.

Larson, D., Milano, G. M., \& Lu, F. (1998). Religion and mental health: The need for cultural sensitivity and synthesis. In S. O. Okpaku (Ed.), Clinical methods in transcultural psychiatry (pp. 191-210). Washington, DC: American Psychiatric Association.

Latham, G. P., \& Pinder, C. C. (2005). Work motivation theory and research at the dawn of the twenty-first century. Annual Review of Psychology, 56, 495-516. doi: 10.1146/annurev.psych.55.090902.142105. 
Lawler, E. E. \& Hall, D. T. (1970). Relationship of job characteristics to job involvement, satisfaction, and intrinsic motivation. Journal of Applied Psychology, 54, 305312 .

Leary, M. (1994). Self-presentation: Impression management and interpersonal behavior. Pacific Grove, CA: Brooks/Cole.

LeBreton, J. M., Binning, J. F., Adorno, A. J., \& Melcher, K. M. (2004). Importance of personality and job-specific affect predicting job attitudes and withdrawal behavior. Organizational Research Methods, 7(3), 300-325. doi: $10.1177 / 1094428104266015$

Lipkus, M., Samsa. G., \& Rimer, B. K. (2001). General performance on a numeracy scale among highly educated samples. Medical Decision Making: An International Journal of the Society for Medical Decision Making, 21, 37-44.

Lips-Wiersma, M., \& Mills, C. (2002). Coming out of the closet: Negotiating spiritual expression in the workplace. Journal of Managerial Psychology 17, 183-202. doi: 10.1108/02683940210423097.

Lobene, E. V. \& Meade, A. W. (2013). The effects of career calling and perceived overqualification on work outcomes for primary and secondary school teachers. Journal of Career Development, 40(3), doi: 10.1177/0894845313495512

Locke, E. A. \& Latham, G. P. (1990). A Theory of Goal Setting and Task Performance. Englewood Cliffs, NJ: Prentice Hall.

Lord, R. G., \& Brown, D. J. (2004). Leadership processes and follower self-identity. Mahwah, NJ: Erlbaum.

Lynn, M. L., Naughton, M. J., Vander Veen, S. (2010). Connecting religion at work: Patterns and influences of work-faith integration. Human Relations, 64, 675-701. doi: $10.1177 / 0018726710386396$.

Mason, W. \& Suri, S. (October, 2010). Conducting behavioral research on Amazon's Mechanical Turk. Behavioral Research Methods, Forthcoming. Available at SSRN: http://ssrn.com/abstract=1691163

Mayfield, C. O. \& Taber, T. D. (2010). A prosocial self-concept approach to understanding organizational citizenship behavior. Journal of Managerial Psychology, 25(7), 741-763. doi: 10.1108/02683941011075283.

McClelland, G.H., \& Judd, C.M. (1993). Statistical difficulties of detecting interactions and moderator effects. Psychological Bulletin, 114(2), 376-390. 
Meyer, J. P. \& Allen, N. J. (1991). A three-component conceptualization of organizational commitment. Human Resource Management Review, 1, 61- 89. doi: $10.1037 / 0021-9010.79 .1 .15$.

Miles, D.E., Borman, W. E., Spector, P. E., \& Fox, S. (2002). Building an integrative model of extra role work behaviors: A comparison of counterproductive work behavior with organizational citizenship behavior. International Journal of Selection and Assessment, 10(1/2), 51-57.

Morgeson, F. P., \& Humphrey, S. E. (2006). The work design questionnaire (WDQ): Developing and validating a comprehensive measure for assessing job design and the nature of work. Journal of Applied Psychology, 91, 1321-1339.

Morrell, K.M., Loan-Clarke, J., \& Wilkinson, A. J. (2004). Organisational change and employee turnover. Personnel Review, 33(2), 161-173. doi:

10.1108/00483480410518022.

Morrison, E. W. (1994). Role definitions and organizational citizenship behavior: The importance of the employee's perspective. Academy of Management Journal, 37, 1543-1567.

Motowidlo, S. J. (2000). Some basic issues related to contextual performance and organizational citizenship behavior in human resource management. Human Resource Management Review, 10(1), 115-126. doi: 10.1016/S10534822(99)00042-X

Motowidlo, S. J., \& Van Scotter, J. R. (1994). Evidence that task performance should be distinguished from contextual performance. Journal of Applied Psychology, 79, 475-480. doi: 10.1037/0021-9010.79.4.475.

Mudrack, P. E. (2006). Understanding workaholism: The case of behavioral tendencies. In R. J. Burke (Ed.), Research companion to working time and work addiction (pp. 108-128). Cheltenham, UK: Edward Elgar.

Muraven, M. Gagne, M., \& Rosman, H. (2008). Helpful self-control: Autonomy support, vitality, and depletion. Journal of Experimental Social Psychology, 44, 573-585.

Myers, D. G. (2010). Social Psychology (pp. 141-145). New York, NY: McGraw Hill Companies, Inc.

Oishi, S., Diener, E. E., Lucas, R. E., \& Suh, E. M. (1999). Cross-cultural variations in predicors of life satisfaction: Perspectives from needs and values. Personality and Social Psychology Bulletin, 25, 980-990. doi: 10.1177/01461672992511006. 
Organ, D. W. (1988). Organizational citizenship behavior: The good soldier syndrome. Lexington, MA: Lexington Publishers.

Organ, D. W. (1990). The motivational basis of organizational citizenship behavior. In B. M. Staw \& L. L. Cummings (Eds.), Research in Organizational Behavior: Vol. 12 (pp. 43-72). Greenwich, CT: JAI Publishing.

Organ, D. W. (1994). Personality and organizational citizenship behavior. Journal of Management, 20, 465-478. doi: 10.1016/0149-2063(94)90023-X.

Organ, D. W. (1997). Organizational citizenship behavior: It's construct clean-up time. Human Performance, 10, 85-97. doi: 10.1207/s15327043hup1002_2.

Paolacci, G., Chandler, J., \& Ipeirotis, P. G. (June, 2010). Running experiments on Amazon Mechanical Turk. Judgment and Decision Making, 5(5), 411-419.

Pedersen-Stevens, D. Minotte, K. L., Mannon, S. E., \& Kiger, G. (2007). Examining the "neglected side of the work-family interface." Journal of Family Issues, 28, 242262. doi: 10.1177/0192513X06294548.

Peter, L. J. \& Hull, R. (1969). The Peter Principle: Why Things Always Go Wrong. New York: William Morrow and Company.

Peterson, C., Park, N., Hall, N., \& Seligman, M. E. (2009). Zest and work. Journal of Organizational Behavior, 30, 161-172. doi: 10.1002/job.584.

Piliavin, J. A., Grube, J. A., \& Callero, P. L. (2002). Role as resource for action in public service. Journal of Social Issues, 58, 469-485.

Pinder, C. C. (1998). Employee Motivation: Organizational Behavior. Upper Saddle River, NJ: Prentice Hall.

Plante, T. G., \& Sharma, N. (2001). Religious faith and mental health outcomes. In T. G. Plante \& A. C. Sherman (Eds.), Faith and health: Psychological perspectives (pp. 240-261). New York: Guilford.

Ployhart, R. E. (2008). The measurement and analysis of motivation. In Kanfer, G., Chen, \& R. D. Pritchard (Eds.) Work Motivation: Past, Present, and Future. New York: Routledge.

Ployhart, R. E. \& Vandenberg, R. J. (2010). Longitudinal research: The theory, design, and analysis of change. Journal of Management, 36(1), 94-120. doi: $10.1177 / 0149206309352110$ 
Podsakoff, P. M., MacKenzie, S. B., Paine, J. B., \& Bachrach, D. G. (2000).

Organizational citizenship behaviors: a critical review of the theoretical and empirical literature and suggestions for future research. Journal of Management 26(3), 513-563.

Pratt, M., \& Ashforth, B. (2003). Fostering meaningfulness in working and at work. In K. Cameron, J. Dutton, \& R. Quinn (Eds.), Positive organizational scholarship (pp. 309-327). San Francisco, CA: Berrett-Koehler Publishers.

Reio, T. G. (2010). The threat of common method variance bias to theory building. Human Resource Development Review, 9(4), 405-411. doi: $10.1177 / 1534484310380331$

Rhoades, L. \& Eisenberger, R. (2002). Perceived organizational support: A review of the literature. Journal of Applied Psychology, 87, 698-714. doi: 10.1037//00219010.87.4.698.

Richardson, H. A., Simmering, M. J., \& Sturman, M. C. (2009). A tale of three perspectives: Examining post hoc statistical techniques for detection and correction of common method variance. Organizational Research Methods, 12, $762-800$.

Rode, J. C. (2004). Job satisfaction and life satisfaction revisited: A longitudinal test of an integrated model. Human Relations, 57, 1205-1230. doi: 10.1177/0018726704047143.

Rotter, J. B. (1966). Generalized expectancies for internal versus external control of reinforcement. Psychological Monographs, 80, 1-28.

Ryan, R. M., \& Connell, J. P. (1989). Perceived locus of causality and internalization: Examining reasons for acting in two domains. Journal of Personality and Social Psychology, 57, 749-761. doi: 10.1037/0022-3514.57.5.749.

Ryan, R. M. \& Deci, E. L. (2000). Self-determination theory and the facilitation of intrinsic motivation, social development, and well-being. American Psychologist, 55, 68-78. doi: 10.1037/0003-066X.55.1.68.

Sackett, P. R. (2002). The structure of counterproductive work behaviors: Dimensionality and relationships with facets of job performance. International Journal of Selection and Assessment, 10(1-2), 5-11.

Saunders, D. R. (1956). Moderator variables in prediction. Educational and Psychological Measurement, 16, 209-222. doi: 10.1177/001316445601600205 
Schaufeli, W. B., Bakker, A. B., Salanova, M. (2006). The measurement of work engagement with a short questionnaire. Educational and Psychological Measurement, 66, 701-716. doi: 10.1177/0013164405282471.

Schaufeli, W.B. \& Salanova, M. (2007). Efficacy or inefficacy, that's the question: Burnout and engagement, and their relationships with efficacy beliefs. Anxiety, Coping \& Stress, 20, 177-196. doi: 10.1080/10615800701217878.

Schaufeli, W. B., Salanova, M., Gonzalez-Roma, V., \& Bakker, A. B. (2002). The measurement of engagement and burnout: A two sample confirmatory factor analytic approach. Journal of Happiness Studies, 3, 71-92. doi: 10.1023/A:1015630930326.

Schleicher, D. J., Hansen, S. D., \& Fox, K. E. (2010). Job attitudes and work values. In S. Zedeck (ed.) APA Handbook of Industrial Organizational Psychology (pp. 137189). Washington, DC, US: American Psychological Association.

Schneider, B. (1987). The people make the place. Personnel Psychology, 40, 437-453. doi: $10.1111 /$ j. $1744-6570$

Schneider, B., Smith, D. B., \& Goldstein, H. W. (2000). Attraction-selection-attrition: Toward a person environment psychology of organizations. In W. B. Walsch, K. H. Craik, \& R. H. Price (Eds.), Person environment psychology: New directions and perspectives (pp. 61-75). London, UK: Lawrence-Erlbaum Associates, Publishers.

Schmidt, F. L. \& Hunter, J. E. (1996). Measurement error in psychological research: Lessons from 26 research scenarios. Psychological Methods, 1(2), 199-223.

Schmidt, F. L. \& Hunter, J. E. (1998). The validity and utility of selection methods in personnel psychology: Practical and theoretical implication of 85 years of research. Psychological Bulletin, 124, 262-274. doi: 0033-2909/98/

Scott, K. S., Moore, K. S., \& Miceli, M. P. (1997). An exploration of the meaning and consequences of workaholism. Human Relations, 50, 287-314.

Scott, S. M. (1992). Personal change through participation in social action: A case study of 10 social activists. Canadian Journal for the Study of Adult Education, 1(2), 47-64.

Serow, R. C. (1994). Called to teach: A study of highly motivated pre-service teachers. Journal of Research and Development in Education, 27, 65-72. 
Sher, R. (August, 2012). Why you need dissatisfied employees. Leadership, retrieved from http://www.forbes.com/sites/robertsher/2012/08/03/why-you-needdissatisfied-employees/

Sherman, D. (2004). Nurses' stress and burnout: How to care for yourself when caring for patients and their families experiencing life-threatening illness. American Journal of Nursing, 104, 48-56.

Shuck, B., Reio, T. G., \& Rocco, T. S. (2011). Employee engagement: An examination of antecedent and outcome variables. Human Resource Development International, 14(4), 427-445. doi: 10.1080/13678868.2011.601587

Slora, K. B. (1989). An empirical approach to determining employee deviance base rates. Journal of Business and Psychology, 4(2), 199-219.

Soper, D.S. (2012) "A-priori Sample Size Calculator for Hierarchical Multiple Regression (Online Software)", http://www.danielsoper.com/statcalc3.

Spector, P. E. (1982). Behavior in organizations as a function of employee's locus of control. Psychological Bulletin, 91, 482-497. doi: 0033-2909/82/9103-0482/

Spector, P. E., Fox, S., Penney, L. M., Bruursema, K., Goh, A., \& Kessler, S. (2006). The dimensionality of counterproductivity: Are all counterproductive behaviors created equal? Journal of Vocational Behavior, 68, 446-460.

Spence, J. T., \& Robbins, A. S. (1992). Workaholism: Definition, measurement, and preliminary results. Journal of Personality Assessment, 58, 160-178. doi: $10.1207 / \mathrm{s} 15327752 \mathrm{jpa} 5801 \_15$.

Steger, M. F., Dik, B. J., \& Duffy, R. D. (2012). Measuring meaningful work: The work and meaning inventory (WAMI). Journal of Career Assessment, 20(3), 322-337. doi: $10.1177 / 1069072711436160$.

Steger, M. F., Pickering, N., Shin, J. Y., \& Dik, B. J. (2010). Calling in work: Secular or sacred? Journal of Career Assessment, 18, 82-96. doi:10.1177/1069072709350905 27.

Stone, J., \& Cooper, J. (2001). A self-standards model of cognitive dissonance. Journal of Experimental Social Psychology, 37, 228-243. doi:10.1006/jesp.2000.1446.

Stone-Romero, E. F, \& Anderson, L. E. (1994). Relative power of moderated multiple regression and the comparison of subgroup correlation coefficients for detecting moderating effects. Journal of Applied Psychology, 79, 354-359. 
Stryker, S. (1987). Identity theory: development and extensions. In Honess, K.Y.T. (Ed.), Self and Identity: Psychosocial Perspectives. Chichester, England:Wiley.

Stryker, S., \& Serpe, R. T. (1994). Identity salience and psychological centrality: Equivalent, overlapping, or complementary constructs? Social Psychology Quarterly, 57, 16-35. doi: 10.2307/2786972.

Tait, M., Padgett, M.Y. \& Baldwin, T.T. (1989). Job and life satisfaction: A reexamination of the strength of the relationship and gender effects as a function of the date of the study. Journal of Applied Psychology, 74, 502-507. doi: 10.1037/0021-9010.74.3.502.

Terranova, L. E. (2006). The experience of being called to serve: A phenomenological study of vocation. (Doctoral Dissertation). Retrieved from ProQuest (UMI Number: 3218527).

Tesser, A. (2000). On the confluence of self-esteem maintenance mechanisms. Personality and Social Psychology Review, 4(4), 290-299. doi: 10.1207/S15327957PSPR0404_1.

Thompson, J. A., \& Bunderson, J. S. (2003). Violations of principle: Ideological currency in the psychological contract. Academy of Management Review, 28, 571-586. doi: $10.2307 / 30040748$.

Tisdell, E. J. (2000). Spirituality and emancipatory adult education in women adult educators for social change. Adult Education Quarterly, 50(4), 308-335.

Tourangeau, R., Rips, L. J., \& Rasinski, K. (2000). The psychology of survey response. New York: Cambridge University Press.

Tischler, L., Bieberman, J., \& McKeage, R. (2002). Linking emotional intelligence, spirituality and workplace performance: Definitions, models and ideas for research. Journal of Managerial Psychology, 17, 203-218. $10.1108 / 02683940210423114$.

Treadgold, R. (1999). Transcendent vocations: Their relationship to stress, depression, and clarity of self-concept. Journal of Humanistic Psychology, 39, 81-105. doi: 10.1177/0022167899391010.

Tybout, A. M. \& Scott, C. A. (1983). Availability of well-defined internal knowledge and the attitude formation process: Information aggregation versus self-perception. Journal of Personality and Social Psychology, 44(3), 474-491. doi: 00223514/83/4403-0474. 
Van Beek, I. Taris, T. W., \& Schaufeli, W. B. (2011). Workaholic and work engaged employees: Dead ringers or worlds apart? Journal of Occupational Health Psychology, 16, 468-482. doi: 10.1037/a0024392.

Van Dyne, L., Cummings, L.L., \& McLean Parks, J. (1995). Extra-Role behaviors: In pursuit of construct and definitional clarity. In L. L. Cummings \& B. M. Staw (Eds.), Research in organizational behavior (pp. 215-285). Greenwich, CT: JAI Press.

Van Dyne, L. \& LePine, J.A. (1998). Helping and voice extra-role behaviors: Evidence of construct and predictive validity. Academy of Management Journal, 41, 108119. doi: $10.2307 / 256902$.

Vinje, H. F., \& Mittelmark, M. B. (2007). Job engagement's paradoxical role in nurse burnout. Nursing \& Health Sciences, 9, 107-111. doi:10.1111/j.14422018.2007.00310.x

Viswesvaran, C. (2001). Assessment of individual job performance: A review of the past century and a look ahead. In N. Anderson, D. S. Onez, H. K. Sinangil, \& C. Visvesvaran (Eds.), Handbook of industrial, work and organizational psychology: Vol. 1. Personnel psychology (pp. 110-126). Thousand Oaks, CA: Sage.

Viswesvaran, C., Schmidt, F.L. and Ones, D.S. (1999) The role of halo error in interdimensional ratings: The case of job performance ratings examined via metaanalysis. Manuscript submitted for publication.

Viswesvaran, C., Schmidt, F. L., \& Ones, D. S. (2002). The moderating influence of job performance dimensions on convergence of supervisory and peer ratings of job performance: Unconfounding construct-level convergence and rating difficulty. Journal of Applied Psychology, 87, 345-354. doi: 10.1037//0021-9010.87.2.345.

Viswesvaran, C., Schmidt, F. L., \& Ones, D. S. (2005). Is there a general factor in ratings of job performance? A meta-analytic framework for disentangling substantive and error influences. Journal of Applied Psychology, 90, 108-131. doi: 10.1037/00219010.90.1.108.

Weinstein, N., \& Ryan, R. M. (2010). When helping helps: Autonomous motivation for prosocial behavior and its influence on well-being for the helper and recipient. Journal of Personality and Social Psychology, 98, 222-244. doi: 10.1037/a0016984.

Weiss, J. W., Skelley, M. F., Haughey, J. C., \& Hall, D. T. (2004). Calling, new careers and spirituality: A reflective perspective for organizational leaders and professionals. In M. L. Pava \& P. Primeaux (Eds.), Spiritual intelligence at work: 
Meaning, metaphor, and morals. Research in ethical issues in organizations (pp. 175-201). London, UK: Elsevier.

Whitmont, E. C. (1969). The symbolic quest. Princeton, NJ: Princeton University Press.

Witt, L. A. \& Spitzmuller, C. (2007). Person-situation predictors of maximum and typical performance. Human Performance, 20(3), 305-315. doi: 10.1080/08959280701333529.

Wrzesniewski, A. (2003). Finding positive meaning in work. In K.S. Cameron, J.E., Dutton, \& R.E. Quinn (eds.), Positive organizational scholarship: Foundations of new discipline (pp. 296-308). San Francisco, CA: Berrett-Koehler.

Wrzesniewski, A., McCauley, C., Rozin, P., \& Schwartz, B. (1997). Jobs, careers, and callings: People's relations to their work. Journal of Research in Personality, 31, 21-33. doi: 0092-6566/97.

Yao, X., Lee, T.W., Mitchell, T.R., Burton, J.P. \& Sablynski, C.S. (2004). Job embeddedness: Current research and future directions. In R. Griffeth \& P. Hom (Eds.), Understanding employee retention and turnover (pp. 153-187).

Greenwich, CT: Information Age.

Yugo, J. E. (2009). The role of calling in emotional labor. (Doctoral dissertation). Retrieved from PsycINFO. Bowling Green State University.

Zedeck, S. (1971). Problems with the use of "moderator" variables. Psychological Bulletin, 76, 295-310. doi: 10.1037/h0031543

Zwart, G.A. (2000) The relationship between spirituality and transformational leadership in public, private and nonprofit sector organizations (published doctoral dissertation), University of La Verne, CA: Dissertation Abstracts International 
APPENDIX A - Measures and Scale Items

\section{Work Orientation - Davidson \& Caddell, 1994}

Instructions: Please read the following three statements about how some people view their work and choose the one that best describes your relationship with work.

Calling Statement. My work has special meaning because I have been called to do what I'm doing regardless of how much time it takes or how little money I earn; I was put on this earth to do what I am doing.

Career Statement. I am pursuing a lifelong career which I feel is important; I chose to do this kind of work throughout my life; I might change where I work, but I'm not likely to change the kind of work I do.

Job Statement. I am paid to perform a service; I have been paid to do other things at other times, and I am willing to do other types of work in the future if the pay and security are better.

\section{Calling Scale Items - Dobrow \& Tosti-Kharas, 2011}

Instructions: Below are several statements about you and your work with which you may agree or disagree. Using the response scale below, indicate your agreement or disagreement with each item by placing the appropriate number on the line preceding that item.

$1=$ Strongly Disagree; 2 = Disagree; $3=$ Neutral 4 = Agree; $5=$ Strongly Agree

I am passionate about the tasks I engage in at work.

I enjoy the things I do at work more than anything else.

Engaging in my work tasks gives me immense personal satisfaction.

I would sacrifice everything to be in my current line of work.

The first thing that I often think about when I describe myself to others is related

to my work activites.

I would continue my current line of work even in the face of sever obstacles.

I know that engaging in my current line of work will always be a part of my life.

I feel a sense of destiny about engaging in my current line of work

Engaging in my work-related activites is always in my mind in some way.

Even when not engaging in my work activities, I often think about my work

My existence would be much less meaningful without my involvement in my work activities

Engaging in my work activities is a deeply moving and gratifying experience for me. 


\section{Job Satisfaction Scale - Hackman \& Oldham, 1975}

Instructions: Please indicate how you personally feel about your job. Each of the statements below is something that a person might say about his or her job. You are to indicate your own personal feelings about your job by marking how much you agree with each of the statements.

$1=$ Strongly Disagree; 2 = Disagree; $3=$ Neutral; 4 = Agree; $5=$ Strongly Agree

Generally speaking, I am very satisfied with my job.

I frequently think I would like to change my current job.

I am generally satisfied with the kind of tasks I do at my job.

\section{Work Engagement Scale - Schaufeli, Salanova, Gonzalez, \& Bakker, 2002}

Instructions: Below are several statements about you and your work with which you may agree or disagree. Using the response scale below, indicate your agreement or disagreement with each item by placing the appropriate number on the line preceding that item.

$1=$ Strongly Disagree; $2=$ Disagree; $3=$ Neutral; $4=$ Agree; $5=$ Strongly Agree

When I get up in the morning, I feel like going to work.

At my work, I feel bursting with energy.

At my job I feel strong and vigorous.

My job inspires me.

I am enthusiastic about my job.

I am proud on the work that I do.

I get carried away when I am working.

I am immersed in my work.

I feel happy when I am working intensely.

\section{Prosocial Motivation Scale - Grant, 2008}

Instructions: Using the response scale below, indicate your level of agreement or disagreement for the following reasons why you are motivated to do your work.

$1=$ Strongly Disagree; 2 = Disagree; 3 = Neutral; 4 = Agree; $5=$ Strongly Agree

Because I care about benefiting others through my work.

Because I want to help others through my work.

Because I want to have a positive impact on others.

Because it is important to me to do good for others through my work. 


\section{Core Self-Evaluation Scale - Judge, Erez, Bono \& Thoresen, 2003}

Instructions: Below are several statements about you with which you may agree or disagree. Using the response scale below, indicate your agreement or disagreement with each item by placing the appropriate number on the line preceding that item.

$1=$ Strongly Disagree; 2 = Disagree; $3=$ Neutral; $4=$ Agree; $5=$ Strongly Agree

I am confident I get the success I deserve in life.

Sometimes I feel depressed. (Reverse Coded)

When I try, I generally succeed.

Sometimes when I fail I feel worthless. (Reverse Coded)

I complete tasks successfully.

Sometimes, I do not feel in control of my work. (Reverse Coded)

Overall, I am satisfied with myself.

I am filled with doubts about my competence. (Reverse Coded)

I determine what will happen in my life.

I do not feel in control of my success in my career. (Reverse Coded)

I am capable of coping with most of my problems.

There are times when things look pretty bleak and hopeless to me. (Reverse

Coded)

\section{Meaningful Work - Hackman \& Oldham, 1975}

Instructions: Please indicate how you personally feel about your job. Each statement below is something that a person might say about his or her job. You are to indicate your own, personal feelings about your job by marking how much you agree with each of the statements.

$1=$ Strongly Disagree; 2 = Disagree; $3=$ Neutral; 4 = Agree; $5=$ Strongly Agree

The work that I do on this job is meaningful to me.

Most of the things that I have to do on this job are useless or trivial.

Instructions: Now, please think of the other people in your organization who hold the same job as you do. If no one has exactly the same job as you, think of the job that is most similar to yours. It is quite alright if your answers here are different from when you described your own reactions to the job. Often different people feel quite different about the same job.

Most people on this job find work very meaningful.

Most people on this job feel that the work is useless or trivial. 


\section{Intrinsic Spirituality Scale - Hodge, 2003}

Instructions: The questions use a sentence completion format to measure various attributes associated with spirituality. An incomplete sentence fragment is provided, followed directly below by two phrases that are linked to a scale ranging from 0 to 5 . The phrases, which complete the sentence fragment, anchor each end of the scale. The 0 to 5 range provides you with a continuum on which to reply, with 0 corresponding to absence or zero amount of the attribute, while 5 corresponds to the maximum amount of the attribute. In other words, the end points represent extreme values, while three corresponds to a medium, or moderate, amount of the attribute. Please circle the number along the continuum that best reflects your initial feeling.

1. In terms of the questions I have about life, my spirituality answers

$$
0 \text { - No questions --- 1--- } 2 \text {--- } 3 \text {--- } 4 \text {--- } 5 \text { - Absolutely all of my questions }
$$

2. Growing spiritually is

0 - Of no importance to me --- 1 --- 2 --- 3 --- 4 --- 5 - More important than anything else

3. When I am faced with an important decision, my spirituality

$$
\begin{gathered}
0-\text { Plays absolutely no role --- } 1 \text {--- } 2 \text {--- } 3 \text {--- } 4 \text {--- } 5 \text {-Is always the overriding } \\
\text { consideration }
\end{gathered}
$$

4. Spirituality is

0 - Not a part of my life --- 1 --- 2 --- 3 --- 4 --- 5 - The master motive of my life, directing every aspect of my life

5. When I think of the things that help me to grow and mature as a person, my spirituality

0 - Has no effect on my personal growth --- 1 --- 2 --- 3 --- 4 --- 5 - Is absolutely the most important factor in my personal growth

6. My spiritual beliefs affect

$$
0 \text { - No aspect of my life --- } 1 \text {--- } 2 \text {--- } 3 \text {--- } 4 \text {--- } 5 \text { - Absolutely every aspect of my life }
$$




\section{Job Performance - Motowidlo \& Van Scotter, 1994}

This subordinate or co-worker's overall job performance

$1-2$ Does not meet standards for job performance

$2-5$ Meets standards for job performance

$6-7$ Exceeds standards for job performance

This subordinate or co-worker's overall job performance

$1-2$ Performs at a low evel compared with others at the same rank

$3-5$ Performs at an average level compared with others at the same rank

6-7 Performs at a high level compare with others at the same rank

This subordinate or co-worker's overall job performance

$1-2$ Contributes less to unit effectiveness than most members of the work unit

3 - 5 Makes an average contribution to unit effectiveness

$6-7$ Contributes more to unit effectiveness than most members of the work unit

\section{Perceived Career Opportunity- Kraimer, Seibert, Wayne, Liden, \& Bravo, 2011}

Instructions: Below are several statements about you with which you may agree or disagree. Using the response scale below, indicate your agreement or disagreement with each item by placing the appropriate number on the line preceding that item.

There are career opportunities in my current organization that are attractive to me.

There are job opportunities available within my company that are of interest to me.

My company offers many job opportunities that match my career goals.

\section{Expanded Numeracy Scale - Lipkus, Samsa, \& Rimer, 2001}

1. Imagine that we rolled a fair, six-sided die 1,000 times. Out of 1,000 rolls, how many times do you think the die would come up even $(2,4$, or 6$)$ ? Answer: 500 out of 1000 .

2. In the BIG BUCKS LOTTERY, the chances of winning a $\$ 10.00$ prize is $1 \%$. What is your best guess about how many people would win a $\$ 10.00$ prize if 1,000 people each buy a single ticket to BIG BUCKS? Answer: 10 persons out of 1000 .

3. In the ACME PUBLISHING SWEEPSTAKES, the chance of winning a car is 1 
in 1,000. What percent of tickets to ACME PUBLISHING SWEEPSTAKES win a car? Answer: 0.1\%

4. Which of the following numbers represents the biggest chance of getting a salary increase? 1 in 100, _ 1 in $1000, X_{-} 1$ in 10

5. Which of the following numbers represents the biggest chance of getting a salary increase? _ 1\%, X_10\%, _ 5\%

6. If Person A's chance of getting a promotion is $1 \%$ in ten years, and person B's chance is double that of A's, what is B's chance? Answer: $2 \%$

7. If Person A's chance of getting a promotion is 1 in 100 in ten years, and person B's chance is double that of A's, what is B's chance? Answer: 2 out of 100

8. If the chance of getting an interview is $10 \%$, how many people would be expected to get an interview: A: Out of 1000 applicants? Answer 100

9. If the chance of getting an interview is 20 out of 100 , this would be the same as having a $\%$ chance of getting an interview.

10. The chance of winning the lottery is .0005 . Out of 10,000 people, about how many of them are expected to win? Answer: 5 People 
VITA

\section{KERRY A. NEWNESS \\ EDUCATION}

Ph.D. in Industrial-Organizational Psychology

Florida International University

Miami, Florida

M.S. in Industrial-Organizational

Florida International University

Miami, Florida

B.S. Psychology

Barry University

Miami Shores, Florida

\section{WORK EXPERIENCE}

Visiting Instructor of Psychology

College of Arts and Sciences

Florida Southern College (August 2013 - Present)

Adjunct Instructor of Psychology

College of Arts and Sciences

Florida International University (Jan. 2012 - Aug. 2013)

Psychology Graduate Assistant (Jan. 2011- Dec. 2011)

Psychology Academic Advisor (Aug. 2010 - Jan. 2011)

Psychology Teaching Assistant (August 2008 - July 2010)

\section{PUBLICATIONS AND PRESENTATIONS}

Newness, K. A., Steinert, J. K., \& Viswesvaran, C. (2012). Effects of personality on social network disclosure: Do emotionally intelligent individuals post inappropriate content? Psychological Topics, 21, 1-14.

Newness, K. A., Szuchman, L., \& Lopez, M. R. (2008). Layers of HIV stigma: The influence of high-risk characteristics on perceptions. Undergraduate Research Journal for the Human Sciences, 7, Located at http://www.kon.org/urc/urc_research_journal7.html 
Michel, J. S., Pichler, S., \& Newness, K. A. (In Press). Integrating leader affect, leader work-family spillover, and leadership. Leadership and Organization Development Journal.

Michel, J. S., Newness, K. A., \& Duniewicz. K. (2013, August). How abusive supervision affects workplace deviance: The impact of negative affect and aggression. Paper presented at the 2013 Annual Meeting of the Academy of Management, Orlando, FL

Newness, K. A. \& Michel, J. S. (2013, April). Work orientation: An exploration of the factors of calling. Poster presented at the national conference of the 28th Annual Conference of the Society for Industrial and Organizational Psychology, Houston, TX

Newness, K. A., Steinert, J. K., \& Viswesvaran, C. (2012, August). Saving face: Effects of personality on posting inappropriate social network content. Poster session presented at the $120^{\text {th }}$ Annual Convention of the American Psychological Association, Orlando, FL.

Steinert, J.,K. Newness, K. A., Rutherford, K., \& Michel, J. S. (2012, August). The experience of stress: Do role-outcomes mediate health outcomes. Poster presented at the $120^{\text {th }}$ Annual Convention of the American Psychological Association, Orlando, Fl.

Steinert, J. \& Newness, K. (2012). Social selection: Should organizations use Facebook in screening applicants. Poster presented at the 2012 annual meeting of IOOB, Orlando, Fl.

Steinert, J.A., Newness, K. A., \& Michel, J. S. (2011, August). Stress type: Does the appraisal affect health and performance outcomes? Poster session presented at the $119^{\text {th }}$ Annual Convention of the American Psychological Association, Washington, D.C.

Newness, K. A. \& Viswesvaran, C. (2009). An analysis and reliability generalization for the Core Self-Evaluation Scale (CSES). Poster presented at the 24th Annual Conference of the Society for Industrial and Organizational Psychology, New Orleans, LA

\section{MANUSCRIPTS UNDER REVIEW}

How abusive supervision affects workplace deviance: A moderated-mediation examination of organization-based and employee-based aggression and workrelated negative affect (Under Review at Journal of Organizational Behavior). With Jesse S. Michel and Krzysztof Duniewicz 